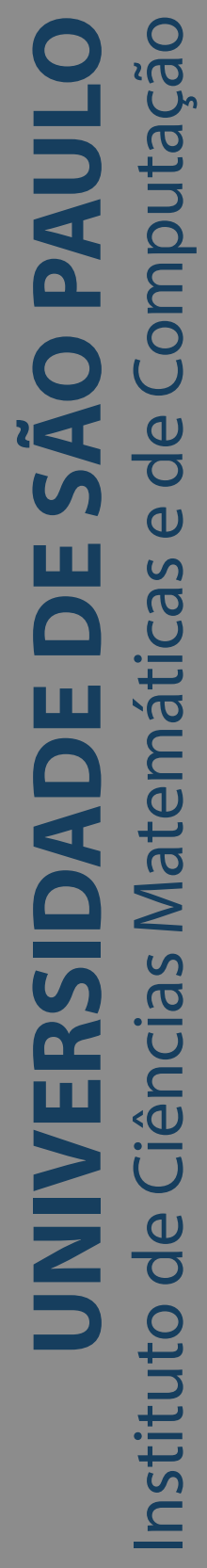

\title{
Logística em redes varejistas: uma visão integrada de cross-docking e roteamento
}

\section{Natan Bissoli}

Dissertação de Mestrado do Programa de Pós-Graduação em Ciências de Computação e Matemática Computacional (PPG-CCMC) 

SERVIÇO DE PÓS-GRADUAÇÃO DO ICMC-USP

Data de Depósito:

Assinatura:

\title{
Natan Bissoli
}

\section{Logística em redes varejistas: uma visão integrada de cross-docking e roteamento}

\begin{abstract}
Dissertação apresentada ao Instituto de Ciências Matemáticas e de Computação - ICMC-USP, como parte dos requisitos para obtenção do título de Mestre em Ciências - Ciências de Computação e Matemática Computacional. VERSÃO REVISADA

Área de Concentração: Ciências de Computação e Matemática Computacional

Orientadora: Profa. Dra. Franklina Maria Bragion de Toledo
\end{abstract}

\section{USP - São Carlos}

Junho de 2021 
Ficha catalográfica elaborada pela Biblioteca Prof. Achille Bassi e Seção Técnica de Informática, ICMC/USP, com os dados inseridos pelo(a) autor(a)

Bissoli, Natan

B6231 Logística em redes varejistas: uma visão integrada de cross-docking e roteamento / Natan Bissoli; orientadora Franklina Maria Bragion de Toledo. -- São Carlos, 2021.

$97 \mathrm{p}$.

Dissertação (Mestrado - Programa de Pós-Graduação em Ciências de Computação e Matemática Computacional) -- Instituto de Ciências Matemáticas e de Computação, Universidade de São Paulo, 2021.

1. Cross-Docking. 2. Matheurísticas. 3. Modelagem Matemática. 4. Roteamento de Veículos. I. Toledo, Franklina Maria Bragion de, orient. II. Título.

Bibliotecários responsáveis pela estrutura de catalogação da publicação de acordo com a AACR2 Gláucia Maria Saia Cristianini - CRB - 8/4938

Juliana de Souza Moraes - CRB - 8/6176 


\section{Natan Bissoli}

\section{Retail chains logistics: an integrated view of cross-docking and routing}

Dissertation submitted to the Instituto de Ciências Matemáticas e de Computação - ICMC-USP - in accordance with the requirements of the Computer and Mathematical Sciences Graduate Program, for the degree of Master in Science. FINAL VERSION

Concentration Area: Computer Science and Computational Mathematics

Advisor: Profa. Dra. Franklina Maria Bragion de Toledo

USP - São Carlos

June 2021 

Agradeço, primeiramente à Deus por todas as conquistas e vitórias em minha vida.

Aos meus pais, João Carlos Bissoli e Maria Salete Bissoli, os quais são grandes exemplos em minha vida. Que sempre me apoiaram, principalmente, emocionalmente em todos os sentidos durante minhas jornadas, me ouvindo e me aconselhando em todos os passos.

As minhas irmãs, Cassia e Karina, que sempre estiveram ao meu lado em todos os momentos apontando meus erros e minhas qualidades sempre buscando o melhor para mim.

Ao meu cunhado Asael, por sempre estar disposto a me ouvir e a minha sobrinha Amábily por todos os momentos divertidos que passamos.

À minha orientadora, Franklina, pela paciência, compreensão e todas as orientações para construção deste trabalho.

Aos professores e funcionários do Instituto de Ciências Matemáticas e Computação (ICMC) que auxiliaram no meu crescimento intelectual e pessoal durante o curso.

Aos meus amigos e colegas do Laboratório de Otimização pelos momentos de ajuda e descontração.

Aos professores do curso de Engenharia de Transportes e Logística da Universidade Federal de Santa Catarina (UFSC) em Joinville, os quais mesmo após o meu egresso ainda acompanham minha jornada desejando o melhor para mim.

Aos meus amigos, em especial a Luíza, Henrique, Kolling e Pedro, que sempre estiveram ao meu lado, torcendo pelo meu sucesso.

Aos meus irmãos em Cristo, por toda a torcida e orações em prol do meu sucesso ao longo do caminho. Em especial ao Pastor Lindomar Xavier, sua família e sua congregação, pelo apoio e suporte desde o inicio da minha jornada na cidade de São Carlos.

À Coordenação de aperfeiçoamento de Pessoal de Nível Superior, pois o presente trabalho foi realizado com apoio da Coordenação de Aperfeiçoamento de Pessoal de Nível Superior Brasil (CAPES) - Código de Financiamento 001.

E todos aqueles que desejaram boas vibrações e torceram por mim um Muito Obrigado! 

"Engradecei ao Senhor comigo;

e juntos exaltemos o Seu Nome."

(Salmos 34:3, Bíblia Sagrada) 



\section{RESUMO}

BISSOLI, N. Logística em redes varejistas: uma visão integrada de cross-docking e roteamento. 2021. 97 p. Dissertação (Mestrado em Ciências - Ciências de Computação e Matemática Computacional) - Instituto de Ciências Matemáticas e de Computação, Universidade de São Paulo, São Carlos - SP, 2021.

Devido à forte globalização dos mercados, a quantidade de produtos transportados no mundo vêm aumentando nos últimos anos. Neste contexto, as empresas buscam reduzir seus custos de distribuição, que segundo a literatura representam cerca de $30 \%$ do preço final dos produtos. Logo, a busca de estratégias eficientes de distribuição é constante e uma das das estratégias utilizadas por empresas de varejo é o sistema cross-docking. Esse sistema consiste em uma instalação intermediária, na qual os produtos são recebidos, reorganizados e expedidos aos clientes. Dentre as decisões operacionais relacionadas ao sistema estão a ordenação das cargas de entrada, de saída e o roteamento dos veículos de entrega. Na literatura, poucos trabalhos estudam o problema integrando esses três conjuntos de decisões e embora já tenha sido destacada sua relevância no contexto de roteamento de veículos, nenhum avalia o impacto do número de veículos utilizados na operação. Desta maneira, o presente trabalho aborda esta lacuna da literatura, tratando o problema como bi-objetivo, ou seja, visando minimizar os custos operacionais do cross-dock e a redução no número de veículos utilizados. Experimentos computacionais realizados para instâncias com 15 clientes mostraram que considerar apenas os custos operacionais leva a uma utilização adicional média de $25 \%$ dos veículos, e considerar apenas o número de veículos pode aumentar os custos operacionais em média em $110 \%$. Porém, o problema bi-objetivo resulta em soluções que permaneçam em média a $3 \%$ e $2 \%$ do melhor custo e do menor número de veículos conhecidos, respectivamente. Para tratar instâncias com um maior número de clientes, foi desenvolvida uma matheurística Proximity Search bi-objetivo, a qual mostrou-se competitiva quanto aos resultados do método exato para instâncias pequenas. Para as instâncias de maior dimensão os resultados superaram em média a abordagem mono-objetivo.

Palavras-chave: Cross-Docking, Roteamento de Veículos, Decisões Integradas, Proximity Search. 



\section{ABSTRACT}

BISSOLI, N. Retail chains logistics: an integrated view of cross-docking and routing. 2021. 97 p. Dissertação (Mestrado em Ciências - Ciências de Computação e Matemática Computacional) - Instituto de Ciências Matemáticas e de Computação, Universidade de São Paulo, São Carlos - SP, 2021.

Due to the intense globalization of the markets, the number of products transported worldwide increased in recent years. In this context, companies seek to reduce their distribution costs, which according to the literature, represent about $30 \%$ of products' final price. Therefore, there is a search for efficient distribution strategies. One of these retail companies' strategies is cross-docking. This system consists of an intermediate installation in which products are received, rearranged, and shipped to customers. Among the operational decisions related to the system are the scheduling of incoming and outgoing loads and the routing of delivery vehicles. A few works have studied the problem of integrating these three sets of decisions. Although the importance of the number of vehicles used has already been highlighted in the context of vehicle routing problems, its impact remains a research gap in cross-docking. In this way, the present work addresses this gap in the literature, treating the problem as a bi-objective model, aiming at the minimization of the cross-dock's operational costs and the number of vehicles used. Computational experiments performed for data with 15 customers that only consider the operating costs lead to an average additional use of $25 \%$ vehicles, and in case of minimizing only the number of vehicles can increase operational costs by an average of $110 \%$. However, the bi-objective approach results in average solutions at $3 \%$ and $2 \%$ of the best operational cost and the lowest number of vehicles knowns, respectively. To solve the problem with a larger number of customers, a bi-objective Proximity Search matheuristic was developed. The method proved to be competitive in terms of the exact solution method's results for small instances. For larger instances, the results outperformed the mono-objective approach on average.

Keywords: Cross-Docking, Vehicle Routing, Integrated Decisions, Proximity Search. 



\section{LISTA DE ILUSTRAÇÕES}

Figura 1 - Representação do Fluxo de Mercadorias no Cross-Dock. . . . . . . . . . . . 26

Figura 2 - Abordagens para Problemas de cross-docking com roteamento de veículos. . 30

Figura 3 - Representação de um Sistema Cross-Docking. . . . . . . . . . . . . . . 38

Figura 4 - Exemplo Ilustrativo. . . . . . . . . . . . . . . . . 46

Figura 5 - Solução do Problema Teste com Objetivo de Custos Operacionais . . . . . . 47

Figura 6 - Solução do Problema Teste com Objetivo de Número de Veículos. . . . . . 48

Figura 7 - Resultados de Algumas Instâncias de 15 Clientes para ASP. . . . . . . . . 52

Figura 8 - Resultados Médios das Instâncias de 15 Clientes para ASP. . . . . . . . 53 

Tabela 1 - Matriz de Custos para o Problema Teste. . . . . . . . . . . . . . . 47

Tabela 2 - Tempo para Transportar uma Unidade do Produto entre as Docas. . . . . . . 47

Tabela 3 - Resultados Médios para APP e APM. . . . . . . . . . . . . . 54

Tabela 4 - Resultados do Teste de Wilcoxon para ASP, APM e APP2. . . . . . . . . 55

Tabela 5 - Resultados da Matheurística PS para Instâncias de 15 Clientes - Cenário 1. . 67

Tabela 6 - Resultados do Teste de Wilcoxon para as Instâncias de 15 Clientes - Cenário 1. 68

Tabela 7 - Resultados da Matheurística PS para Instâncias de 15 Clientes - Cenário 2. . 69

Tabela 8 - Resultados do Teste de Wilcoxon para as Instâncias de 15 Clientes - Cenário 2. 70

Tabela 9 - Resultados da PSM para Instâncias de 40 Clientes - Cenário 1. . . . . . . 71

Tabela 10 - Resultados da PSB para Instâncias de 40 Clientes - Cenário 1. . . . . . . . 72

Tabela 11 - Resultados da PSM para Instâncias de 40 Clientes - Cenário 2. . . . . . . . 73

Tabela 12 - Resultados da PSB para Instâncias de 40 Clientes - Cenário 2 . . . . . . . . 74

Tabela 13 - Resultados para ASP 15 Clientes Cenário 1 - Parte 1. . . . . . . . . . . 86

Tabela 14 - Resultados para ASP 15 Clientes Cenário 1- Parte 2 . . . . . . . . . . . . 87

Tabela 15 - Resultados para ASP 15 Clientes Cenário 1 - Parte 3. . . . . . . . . . . . 88

Tabela 16 - Resultados para ASP 15 Clientes Cenário 2 - Parte 1. . . . . . . . . . . 89

Tabela 17 - Resultados para ASP 15 Clientes Cenário 2 - Parte 2. . . . . . . . . . . . 90

Tabela 18 - Resultados para ASP 15 Clientes Cenário 2 - Parte 3. . . . . . . . . . . . 91

Tabela 19 - Resultados para as abordagens APP e APM 15 Clientes - Cenário 1. . . . . 92

Tabela 20 - Resultados para as abordagens APP e APM 15 Clientes - Cenário 2. . . . . 93

Tabela 21 - Resultados do Teste de Wilcoxon do Custo Operacional para Abordagens Bi-Objetivo - Cenário 1. . . . . . . . . . . . . . . . . 95

Tabela 22 - Resultados do Teste de Wilcoxon do Número de Veículos para Abordagens Bi-Objetivo - Cenário 1. . . . . . . . . . . . . . . . . . 96

Tabela 23 - Resultados do Teste de Wilcoxon do Tempo de Processamento para Abordagens Bi-Objetivo - Cenário 1. . . . . . . . . . . . . . . . 96

Tabela 24 - Resultados do Teste de Wilcoxon do Custo Operacional para Abordagens Bi-Objetivo - Cenário 2. . . . . . . . . . . . . . . . . . . 96

Tabela 25 - Resultados do Teste de Wilcoxon do Número de Veículos para Abordagens Bi-Objetivo - Cenário 2 . . . . . . . . . . . . . . . . . . . . 97

Tabela 26 - Resultados do Teste de Wilcoxon do Tempo de Processamento para Abordagens Bi-Objetivo - Cenário 2. . . . . . . . . . . . . . . . 



\section{LISTA DE ABREVIATURAS E SIGLAS}

AMP Adaptative Memory Procedure

APM Abordagem por Metas

APP Abordagem por Preempção

ASP Abordagem por Somas Ponderadas

BATA Backtracking Adaptative Threshold Accepting

CDSP Cross-Dock Scheduling Problem

FSMLRPTW Fleet Size and Mix Location-Routing Problem with Time Windows

FSMVRP Fleet Size and Mix Vehicle Routing Problem

FSMVRPTW Fleet Size and Mix Vehicle Routing Problem with Time Windows

GENI Generalized Insertion

GVNS General Variable Neighborhood Search

HESA Hybrid Evolutionary Search Algorithm

HFFVRP Heterogeneous Fixed Fleet Vehicle Routing Problem

ILS Iterated Local Search

MA Modelo Auxiliar

MOEA Multi-objective evolutionary algorithm

PDPCD Pickup and Delivery Problem with Cross-Docking

PSB Proximity Search de Bernardes (2019)

PSM Proximity Search Modificada

US Unstringing and Stringing

VRPCD Problema de Roteamento de Veículos com Cross-Docking

VRPCD-SCM Vehicle Routing Problem with Cross-Docking in Supply Chain Management

VRSP Problema de Roteamento de Veículos e Programação do Cross-Dock 



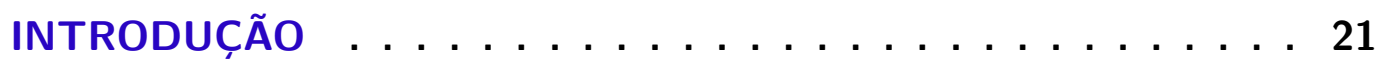

REVISÃO DA LITERATURA . . . . . . . . . . . . . . . . . . . 25

$2.1 \quad$ Características do Cross-Docking . . . . . . . . . . . . . . 27

2.2 Decisões Operacionais do Cross-Dock . . . . . . . . . . . . . 27

2.3 Modelos para Operação do Cross-Dock . . . . . . . . . . . . . . . . 28

2.4 Problema de Cross-Docking com Roteamento de Veículos . . . . 29

2.4.1 Problema de Roteamento de Veículos com Cross-Docking . . . . 29

2.4.2 Problema de Roteamento de Veículos e Programação do Cross-Dock 32

2.5 Dimensionamento da Frota de Veículos . . . . . . . . . . . . . 33

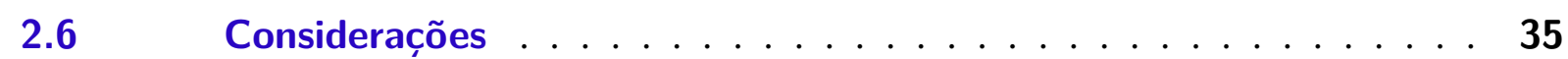

3 DEFINIÇÃO dO PROBLEMA E MODELAGEM . . . . . . . . . 37

$3.1 \quad$ Definição do Problema . . . . . . . . . . . . . . . 37

$3.2 \quad$ Modelagem do Problema . . . . . . . . . . . . . . . 39

3.2.1 Modelo Literatura . . . . . . . . . . . . . . . . . . . . . . . . . 40

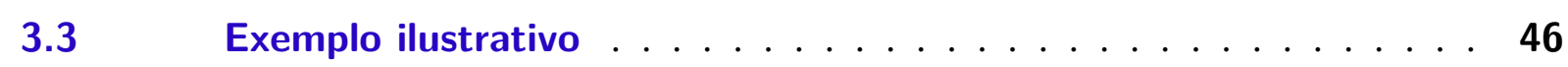

$3.4 \quad$ Considerações $\ldots \ldots \ldots \ldots \ldots \ldots$

4 ABORDAGENS DE RESOLUÇÃO . . . . . . . . . . . . . . . 49

$4.1 \quad$ Abordagem por Somas Ponderadas . . . . . . . . . . . . 49

$4.2 \quad$ Abordagem por Preempção . . . . . . . . . . . . . . 50

$4.3 \quad$ Abordagem por Metas . . . . . . . . . . . . . 50

$4.4 \quad$ Experimentos Computacionais . . . . . . . . . . . . 51

4.4.1 Testes Estatísticos . . . . . . . . . . . . . . . . 54

$4.5 \quad$ Considerações $\ldots \ldots \ldots \ldots \ldots$

5 MATHEURÍSTICA BI-OBJETIVO . . . . . . . . . . . . . . 57

$5.1 \quad$ Matheurística Proximity Search . . . . . . . . . . . . . 57

$5.2 \quad$ Solução Inicial . . . . . . . . . . . . . . . . 58

5.2.1 Critério de Prioridade . . . . . . . . . . . . . . . . 59

5.2.2 Critério de Compatibilidade . . . . . . . . . . . . . . 60

5.2.3 Obtenção de $\bar{X} \ldots \ldots \ldots \ldots \ldots$. . . . . . . . . . . . . . . .

5.2.4 Estratégias de Refinamento da Solução Inicial . . . . . . . . . . . . 61 
$5.3 \quad$ Modelo Auxiliar . . . . . . . . . . . . . . . . . . . 62

5.3.1 Critérios de Parada do Modelo Auxiliar . . . . . . . . . . . . . 63

$5.4 \quad$ Adaptações da Proximity Search . . . . . . . . . . . . . . 64

$5.5 \quad$ Refinamento da Solução . . . . . . . . . . . . . . 64

5.6 Experimentos Computacionais . . . . . . . . . . . . 65

5.6.1 Análise da Competitividade da Proximity Search . . . . . . . . 65

5.6.2 Análise da Robustez da Proximity Search . . . . . . . . . . . . 66

5.7 Considerações . . . . . . . . . . . . . . . . . 70

6 CONCLUSÕES E TRABALHOS FUTUROS $\ldots \ldots \ldots 77$

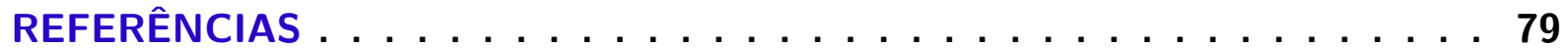

APÊNDICE A EXPERIMENTOS COMPUTACIONAIS DAS ABOR-

DAGENS BI-OBJETIVO . . . . . . . . . . 85

APÊNDICE B RESULTADOS DOS TESTE DE WILCOXON . . . . 95 
Segundo Boysen e Fliedner (2010), devido à forte globalização dos mercados, a quantidade de produtos transportados no mundo vêm sendo significativamente elevada nos últimos anos. Logo, a necessidade das empresas de se manterem competitivas, as levou a buscarem métodos capazes de atender as demandas de clientes distantes mantendo seus custos reduzidos. Nesse contexto, as empresas buscam melhores estratégias de distribuição de seus produtos, pois como destacam Apte e Viswanathan (2000), cerca de 30\% do preço dos produtos está associado aos custos de distribuição.

Recentemente, Speranza (2018) ressalta que, com o auxílio de estratégias da área de Pesquisa Operacional, os custos logísticos e de transportes podem ser minimizados de maneira eficiente. Essa área de pesquisa possibilita o desenvolvimento de modelos e de ferramentas que facilitam a tomada de decisões. Entre tais decisões, pode-se apontar, por exemplo, a estratégia de consolidação de carga e sua operação, a ordem de entrega dos produtos para os clientes e a seleção de pedidos a serem inseridos em cada veículo de entrega.

Dentre as estratégias de distribuição de cargas, Buijs, Vis e Carlo (2014) destacam quatro tipos: entrega direta, milk-run, warehousing e cross-docking. A estratégia de entrega direta consiste em transportar as entregas diretamente do fornecedor para o cliente. A milk-run busca encontrar rotas de maneira a realizar múltiplas coletas e entregas de maneira sequencial. Os autores destacam que tais estratégias são eficazes quando as cargas transportadas tem grandes volumes. No entanto, para cargas pequenas e clientes dispersos, tais estratégias costumam resultar em veículos pouco ocupados, logo o transporte é pouco eficiente. A estratégia de Warehousing permite que as cargas sejam estocadas, consolidadas e enviadas de um armazém aos clientes conforme a necessidade dos mesmos. Em contra partida, a operação de cross-docking utiliza uma instalação intermediária, chamada cross-dock, para a operação. Nessa instalação, após o recebimento das cargas, é realizada a imediata consolidação das mesmas para enviá-las aos clientes rapidamente, de maneira a não gerar grandes estoques. Essas duas estratégias buscam 
utilizar os veículos para cargas menores, porém aproveitando da melhor maneira o uso dos mesmos. Ambas necessitam de uma instalação intermediária para operação e, segundo Stephan e Boysen (2011), a principal diferença entre elas é que na estratégia cross-docking os estoques permanecem na instalação por um tempo limite de $24 \mathrm{~h}$. Portanto, segundo Yu, Jewpanya e Redi (2016), a estratégia cross-docking auxilia na redução de custos e de estoques, além de permitir a agilidade, confiabilidade e flexibilidade do sistema de distribuição.

Em um sistema cross-docking, a ordenação das cargas de entrada, de saída e o roteamento dos veículos de entrega são algumas das decisões operacionais. Na literatura, é de nosso conhecimento, apenas quatro trabalhos que tratam as decisões operacionais do cross-docking de forma integrada ao roteamento de veículos: Agustina, Lee e Piplani (2014), Rahbari et al. (2019), Bernardes (2019) e Liao (2020). Como destacado em Bernardes (2019), o planejamento das rotas reduz os custos de distribuição, em especial, quando as cargas dos clientes ocupam até $50 \%$ da capacidade dos veículos.

Na literatura de roteamento de veículos, é apontado que a redução do número de veículos utilizados na distribuição pode acarretar em benefícios econômicos e ambientais para as empresas. No entanto, não foi encontrado nenhum trabalho que a redução do número de veículos em ambientes cross-docking. Neste trabalho, é analisado o impacto ao considerar o número de veículos na redução dos custos operacionais de um cross-dock.

Modelos bi-objetivo foram desenvolvidos para tratar os custos operacionais e o número de veículos. Os experimentos computacionais realizados mostraram que é possível reduzir o número médio de veículos utilizados em $24,56 \%$ à um acréscimo médio de 7,43\% nos custos operacionais para as instâncias estudadas.

Devido à complexidade do problema estudado, mostrou-se necessário utilizar um método aproximado para resolução de instâncias maiores do problema. No presente trabalho, foi desenvolvida uma matheurística Proximity Search para obter soluções de qualidade em tempo computacional viável. Os resultados da matheurística se mostram competitivos às abordagens exatas.

Em resumo, este trabalho tem duas contribuições principais: $i$ ) o estudo do problema integrado, considerado dois objetivos centrais, ou seja, minimizar os custos operacionais e reduzir o número de veículos utilizados na operação; e ii) o desenvolvimento de um matheurística Proximity Search para tratar o problema bi-objetivo.

Este texto está organizado da seguinte forma. No Capítulo 2, é realizado um levantamento bibliográfico dos principais trabalhos científicos relacionados ao problema de cross-dock estudado. No Capítulo 3, são descritos o problema estudado, especificando hipóteses levantadas no estudo, e um modelo matemático para representá-lo. O Capítulo 4 apresenta as abordagens consideradas para resolução do problema bi-objetivo, bem como os testes computacionais realizados para analisá-los. O método matheurístico desenvolvido para tratar instâncias maiores é 
detalhado no Capítulo 5. Por fim, o Capítulo 6 apresenta a conclusão do problema estudado e propostas para trabalhos futuros. 



\section{REVISÃO DA LITERATURA}

Diversas são as estratégias utilizadas na distribuição de mercadorias. Buijs, Vis e Carlo (2014) destacam quatro os principais tipos dessas estratégias: entregas diretas, milk-run, warehousing e cross-docking. As estratégias de entregas diretas e milk-run consistem em entregas dos fornecedores para os clientes sem a necessidade de instalações intermediárias. Já as estratégias warehousing e cross-docking utilizam uma instalação intermediária no processo de distribuição. A estratégia cross-docking utiliza a instalação intermediária, nomeada cross-dock, como uma ponte para rearranjar os produtos oriundos dos fornecedores conforme as demandas dos clientes, enquanto a estratégia warehousing estoca os produtos por períodos maiores de tempo.

Neste trabalho, vamos estudar a estratégia de cross-docking que, segundo Apte e Viswanathan (2000), é apropriada para cargas que possuem demanda estável e constante, uma vez que os estoques no cross-dock são inexistentes ou pequenos. Há uma grande concentração de trabalhos na literatura que visam reduzir os custos operacionais e de roteamento ao utilizar a estratégia cross-docking. Também, é possível destacar como vantagens do sistema cross-docking a melhoria do nível de serviço, da velocidade de entrega e a redução de avarias nos produtos (BERNARDES, 2019).

A Figura 1 ilustra o fluxo de mercadorias no cross-dock em três principais etapas: recebimento de mercadorias, consolidação e carregamento. Durante a fase de recebimento, os veículos são direcionados para docas de entradas, nas quais as cargas são descarregadas. Em seguida, elas são enviadas para a área de consolidação ou para um estoque temporário de até 24h (STEPHAN; BOYSEN, 2011). Por fim, a consolidação consiste em separar as cargas e rearranja-las conforme a necessidade dos clientes. Concluída a consolidação, as demandas dos clientes são carregadas nos veículos utilizando as docas de saída.

De acordo com Agustina, Lee e Piplani (2014), Buijs, Vis e Carlo (2014) e Boysen e Fliedner (2010), as decisões relacionadas aos cross-docking podem ser separadas em operacionais, táticas e estratégicas. As decisões estratégicas, tomadas a longo prazo, estão associadas às 
Figura 1 - Representação do Fluxo de Mercadorias no Cross-Dock.

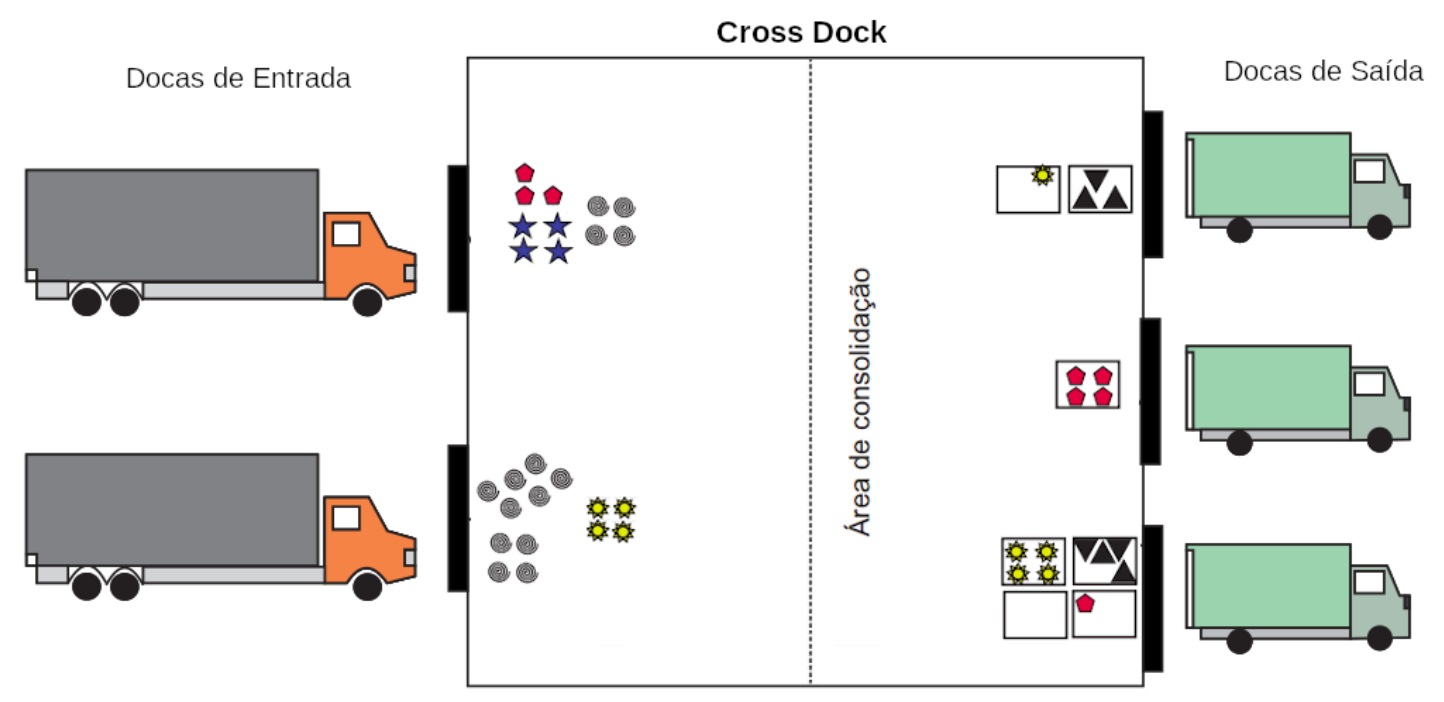

Fonte: Adaptado de Bernardes (2019).

decisões de infraestrutura da rede, por exemplo, determinar a localização para instalação do cross-dock, ou definir a quantidade de docas da instalação para suportar o fluxo de carga da mesma. As decisões táticas, de médio prazo, referem-se à definição de recursos e configurações (layout) necessários para funcionamento da instalação. Boysen e Fliedner (2010) afirmam que as decisões referentes as atribuições das docas de saída podem ser classificadas tanto como táticas, quando uma doca de saída for configurada para um objetivo específico fixo por um período mais longo de tempo, por exemplo um mês, quanto operacionais, quando não há um objetivo fixo para a doca. De modo geral, as decisões operacionais estão relacionadas com decisões diárias (de curto prazo), por exemplo, a designação de docas para as cargas de entrada e de saída, roteamento dos veículos para realização das entregas, alocação de recursos dentro da instalação e empacotamento dos veículos.

O presente trabalho busca analisar apenas aspectos operacionais do cross-dock. Entretanto, embora o empacotamento das cargas nos veículos possa influenciar o processamento das cargas no cross-dock (BOYSEN; FLIEDNER, 2010), neste trabalho o consideraremos de forma aproximada como é frequente na literatura (AGUSTINA; LEE; PIPLANI, 2014). Também considera-se que não seja necessário realizar a alocação de recursos dentro da instalação e que sempre haja mão-de-obra disponível quando necessário. Desta forma, a revisão da literatura está focada apenas nas questões de designação de docas de entrada e de saída, bem como no roteamento de veículos.

A revisão da literatura é apresentada da seguinte maneira: inicialmente, são descritas algumas características do cross-dock e, em seguida, decisões operacionais a ele relacionadas. Em sequência, é apresentada uma revisão de trabalhos que consideram o problema de cross-dock com roteamento de veículos e, finalmente, aqueles que consideram a integração de decisões do 
cross-dock com o roteamento de veículos.

\subsection{Características do Cross-Docking}

De acordo com Van Belle, Valckenaers e Cattrysse (2012), diversas características podem ser consideradas para a classificação de um sistema cross-docking. Um sistema cross-docking pode ser classificado como puro quando os produtos são recebidos nas docas de entrada e enviados diretamente para as docas de saída. Enquanto que, um cross-dock de dois estágios possui uma área intermediária para reconfiguração da carga a ser enviada para as docas de saída e, posteriormente, para os clientes.

De acordo com Yan e Tang (2009), o cross-dock pode possuir classificações de pré e pósdistribuição: a primeira está fortemente associada a cross-dockings puros, pois os fornecedores são responsáveis por realizar a separação dos pedidos dos clientes e o cross-dock é apenas um agente intermediário para alocação das cargas. Em contrapartida, na segunda classificação, a instalação cross-dock possui a responsabilidade de realizar a separação dos pedidos conforme a demanda dos clientes.

A estratégia de utilizar um cross-docking puro está mais associada aos problemas de umpara-muitos, uma vez que os fornecedores realizam a separação das cargas para os seus clientes. Enquanto um cross-docking de dois estágios pode ser utilizado para cargas muitos-para-muitos, na qual diversas cargas compõem as cargas de diversos clientes e cabe ao cross-dock realizar a separação das mesmas.

\subsection{Decisões Operacionais do Cross-Dock}

Os principais trabalhos que analisam questões operacionais do cross-dock abordam decisões para execução da operação de descarregamento dos veículos de entrada e carregamento dos veículos de saída. Boysen e Fliedner (2010) afirmam que determinar tal ordenação afeta de maneira direta a eficiência das operações no interior da instalação. Por tal motivo, diversos trabalhos apresentam propostas operacionais no contexto do problema de designação e/ou ordenação dos veículos.

Ladier e Alpan (2016) apresentam duas classificações para o problema de designação e/ou ordenação dos veículos. A primeira considera o problema de sequencing, o qual consiste em determinar apenas a ordem de chegada dos veículos (e cargas), pois a própria ordenação determina o instante de processamento dos mesmos. A segunda classificação é o problema de scheduling, o qual consiste em determinar o instante de início e de término do processamento de cada carga, ou seja, o tempo é determinado de maneira explícita. 


\subsection{Modelos para Operação do Cross-Dock}

A complexidade do problema de ordenação de cargas do cross-dock considerando questões encontradas na prática foi destacada em Chen e Lee (2009), Alvarez-Pérez, GonzálezVelarde e Fowler (2009) e Ladier e Alpan (2014). Ladier e Alpan (2016) citam que muitos trabalhos tratam simplificações dos problemas encontrados na prática. Devido à sua complexidade computacional, muitos trabalhos apresentam métodos heurísticos ou meta-heurísticos para resolução do problema. Em Bernardes (2019), ressalta-se que os métodos exatos de solução podem não ser adequados para resolução de problemas de dimensões reais (grandes).

Em geral, para problemas de ordenação e designação de cargas, Bernardes (2019) indica que os modelos apresentados possuem, em geral, a sua estrutura dividida em três partes: designação e ordenação das cargas de entrada, designação e ordenação das cargas de saída e a conexão entre as cargas. A primeira busca alocar e ordenar os veículos nas docas de entrada, enquanto a segunda parte busca realizar a mesma operação nas docas de saída. A conexão entre as cargas interligam essas decisões que são fortemente dependentes.

Os problemas de designação e de ordenação de cargas apresentam semelhanças com o problema de scheduling de tarefas em máquinas. O problema de scheduling foi abordado, inicialmente, de três maneiras diferentes (PAN, 1997). A primeira, apresentada por Wagner (1959), consiste em definir uma variável binária que indica se um trabalho que é executado em uma determinada máquina em uma posição de uma fila fictícia. Em outras palavras, buscase encontrar qual a sequência de trabalhos para uma determinada máquina. A abordagem de Bowman (1959) apresenta uma modelagem em que as tarefas são processadas em períodos de tempo discretizados. Já na terceira abordagem, proposta por Manne (1960), encontra-se a sequência de tarefas a serem processadas em uma máquina por meio de precedência, ou seja, encontra-se quais tarefas são precedidas a outra tarefa (não necessariamente imediatamente) em uma máquina.

Estas três abordagens do problema de scheduling de tarefas foram utilizadas na literatura para resolução do problema de ordenação e/ou designação de cargas no cross-dock, CrossDock Scheduling Problem (CDSP). Embora sejam distintas, as mesmas podem ser dividas em duas estratégias de modelagem: precedência (MANNE, 1960) e designação (WAGNER, 1959; BOWMAN, 1959). Para revisão dos trabalhos baseados em precedência e designação sugere-se a leitura de Bernardes (2019).

Mais recentemente, foram propostas três abordagens para o problema. Nogueira et al. (2020) apresentam um método heurístico com tempo polinomial para solução do problema de sequenciamento de veículos no cross-docking utilizando uma abordagem baseada no sequenciamento de máquinas paralelas. Os autores discutem que o algoritmo, devido ao seu baixo tempo de processamento e facilidade de implementação, pode ser utilizado como uma etapa de outros algoritmos mais sofisticados afim de obter melhores resultados. Shahmardan e Sajadieh 
(2020) desenvolvem um modelo no qual é permitido que as docas do cross-docking tenham dupla função, ou seja, possam ser realizadas operações de carga e descarga na mesma doca, permitindo, por exemplo, o início das operações de carga sem que os veículos necessitem trocar de docas. Desta maneira, o modelo também permite que os veículos sejam parcialmente carregados (ou descarregados). Ainda são apresentadas implementações de um método heurístico construtivo e uma meta-heurística Simulated Annealing utilizando uma abordagem de aprendizado de máquina reforçado para avaliar a qualidade de uma vizinhança. Buakum e Wisittipanich (2020) abordaram o problema de cross-docking do ponto de vista estocástico em que o objetivo é de minimizar o atraso total nas entregas. No modelo, os processos de carga e descarga, bem como a data de entrega para os clientes, são considerados estocásticos.

\subsection{Problema de Cross-Docking com Roteamento de Veí- culos}

O problema de cross-docking associado ao roteamento de veículos é abordado na literatura de duas formas. A primeira, de acordo com Wen et al. (2009), pode ser considerada como um Problema de Roteamento de Veículos com Cross-Docking (VRPCD). Este problema consiste em determinar as rotas de coleta de mercadorias dos fornecedores para o cross-dock e as rotas de entrega das mesmas aos respectivos clientes, respeitando a devida ordem de coleta. Já a segunda forma, busca conciliar as cargas de entrada e de saída no cross-dock. Nesse caso, o roteamento das cargas de saída é planejado considerando a ordem das cargas de entrada. Tal abordagem é denominada por Agustina, Lee e Piplani (2014) como o Problema de Roteamento de Veículos e Programação do Cross-Dock (VRSP), ou Vehicle Routing and Scheduling Problem of cross-dock, em inglês. Essas abordagens são ilustradas na Figura 2. Nas Seções 2.4.1 e 2.4.2, é apresentada uma revisão bibliográfica sobre estes problemas.

\subsubsection{Problema de Roteamento de Veículos com Cross-Docking}

Os pioneiros a tratarem o VRPCD foram Lee, Jung e Lee (2006). O problema consiste em determinar as rotas de coleta e de entrega das mercadorias, sendo o cross-dock o ponto de partida e destino final das rotas. Os autores estabelecem um tempo limite de percurso para cada veículo utilizado. Além disso, os tempos de chegada de todas as mercadorias no cross-dock é o mesmo, desta forma é assegurada a disponibilidade de todas as mercadorias para a etapa de consolidação. Alguns aspectos não considerados no modelo são: o processo de movimentação interna das mercadorias no cross-dock e a existência de janelas de tempo para as entregas.

A partir do trabalho anterior, Wen et al. (2009) desconsideraram a condição na qual todas as mercadorias devem chegar ao mesmo tempo no cross-dock para incorporar ao problema janelas de tempo tanto para coleta quando para entrega das mercadorias. O modelo matemático apresentado determina que as mercadorias de uma rota são despachadas apenas quando todas 
Figura 2 - Abordagens para Problemas de cross-docking com roteamento de veículos.
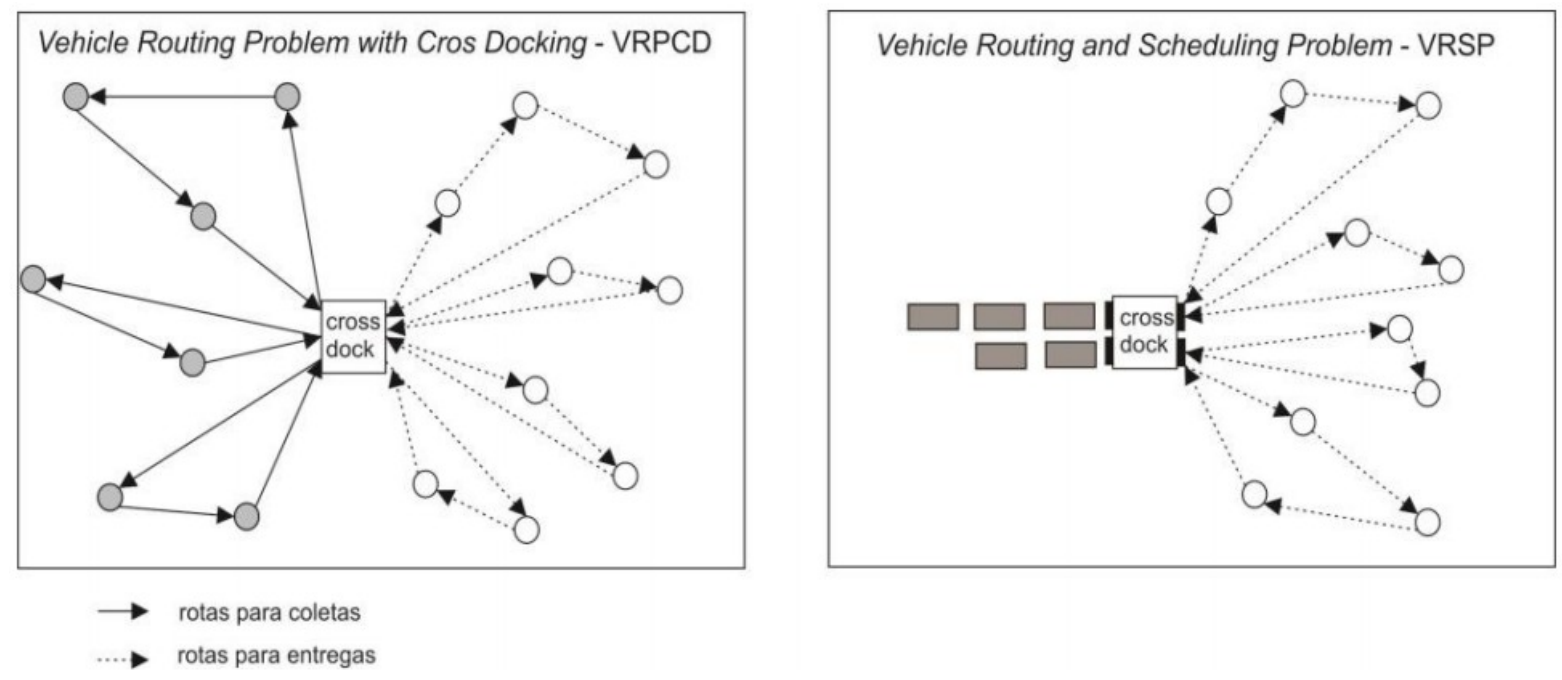

Fonte: Bernardes (2019).

as mercadorias que compõem tal rota estiverem disponíveis. Isto é possível devido a utilização de variáveis que representam os instantes de término do descarregamento das cargas de entrada e de início do carregamento das cargas de saída. Logo, a decisão referente a saída das cargas depende do momento em que as mesmas estão disponíveis, ou seja, existe uma integração entre o procedimento interno do cross-dock e os roteamentos de coleta e de entrega.

Devido à dificuldade de encontrar soluções para instâncias de dimensões reais do VRPCD, surge a necessidade de desenvolver métodos heurísticos para resolução do mesmo. Wen et al. (2009) propuseram uma Busca Tabu Adaptativa, que obteve resultados próximos a solução ótima (cerca de 5\%). Tarantilis (2013) e Morais, Mateus e Noronha (2014) desenvolveram novos métodos de resolução para o problema. Moghadam, Ghomi e Karimi (2014) adaptaram o modelo de Wen et al. (2009) afim de incluir a possibilidade de realizar a entrega fracionada ao cliente (split de carga), isto é, a carga de um cliente pode ser separada e entregue por mais de um veículo. Enquanto Yin, Lyu e Chuang (2016) abordam o problema de forma multi-objetivo, no qual visam facilitar a logística verde, utilizando-se de decisões referentes à designação e à ordenação das cargas de entrada e de saída. Maknoon e Laporte (2017) também propõem uma adaptação de Wen et al. (2009) considerando uma rede com múltiplas instalações cross-docking e permitindo o intercambio de produtos entre as mesmas.

Santos, Mateus e Cunha (2013) estudaram uma variante do VRPCD, denominada Pickup and Delivery Problem with Cross-Docking (PDPCD). Nesta variante, há a possibilidade de alguns veículos realizarem o procedimento Milk Run, desta forma os veículos podem coletar mercadorias e entregá-las para os clientes sem a necessidade de utilizar uma instalação intermediária. Os autores consideram a existência de custo de movimentação caso uma mercadoria seja recolhida por um veículo e entregue por outro, passando desta forma pela instalação intermediária. 
Outros trabalhos que tratam o VRPCD consideram questões de descarregamento e carregamento dos veículos no cross-dock. Em Dondo e Cerdá (2013), são levados em consideração os instantes de processamento da carga e o objetivo é minimizar o custo de transportes juntamente com o makespan. Já em Dondo e Cerdá (2014), tratam um número de docas menor que o número de cargas, logo há decisões referentes à ordenação das cargas. Este mesmo problema é estudado por Dondo e Cerdá (2015), entretanto, neste caso, a frota de veículos é heterogênea e o tempo de deslocamento entre as docas de entrada e de saída é relevante.

Nos trabalhos citados anteriormente, assume-se que há uma única conexão entre fornecedores e clientes (um para um), ou seja, um fornecedor envia carga para apenas um cliente. Porém, em Dondo, Meńdez e Cerdá (2009) e Dondo, Méndez e Cerdá (2011), os autores consideram uma abordagem mais ampla para o VRPCD e a gestão da cadeia de suprimentos, Vehicle Routing Problem with Cross-Docking in Supply Chain Management (VRPCD-SCM). Neste caso, é considerado um sistema de múltiplas estratégias de distribuição, bem como um sistema no qual a relação de fornecedores e de clientes é de muitos para muitos, ou seja, um fornecedor pode ter sua entrega para vários clientes e os clientes podem receber suas entregas de múltiplos fornecedores. Entretanto, os problemas são resolvidos para dimensões pequenas com até seis tipos de produtos (DONDO; MÉNDEZ; CERDÁ, 2011).

Dos trabalhos revisados, poucos consideram a frota de veículos heterogênea Dondo e Cerdá (2013), Baniamerian, Bashiri e Zabihi (2018), Theeb, Al-Araidah e Aljarrah (2019) e Baniamerian, Bashiri e Tavakkoli-Moghaddam (2019). O primeiro, busca minimizar os custos de transportes. Em Baniamerian, Bashiri e Zabihi (2018), avalia-se o VRPCD com janelas de tempo considerando a satisfação dos clientes da rede, os autores propõem minimizar a rota dos veículos e o número de clientes não satisfeitos. Baniamerian, Bashiri e Tavakkoli-Moghaddam (2019) consideram uma variação onde nem todos os clientes são atendidos, e o modelo proposto busca realizar entregas para os clientes que são mais lucrativos. Outra modificação no problema pode levar em consideração a minimização do desvio de mercadorias Theeb, Al-Araidah e Aljarrah (2019).

Mais recentemente, Hasani Goodarzi, Tavakkoli-Moghaddam e Amini (2020) propõem um modelo para o VRPCD que visa minimizar os custos operacionais e as violações nas janelas de tempo dos clientes. Um algoritmo evolucionário multi-objetivo, Multi-objective evolutionary algorithm (MOEA), foi desenvolvido para resolução do problema e comparado com outros dois algoritmos (NSGA-II e PAES). O algoritmo proposto apresentou resultados superiores para a abordagem bi-objetivo encontrando soluções que dominavam as soluções encontradas pelos demais algoritmos.

Para maiores informações sobre estudos relacionados ao VRPCD, sugere-se a leitura de Mavi et al. (2020), no qual é apresentada uma revisão sistemática da literatura sobre o tema. 


\subsubsection{Problema de Roteamento de Veículos e Programação do Cross- Dock}

Estudos sobre o problema de roteamento de veículos e programação do cross-dock não são frequentes na literatura. O objetivo é tratar decisões integradas entre o roteamento de veículos e a ordenação das docas de entrada e de saída do cross-dock (VRSP). Agustina, Lee e Piplani (2014) apresentam o problema para um conjunto de pedidos que devem ser atendidos pelos fornecedores, os quais enviam suas cargas para um cross-dock em que elas são recebidas e reorganizadas afim de atender aos pedidos. Esta abordagem integra a programação das rotas de entrega com decisões internas do cross-dock. Tais decisões incluem: seleção da doca de entrada de uma carga, momento de recebimento da carga, seleção da doca de saída e ordenação das cargas na doca de saída. Os autores consideram que os pedidos estão consolidados em paletes, que cada carga de chegada pode conter mais de um pedido (um para muitos) e que o manuseio no cross-dock se dá por tais paletes. Agustina, Lee e Piplani (2014) tratam o problema no contexto de produtos perecíveis, os quais devem ficar o menor tempo possível na instalação cross-dock afim de garantir o maior frescor dos produtos.

Rahbari et al. (2019) apresentam uma extensão do problema que considera uma frota de veículos heterogênea e a possibilidade de um pedido ser composto por produtos de diferentes cargas de entrada (muitos para muitos). Logo, as cargas recebidas podem ser desmontadas, rearranjadas e consolidadas novamente para atender as demandas dos clientes, ou seja, um pedido pode ser composto por produtos de diferentes fornecedores. Os autores ainda consideram uma função bi-objetivo para redução de custos associados ao cross-docking e maximizar o frescor dos produtos, que são perecíveis. Os dois trabalhos considerem o contexto de produtos perecíveis, porém Rahbari et al. (2019) também trata a incerteza nos tempos de viagem e na validade dos produtos.

Bernardes (2019) aborda o problema para produtos não perecíveis, logo é possível desconsiderar a validade dos produtos. Em seu trabalho, também é considerado o sistema de fornecedores e de clientes de muitos para muitos. Diferentemente dos autores anteriores, o autor aborda tempos internos de transferência das mercadorias durante o processo de cross-docking. Outra diferença está associada à quantidade de veículos a serem utilizados, para Bernardes (2019) isto é uma variável de decisão do modelo, enquanto para Agustina, Lee e Piplani (2014) e Rahbari et al. (2019) são parâmetros conhecidos do problema.

Liao (2020) propõe uma abordagem que, dentre um dos objetivos, busca minimizar o número de docas necessárias na operação de carregamento dos veículos. O procedimento utiliza uma meta heurística Iterated Local Search (ILS) para solucionar o problema do roteamento de veículos e uma abordagem gulosa para reduzir o número de docas necessárias no operação de entrega. $\mathrm{O}$ autor também propõe como objetivos a redução dos custos de viagem, do tempo de utilização dos veículos e da violação nas janelas de tempo de atendimento aos clientes. Diferentemente de Bernardes (2019), Liao (2020) não trata os tempos internos de transferência 
dos produtos entre docas e o tempo para encerramento da operação do cross-dock.

\subsection{Dimensionamento da Frota de Veículos}

Um dos objetivos do presente trabalho é a redução do número de veículos utilizados na operação do cross-dock, desta maneira, a presente seção apresenta uma revisão para problemas relacionados ao dimensionamento da frota. Os trabalhos relacionados ao dimensionamento da frota de veículos estão, na revisão levantada, associados a problemas com frotas heterogêneas, nos quais busca-se determinar a frota de menor custo, também considerando os custos de roteamento. Gheysens, Golden e Assad (1984) destacam que o Fleet Size and Mix Vehicle Routing Problem (FSMVRP), ou Problema de Roteamento de Veículos com Dimensionamento e Combinação da Frota em português, busca determinar, a partir de um conjunto de veículos heterogêneos, quais e quantos dos mesmos serão utilizados na operação, enquanto o VRP assume uma frota homogênea fixa para a operação. A primeira abordagem para resolução do FSMVRP foi apresentada por Golden et al. (1984), na qual os autores apresentaram uma abordagem na qual a utilização de cada veículo é associada a um custo fixo. No mesmo trabalho, ainda são apresentados métodos heurísticos para tratar o problema.

Desrochers e Verhoog (1991) propuseram uma heurística adaptada do algoritmo de economia baseado em correspondência, a qual considera as economias de rotas a partir de veículos distintos para melhorar novas rotas. $\mathrm{O}$ algoritmo considera as economias como Golden et al. (1984). Ronen (1992) apresenta uma variação do FSMVRP, na qual o problema consiste em alocar aos veículos, um conjunto de rotas pré-definidas, de maneira a minimizar os custos de viagem. Em tal abordagem, Ronen (1992) também considera penalidades por sub (ou super) utilização dos veículos. Salhi et al. (1992) apresentam pequenas adaptações de heurísticas desenvolvidas anteriormente para o FSMVRP. Os melhores resultados são obtidos por uma abordagem baseada no procedimento de perturbação de rota, detalhada em Salhi e Rand (1993), a qual encontrou soluções $0,90 \%$ distantes das melhores conhecidas.

Gendreau et al. (1999) desenvolvem uma heurística de busca tabu, utilizando a heurística GENIUS para obter uma solução de partida. O método possui uma fase de construção, Generalized Insertion (GENI), e uma fase de melhoria da solução, Unstringing and Stringing (US). Na etapa de busca tabu, é utilizado o método de memória adaptativa, Adaptative Memory Procedure (AMP), proposta por Rochat e Taillard (1995). Wassan e Osman (2002) também utilizam de uma busca tabu para o FSMVRP, entretanto os mesmos apresentam novas variações para diferentes componentes, vizinhanças e estruturas de memória.

Taillard (1999) trata um contexto diferente dos anteriores, no qual o número de veículos de um determinado tipo não é ilimitado, denominado Heterogeneous Fixed Fleet Vehicle Routing Problem (HFFVRP), Problema de Roteamento de Veículos de Frota Heterogênea Fixa, em português. Sendo assim, Taillard (1999) busca encontrar a melhor utilização de uma determinada 
frota de veículos, por meio de uma heurística de geração de colunas. Tarantilis, Kiranoudis e Vassiliadis (2004) propuseram uma meta-heurística denominada Backtracking Adaptative Threshold Accepting (BATA) para resolução do HFFVRP. Os autores obtiveram melhores resultados em várias instâncias em relação à Taillard (1999).

Na literatura, são apresentados diversos trabalhos relacionados ao Fleet Size and Mix Vehicle Routing Problem with Time Windows (FSMVRPTW), ou FSMVRP com Janelas de Tempo, o qual foi introduzido por Liu e Shen (1999). Os autores apresentam o problema e uma heurística de inserção sequencial para resolução do mesmo. Tal heurística utiliza um parâmetro $\eta$ para controlar a construção das rotas, afim de evitar que sejam geradas soluções de baixa qualidade. Dullaert et al. (2002) apresentam uma heurística considerada uma extensão de Solomon (1987), com adaptações para avaliar as economias de uma inserção de Golden et al. (1984), capaz de encontrar melhores resultados que Liu e Shen (1999). Belfiore e Fávero (2007) desenvolvem um algoritmo scatter search, de Glover (1977) e Glover (1998), para obter melhores soluções que Liu e Shen (1999) e Dullaert et al. (2002). O algoritmo utiliza os métodos de Dullaert et al. (2002) e uma adaptação de Golden et al. (1984) para gerar soluções iniciais para o algoritmo scatter search.

Dell'amico et al. (2007) apresentam uma heurística construtiva paralela, bem como um procedimento de destruição e reconstrução para melhoria das soluções do FSMVRPTW. Um algoritmo de três fases é proposto por Bräysy et al. (2008). A primeira fase do algoritmo proposto consiste em construir soluções iniciais baseadas nos algoritmos de economia em conjunto com mecanismos de diversificação, de modo que a segunda fase consiste em reduzir a quantidade de veículos com buscas locais, enquanto a última fase busca melhorar as soluções obtidas da segunda fase por meio de quatro buscas locais. Posteriormente, Bräysy et al. (2009) retomam o algoritmo com três fases, porém com modificações nas mesmas afim de aumentar a eficiência do algoritmo para problemas de dimensões maiores.

Repoussis e Tarantilis (2010) apresenta um método de solução baseado em memória adaptativa. O procedimento consiste em duas fases: determinar um conjunto inicial de soluções diversificadas e de boa qualidade e realizar a exploração e atualização deste conjunto. Tal procedimento gerou algumas soluções melhores que as conhecidas para a literatura.

Mais recentemente, Koç et al. (2016) introduzem ao problema e apresentam um algoritmo para o Fleet Size and Mix Location-Routing Problem with Time Windows (FSMLRPTW), Problema de Localização e Roteamento de Veículos com Dimensionamento e Combinação da Frota com Janelas de Tempo em português, o qual consiste em determinar o número e rotas dos veículos, localização, alocação de clientes ao depósitos simultaneamente. Os autores utilizam de um Hybrid Evolutionary Search Algorithm (HESA), ou Algoritmo Hibrido Evolucionário de Busca. Asefi et al. (2019) apresentam um modelo matemático com resolução via otimização multiobjetivo do FSMVRP considerando um contexto de lixo sólido, buscando minimizar os custos operacionais e equilibrar a alocação de cargas em estações de transferência. Karakostas, 
Sifaleras e Georgiadis (2020) propõe uma General Variable Neighborhood Search (GVNS), ou Busca de Vizinhança Variável Generalizado para um contexto de poluição. Os autores buscam reduzir o custo de abertura de facilidades, custo de estoques dos produtos e custos de roteirização.

\subsection{Considerações}

Como é possível observar, diversos são os trabalhos que abordam problemas que envolvem um cross-dock. Os trabalhos variam suas características e seus objetivos de acordo com o contexto estudado. Embora os trabalhos apresentados na Seção 2.4.1 não considerem uma integração entre o roteamento de veículos e o processamento interno do cross-dock, Buijs, Vis e Carlo (2014) descrevem a importância de se considerar estes problemas de maneira integrada. Boysen e Fliedner (2010) apontam que tais fatores estão relacionados e Yin, Lyu e Chuang (2016) destacam a necessidade de considerar os problemas de maneira integrada, uma vez que estão presentes na prática.

O problema estudado no presente trabalho, o qual é detalhado no próximo capítulo é o VRSP inspirado em um sistema de distribuição de uma rede de varejo de produtos não perecíveis. A rede varejista possui diversos fornecedores que enviam diferentes tipos de produtos para vários clientes, o que caracteriza uma rede de distribuição de muitos para muitos. Os produtos são recebidos e reorganizados no cross-dock, em seguida, são carregados e despachados para os clientes. A rota de entrega também é parte do problema. Como apresentado na Seção 2.4.2, embora todos os trabalhos citados estudem variantes do VRSP, nenhum avalia o número de veículos utilizados na operação, o que é um fator de grande impacto ambiental no sistema rodoviário de transporte. De acordo com estatísticas do Reino Unido, o setor de transportes foi responsável, no ano de 2010 por um total de $23 \%$ das emissões de dióxido de carbono $\left(\mathrm{CO}_{2}\right)$, sendo mais de $70 \%$ oriundos do transporte rodoviário, além disto os veículos circulam com menos de $60 \%$ da sua capacidade e cerca de 30\% dos veículos circulam vazios (Freight Transport Association, 2014). 



\section{3}

\section{DEFINIÇÃO DO PROBLEMA E MODELAGEM}

O problema estudado aborda o planejamento operacional de um sistema cross-docking integrando decisões de designação, ordenação e consolidação de cargas juntamente às decisões de roteamento dos veículos para entrega das mercadorias. Embora os estudos sobre os dois problemas apresentem resultados relevantes, poucos abordam os problemas de maneira integrada. Conforme discutido na Seção 2.4.2, é de nosso conhecimento que Agustina, Lee e Piplani (2014), Rahbari et al. (2019), Bernardes (2019) e Liao (2020) estudam o problema de maneira integrada. O presente trabalho foi inspirado no modelo proposto por Bernardes (2019), considerando, adicionalmente, reduzir o número de veículos utilizados na operação de entrega. Neste capítulo, são apresentados a definição do problema estudado bem como um modelo de programação inteira mista para descreve-lo.

\subsection{Definição do Problema}

O problema estudado teve por inspiração um sistema de distribuição de uma rede de varejo. Busca-se minimizar os custos envolvidos na operação de cross-docking para distribuição dos produtos da rede, bem como a redução no número de veículos utilizados na operação. Os produtos são enviados dos fornecedores para uma instalação de cross-dock. No cross-dock, os produtos são manipulados e reorganizados a fim de atender as demandas de cada uma das lojas da rede para a qual são enviados.

A Figura 3 ilustra de maneira esquemática um sistema de cross-docking, no qual as cargas de entrada são recebidas, processadas e temporariamente estocadas ou encaminhadas para as docas de saída. É possível que cada carregamento seja composto por diversos paletes de diferentes produtos, entretanto, cada palete possui um único tipo de produto. Os produtos são separados e transferidos para uma área de consolidação, onde são organizados conforme a demanda de cada loja. 
Figura 3 - Representação de um Sistema Cross-Docking.

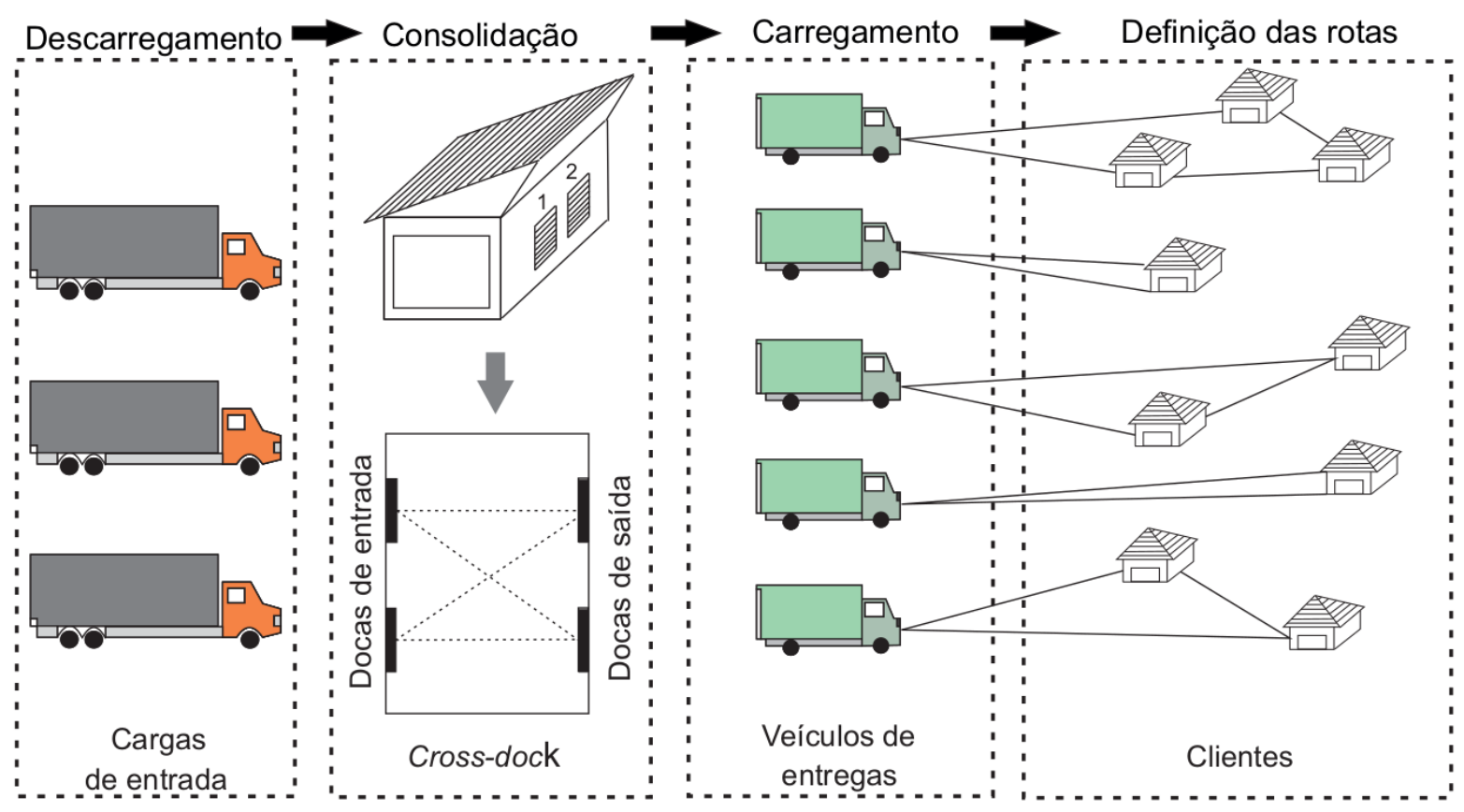

Fonte: Bernardes (2019)

Afim de tornar a distribuição dos produtos mais eficiente, conforme apresentado por Agustina, Lee e Piplani (2014), é necessário realizar o planejamento integrado entre o recebimento de mercadorias e a distribuição final. Pode-se notar na Figura 3 que a entrega dos produtos pode ser realizada passando por diversos clientes em uma mesma rota. Desta maneira, um veículo só poderá iniciar uma rota quando todas as mercadorias da rota estiverem consolidadas. Estes, por sua vez, estarão consolidados apenas quando todas as mercadorias necessárias estiverem disponíveis. Assim, fica evidente a necessidade de se planejar o recebimento de mercadorias e a entrega das mesmas.

Sendo assim, como discutido anteriormente, ressaltam-se as decisões necessárias para o planejamento eficiente de um cross-dock como o estudado:

- decisão sobre a designação dos veículos nas docas de entrada;

- decisão da ordem de descarregamento dos veículos;

- decisão de consolidação direta da carga ou estocagem da mesma;

- decisão sobre a designação das docas de saída e da ordem de consolidação das cargas de saída, visto que as janelas de tempos dos clientes devem ser atendidas;

- decisão sobre o roteamento e o momento de saída dos veículos utilizados nas entregas aos clientes. 
Outro tópico, geralmente não abordado na literatura de cross-docking quando ao roteamento de veículos, é o número de veículos utilizados na operação. Em modelos presentes na literatura, o número de veículos utilizados na operação pode ser considerado como parâmetro, ou variável de decisão, contudo nenhum dos modelos busca reduzir este número, o que pode gerar um impacto ambiental caso muitos veículos estejam transitando.

Desta maneira, tem-se por objetivo obter a programação interna do cross-dock, bem como o roteamento que minimizam o custo total e o número de veículos utilizados na operação. O custo está associado ao custo de transporte e de operação do cross-dock. Com a redução no número de veículos, busca-se avaliar o impacto causado ao sistema de maneira a tentar reduzir o espaço ocioso nos veículos, uma vez que reduzir o número de veículos implica em uma melhor utilização dos mesmos.

\subsection{Modelagem do Problema}

Na presente seção, são apresentados primeiramente o modelo de programação inteira mista para o VRCDSP de Bernardes (2019) e na sequência um modelo que encorpora as questões não consideradas anteriormente. A diferença está na inclusão do número de veículos como um objetivo do modelo.

As hipóteses consideradas para a modelagem do problema são:

- as cargas de entrada estão disponíveis para a programação no início da operação;

- os tempos de processamento das cargas de entrada podem ser distintos e incluem os tempos de posicionamento da carga na doca, de descarga dos paletes, de desmontagem dos mesmos, quando necessário e de identificação dos produtos;

- o tempo de transferência de uma unidade de cada tipo de produto é conhecido. Os mesmos podem ser distintos devido à complexidade de manuseio da carga e doca de descarga dos produtos;

- o tempo de processamento de um carga de saída é equivalente ao tempo gasto para transportar os paletes consolidados para o interior do veículo a partir da doca de saída. Tal tempo é proporcional ao número de paletes da carga consolidada. Além disso, considera-se que o tempo para troca dos veículos em uma doca de saída independe da sequência dos carregamentos e é conhecido;

- o processamento de uma carga de entrada ou de saída, uma vez iniciado, deve ser finalizado e não pode ser interrompido;

- os produtos de um carga de entrada estão disponíveis apenas após o término do processamento da mesma; 
- as demandas dos clientes são conhecidas e o número de paletes necessário para anteder a demanda é sempre menor ou igual que a capacidade do veículo;

- todos os veículos utilizados têm a mesma capacidade de carregamento (em paletes) e a mesma velocidade de deslocamento (Frota homogênea);

- não é possível realizar split de cargas, ou seja, cada cliente recebe a entrega por apenas um veículo;

- o custo de viagem entre clientes é diretamente proporcional ao tempo de viagem;

- o tempo de serviço em cada cliente para descarga da entrega é proporcional ao número de paletes requeridos;

- as janelas de tempo para as entregas aos clientes são conhecidas, entretanto, são permitidas antecipações ou atrasos, os quais são penalizados por unidade de tempo da antecipação ou atraso;

- as operações para realizar a distribuição devem ser efetuadas dentro de um intervalo de tempo conhecido e pré-determinado;

\subsubsection{Modelo Literatura}

Bernardes (2019) apresenta dois modelos para o VRCDSP, bem como os desempenhos computacionais dos mesmos. O autor conclui que um de seus modelos tem melhor desempenho computacional. Desta maneira, escolheu-se por base tal modelo que apresentou os melhores resultados que foi escolhido neste trabalho e é descrito a seguir.

Primeiramente são apresentados os conjuntos, os índices, os parâmetros e as variáveis utilizados para a modelagem de Bernardes (2019).

\section{Conjuntos:}

$\mathscr{L}: \quad$ conjunto de $L$ cargas de entrada,

$\mathscr{P}: \quad$ conjunto de $P$ tipos de produtos,

$\mathscr{N}: \quad$ conjunto de $N$ clientes,

$\mathscr{F}$ : conjunto de $F$ docas de entrada,

$\mathscr{H}$ : conjunto de $H$ docas de saída.

\section{Índices:}

$l, m: \quad$ cargas de entrada

$p: \quad$ tipo de produto 

$i, j, n: \quad$ cliente
$f: \quad$ doca de entrada
$h: \quad$ doca de saída

\section{Parâmetros:}

$\begin{array}{ll}P T_{l}: & \text { tempo de processamento da carga de entrada } l, \\ R_{l}^{p}: & \text { número de produtos do tipo } p \text { na carga de entrada } l, \\ T R_{f h}^{p}: & \text { tempo para a transferência de uma unidade do produto } p \text { da doca de entrada }\end{array}$ $f$ para a doca de saída $h$,

LT : $\quad$ tempo para movimentar um palete da área de consolidação para o interior do veículo,

$C T: \quad$ tempo de troca dos veículos na doca de saída,

CAP : $\quad$ capacidade (em paletes) de cada veículo de entrega,

$D_{i}^{p}: \quad$ número de produtos $p$ demandados pelo cliente $i$,

$Q_{i}$ : $\quad$ número de paletes necessários para organizar o pedido do cliente $i$,

$C O$ : $\quad$ custo operacional do cross-dock por unidade de tempo,

$T T_{i j}\left(C T_{i j}\right): \quad$ tempo (ou custo) de viagem entre o cliente $i$ e $j$,

$C E(C L)$ : $\quad$ penalidade por unidade de tempo de antecipação (ou atraso) nas entregas, $S T_{i}: \quad$ tempo de serviço para descarregar os paletes do pedido do cliente $i$, $\left[A_{i}, B_{i}\right]: \quad$ janela de tempo para entrega do pedido do cliente $i$, na qual $A_{i}$ é o início da janela e $B_{i}$ é o final,

$T^{m a x}: \quad \quad \quad$ tempo máximo para completar todas as atividades do cross-dock, incluindo as entregas de mercadoria e o retorno dos veículos ao cross-dock,

$M$ : $\quad$ uma constante com valor suficientemente grande.

\section{Variáveis Binárias:}

$z_{l f}^{i n} \in\{0,1\}: \quad$ assume o valor 1 , se a carga de entrada $l$ é processada na doca $f$, e 0 , caso contrário,

$w_{l m}^{i n} \in\{0,1\}$ : assune o valor 1 , se as cargas de entrada $l$ e $m$ são processadas na mesma doca e o processamento de $l$ precede o processamento de $m$, e 0 , caso contrário, $z_{i h}^{\text {out }} \in\{0,1\}:$ assume o valor 1 , se o veículo cujo primeiro cliente visitado é o cliente $i$ e coleta sua carga na doca de saída $h$, e 0 , caso contrário,

$w_{i j}^{\text {out }} \in\{0,1\}$ : assume o valor 1 , se os veículos que iniciam suas rotas nos cliente $i$ e $j$ coletam suas cargas na mesma doca de saída, sendo que o veículo que inicia a rota em $i$ precede o veículo que inicia a rota em $j$, e 0 , caso contrário, 
$y_{l i} \in\{0,1\}: \quad$ assume o valor 1 , se pelo menos um tipo de produto é transferido da carga de entrada $l$ para a carga de saída coletada pelo veículo que inicia sua rota em $i$, e 0 , caso contrário,

$x_{i j} \in\{0,1\}:$ assume o valor 1 , se o veículo viaja do cliente $i$ para o cliente $j$, e 0 , caso contrário,

$v_{i j} \in\{0,1\}: \quad$ assume o valor 1 , se o cliente $i$ pertence a rota que inicia com a entrega do cliente $j$, e 0 , caso contrário.

\section{Variáveis Contínuas:}

$u t_{l} \geq 0: \quad$ instante de encerramento do processamento da carga de entrada $l$,

$r t_{i} \geq 0: \quad$ instante da liberação para o carregamento da carga de saída coletada pelo veículo cuja rota inicia com a entrega do cliente $i$,

$d t_{i} \geq 0: \quad$ instante de encerramento da operação de carregamento do veículo cuja rota inicia com a entrega do cliente $i$,

$d t^{\max } \geq 0: \quad$ instante de encerramento da operação de carregamento do último veículo de entrega,

$\rho_{l f i h}^{p} \geq 0: \quad$ número de produtos $p$ transferidos da carga de entrada $l$ recebida na doca $f$ para a carga de saída coletada pelo veículo cuja rota inicia com a entrega do cliente $i$ e é carregado na doca de saída $h$,

$t_{i} \geq 0: \quad$ instante de chegada ao cliente $i$,

$t_{N+1} \geq 0: \quad$ instante de chegada ao cross-dock

$e t_{i}\left(l t_{i}\right) \geq 0: \quad$ tempo de antecipação (atraso) na entrega da demanda do cliente $i$.

De acordo com Bernardes (2019), os modelos desenvolvidos para o VRCDSP podem ser dividos em quatro subconjuntos de restrições devido aos tipos de decisões a serem tomadas no problema. Tais subconjuntos podem ser descritos como decisões de designação e ordenação das cargas de entrada, designação e ordenação das cargas de saída, definição das rotas e a conexão entre as cargas e rotas.

Sendo assim, o modelo de Bernardes (2019) é apresentado por subconjuntos a seguir.

$$
\min \sum_{i \in \mathscr{N} \cup\{0\}} \sum_{j \in \mathscr{N} \cup\{N+1\}, i \neq j} C T_{i j} x_{i j}+\sum_{i \in \mathscr{N}} C E e t_{i}+\sum_{i \in \mathscr{N}} C L l t_{i}+C O d t^{\max }
$$

Sujeito a: 


\section{Designação e ordenação das cargas de entrada}

$$
\begin{array}{lr}
\sum_{f \in \mathscr{F}} z_{l f}^{i n}=1 & \forall l \in \mathscr{L} \\
w_{l m}^{i n}+w_{m l}^{i n} \geq z_{l f}^{i n}+z_{m f}^{i n}-1 & \forall l, m \in \mathscr{L}(l<m) ; f \in \mathscr{F} \\
u t_{l} \geq P T_{l} & \forall l \in \mathscr{L} \\
u t_{m} \geq u t_{l}+P T_{m}-M\left(1-w_{l m}^{i n}\right) & \forall l, m \in \mathscr{L}(l \neq m)
\end{array}
$$

A função objetivo expressada em (3.1) visa minimizar os custos considerados e relacionados ao cross-dock. A primeira parcela representa a soma dos custos de transportes, as parcelas intermediarias são custos de atraso e antecipação nas entregas, enquanto a última parcela é o custo de operação do cross-dock por unidade de tempo.

As restrições (3.2) garantem que as cargas de entrada sejam alocadas a apenas uma doca de entrada. As restrições (3.3) e (3.5) apresentam relações de precedência para as cargas alocadas em uma doca de entrada. As restrições (3.3) definem a ordem de processamento das cargas em uma determinada doca de entrada, ou seja, caso as cargas de entrada $l$ e $m$ sejam processadas na doca $f\left(z_{l f}^{i n}=z_{m f}^{i n}=1\right)$, o valor de pelo menos uma das variáveis $w_{l m}^{i n}$ ou $w_{m l}^{i n}$ será 1 determinando qual carga $m$ ou $l$ será processada primeiro. Embora o conjunto de restrições (3.3) permita que as variáveis $w_{l m}^{i n}$ e $w_{m l}^{i n}$ possam ter valor 1, as restrições (3.5) garantem que caso tal fato ocorra, a solução se torne infactível, uma vez que seria necessário satisfazer as restrições $u t_{m} \geq u t_{l}+P T_{m}$ e $u t_{m} \leq u t_{l}-P T_{l}$ simultaneamente. Desta maneira, como discutido anteriormente, as restrições (3.3) e (3.5) definem a ordem de processamento das cargas de entrada, bem como o instante de término do processamento das mesmas. As restrições (3.4) define o instante mínimo do término de processamento cargas nas docas de entrada. Este é o instante para as primeiras cargas alocadas em uma determinada doca de entrada, uma vez que o instante de término para as demais é definido pelas restrições (3.5).

\section{Designação e ordenação das cargas de saída}

$$
\begin{array}{lr}
\sum_{h \in \mathscr{H}} z_{i h}^{\text {out }}=x_{0 i} & \forall i \in \mathscr{N} \\
w_{i j}^{\text {out }}+w_{j i}^{\text {out }} \geq z_{\text {out }}^{\text {out }}+z_{j h}^{\text {out }}-1 & \forall i, j \in \mathscr{N}(i<j) ; h \in \mathscr{H} \\
d t^{\text {max }} \geq d t_{i} & \forall i \in \mathscr{N} \\
d t_{j} \geq d t_{i}+C T+L T\left(Q_{j} x_{0 j}+\sum_{n \in \mathscr{N}, i \neq j} Q_{n} v_{n j}\right)-M\left(1-w_{i j}^{\text {out }}\right) & \forall i, j \in \mathscr{N}(i \neq j)
\end{array}
$$

As restrições referentes a designação e ordenação das cargas de saída são análogas às restrições (3.2)-(3.5). As restrições (3.6) indicam que todas as cargas de uma doca de saída $h$ devem ser alocadas a um cliente inicial $i$. As restrições (3.7) apresentam a precedência das cargas de saída, análogo a (3.3). As restrições (3.8) impõem que o tempo de operação do cross-dock será pelo menos igual ao instante do encerramento do carregamento da última carga de saída do 
cross-dock, equivalente ao makespan do cross-dock. As restrições (3.9) impõem as relações do instante de término de operação de cargas que são processadas em uma mesma doca, levando em consideração o tempo total gasto na entrega das mercadorias por um determinado veículo.

\section{Conexão entre as cargas e as rotas}

$$
\begin{array}{lr}
\sum_{i \in \mathscr{N}} \sum_{h \in \mathscr{H}} \rho_{l f i h}^{p}=R_{l}^{p} z_{l f}^{i n} & \forall p \in \mathscr{P} ; l \in \mathscr{L} ; f \in \mathscr{F} \\
\sum_{p \in \mathscr{P}} \sum_{l \in \mathscr{L}} \sum_{f \in \mathscr{F}} \rho_{l f i h}^{p} \leq\left(\sum_{p \in \mathscr{P}} \sum_{l \in \mathscr{L}} R_{l}^{p}\right) z_{i h}^{\text {out }} & \forall i \in \mathscr{N} ; h \in \mathscr{H} \\
\sum_{p \in \mathscr{P}} \sum_{f \in \mathscr{F}} \sum_{h \in \mathscr{H}} \rho_{l f i h}^{p} \leq\left(\sum_{p \in \mathscr{P}} R_{l}^{p}\right) y_{l i} & \forall l \in \mathscr{L} ; i \in \mathscr{N} \\
r t_{i} \geq u t_{l}+\sum_{p \in \mathscr{P}} \sum_{f \in \mathscr{F}} \sum_{h \in \mathscr{H}} T R_{f h}^{p} \rho_{l f i h}^{p}-M\left(1-y_{l i}\right) & \forall l \in \mathscr{L} ; i \in \mathscr{N} \\
t_{i} \geq d t_{i}+T T_{0 i}-M\left(1-x_{0 i}\right) & \forall i \in \mathscr{N} \\
d t_{i} \geq r t_{i}+L T\left(Q_{i} x_{0 i}+\sum_{j \in \mathscr{N} ; j \neq i} Q_{j} v_{j i}\right)-M\left(1-x_{0 i}\right) & \forall i \in \mathscr{N} \\
\sum_{l \in \mathscr{L}} \sum_{f \in \mathscr{F}} \sum_{h \in \mathscr{H}} \rho_{l f i h}^{p}=D_{i}^{p} x_{0 i}+\sum_{j \in \mathscr{Y} ; j \neq i} D_{j}^{p} v_{j i} & \forall p \in \mathscr{P} ; i \in \mathscr{N}
\end{array}
$$

O conjunto de restrições (3.10)-(3.16) apresentam a integração entre a operação no cross-dock e o roteamento de veículos. As restrições (3.10) impõem um balanceamento das cargas recebidas e expedidas no cross-dock, uma vez que é imposto que todas as cargas recebidas devem ser expedidas por alguma doca de saída. As restrições (3.11) estabelecem a quantidade máxima de produtos a serem transferidos a uma doca de saída. As restrições (3.12) permitem a transferência de produtos entre a carga de entrada $l$ e a carga de saída $i$ caso a variável $y_{l i}$ assumir o valor 1. Desta maneira, quando houver a transferência de algum produto de uma carga de entrada para uma carga de saída as restrições (3.13) impõem que a carga de saída deve respeitar o término do processamento da carga de entrada. As restrições (3.14) estabelecem que o instante de chegada nos primeiros clientes visitados deve respeitar o término do processamento da carga de saída. Desta maneira, as restrições (3.15) indicam que o término da operação do carregamento de uma carga de saída deve ser posterior à disponibilidade para transferência dos paletes consolidados para o interior do veículo. Já em (3.16) são impostas as condições necessárias para que a carga presente em veículo seja suficiente para atender a demanda dos clientes da rota. 


$$
\begin{array}{lr}
\sum_{i \in \mathscr{N} \cup\{0\} ; i \neq j} x_{i j}=1 & \forall j \in \mathscr{N} \\
\sum_{j \in \mathscr{N} \cup\{N+1\} ; i \neq j} x_{i j}=1 & \forall i \in \mathscr{N} \\
v_{i j} \geq x_{0 j}-\left(1-x_{j i}\right) & \forall i, j \in \mathscr{N}(i \neq j) \\
v_{i j} \geq v_{n j}-\left(1-x_{i n}\right) & \forall i, j, n \in \mathscr{N}(i \neq j, i \neq n, j \neq n) \\
\sum_{j \in \mathscr{N} ; j \neq i} v_{i j}+x_{0 i}=1 & \forall i \in \mathscr{N} \\
\sum_{i \in \mathscr{N} ; i \neq j} Q_{i} v_{i j}+Q_{j} x_{0 j} \leq C A P x_{0 j} & \forall j \in \mathscr{N} \\
t_{j} \geq t_{i}+S T_{i}+T T_{i j}-M\left(1-x_{i j}\right) & \forall i \in \mathscr{N}, j \in \mathscr{N} \cup\{N+1\}(i \neq j) \\
A_{i}-e t_{i} \leq t_{i} \leq B_{i}+l t_{i} & \forall i \in \mathscr{N} \\
t_{N+1} \leq T^{\max } &
\end{array}
$$

As restrições apresentadas em (3.17)-(3.25) são referentes ao roteamento dos veículos. As restrições (3.17) e (3.18) asseguram que cada cliente seja visitado uma única vez. Vale indicar que tais restrições não se aplicam ao cross-dock, pois o mesmo é o ponto de partida e o destino final de todos os veículos utilizados na entrega. As restrições (3.19), (3.20) e (3.21) são utilizadas para indicar a existência de um cliente em uma determinada rota, ou seja, impõem que a variável $v_{i j}$ assuma valor 1 caso o cliente $i$ esteja presente na rota que inicia no cliente $j$. As restrições (3.22) restringem a quantidade de mercadorias no veículo pela capacidade máxima do mesmo. As restrições (3.23) estabelecem a sucessão de tempos de chegada nos clientes, respeitando a ordenação estabelecida, enquanto as restrições (3.24) estabelecem as janelas de tempo para visita ao cliente. É possível notar que são permitidas antecipações ou atrasos na entrega das mercadorias, e que os mesmos são penalizados na função objetivo. Por fim, as restrições (3.25) impõem o tempo máximo de operação do cross-dock por meio do retorno dos veículos ao mesmo. O domínio das variáveis é expresso acima, juntamente com a descrição das variáveis.

O modelo de Bernardes (2019) considera diversas características do problema do crossdock. Entretanto, devido as crescentes preocupações referentes à questão ambiental, é proposta uma adaptação do modelo, a fim de tratar o número de veículos utilizados nas entregas, incluindo ao modelo (3.1)-(3.25) o objetivo (3.26).

$$
\min \sum_{j \in \mathscr{N}} x_{0 j}
$$


Figura 4 - Exemplo Ilustrativo.

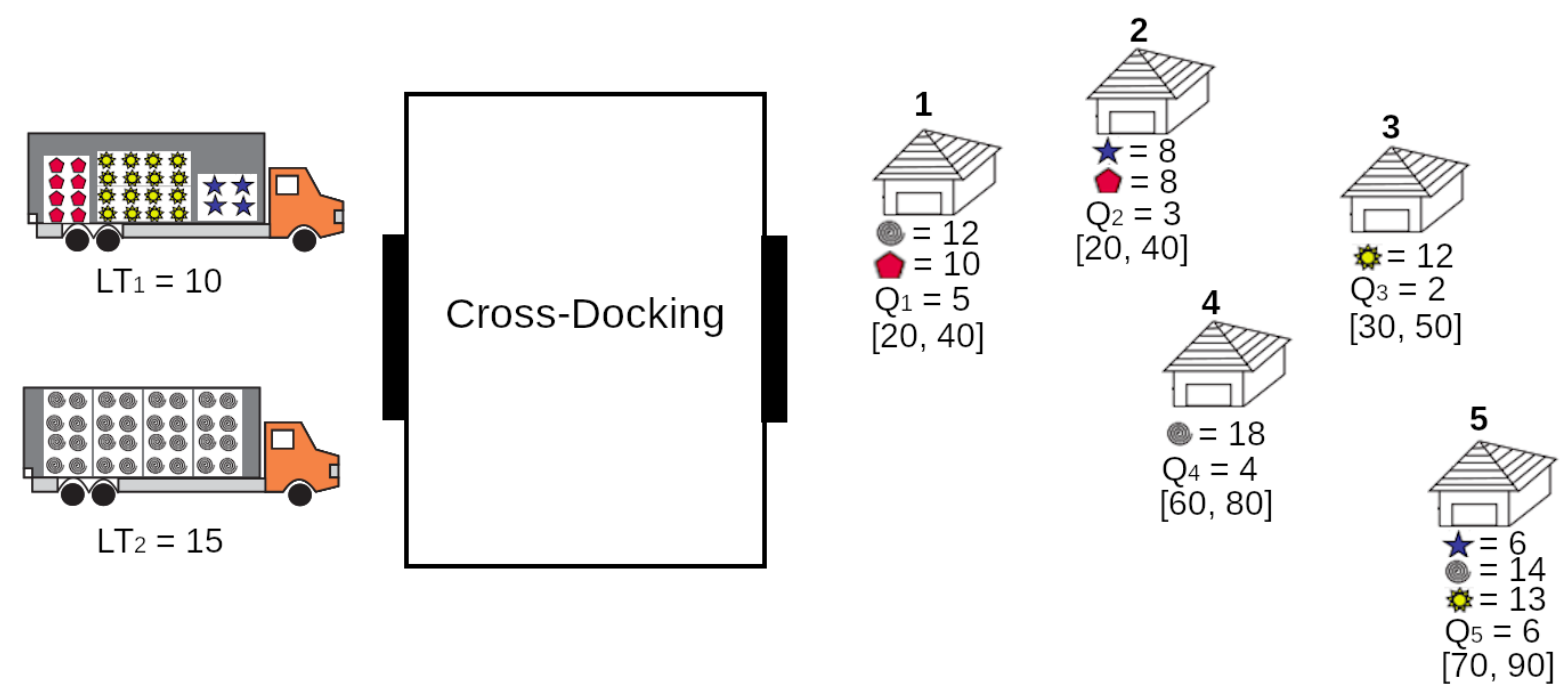

Fonte: Elaborado pelo Autor.

\subsection{Exemplo ilustrativo}

Considere o problema de determinar a operação de uma instalação cross-docking, a qual possui alguns parâmetros descritos na Figura 4. É possível verificar que existem duas cargas de entrada para uma única doca de entrada. Também é possível notar que há quatro tipos de produtos a serem distribuídos a cinco clientes com suas demandas, quantidade de paletes necessários para consolidar o pedido e janelas de tempo explicitadas na Figura 4. Ainda é possível verificar o tempo de processamento das cargas de entrada de cada um dos veículos.

No exemplo, cada veículo de entrega possui capacidade de 20 paletes. Os tempos para carregar os paletes nos veículos, para descarregar os paletes nos clientes e o tempo de troca dos veículos na doca de saída são iguais a 2 unidades.

A matriz de custos de viagem é dada na Tabela 1 . O índice 0 representa a instalação crossdock. O tempo para transferir os produtos entre as docas de entrada e saída são apresentados na Tabela 2 e o tempo máximo para operação no cross-dock é igual a 200 unidades. As penalidades de atraso e adiantamento, bem como o custo operacional do cross-dock por unidade de tempo são considerados unitários.

Por se tratar de um problema com dois objetivos, na Figura 5 é apresentada a solução do problema do ponto de vista dos custos operacionais, enquanto na Figura 6 é apresentada a solução ao considerar apenas o objetivo de reduzir o número de veículos. Ambas as soluções do problema teste são soluções ótimas.

É possível notar na Figura 5 que na doca de entrada o primeiro veículo a ser processado é o veículo 1 (que possui uma maior variedade de produtos) e, em seguida o veículo 2. Para a entrega dos produtos são utilizados 3 veículos que realizam as rotas: $0->1->0 ; 0->$ 
Tabela 1 - Matriz de Custos para o Problema Teste.

\begin{tabular}{c|cccccc}
\hline & 0 & 1 & 2 & 3 & 4 & 5 \\
\hline 0 & 0,00 & 3,16 & 5,83 & 6,40 & 4,47 & 6,08 \\
1 & 3,16 & 0,00 & 2,83 & 4,12 & 3,16 & 5,39 \\
2 & 5,83 & 2,83 & 0,00 & 2,24 & 3,16 & 5,00 \\
3 & 6,40 & 4,12 & 2,24 & 0,00 & 2,24 & 3,16 \\
4 & 4,47 & 3,16 & 3,16 & 2,24 & 0,00 & 2,24 \\
5 & 6,08 & 5,39 & 5,00 & 3,16 & 2,24 & 0,00 \\
\hline
\end{tabular}

Fonte: Elaborado pelo Autor.

Tabela 2 - Tempo para Transportar uma Unidade do Produto entre as Docas.

\begin{tabular}{cccc}
\hline 1 & 2 & 3 & 4 \\
\hline 0,23 & 0,13 & 0,03 & 0,16 \\
\hline
\end{tabular}

Fonte: Elaborado pelo Autor.

Figura 5 - Solução do Problema Teste com Objetivo de Custos Operacionais

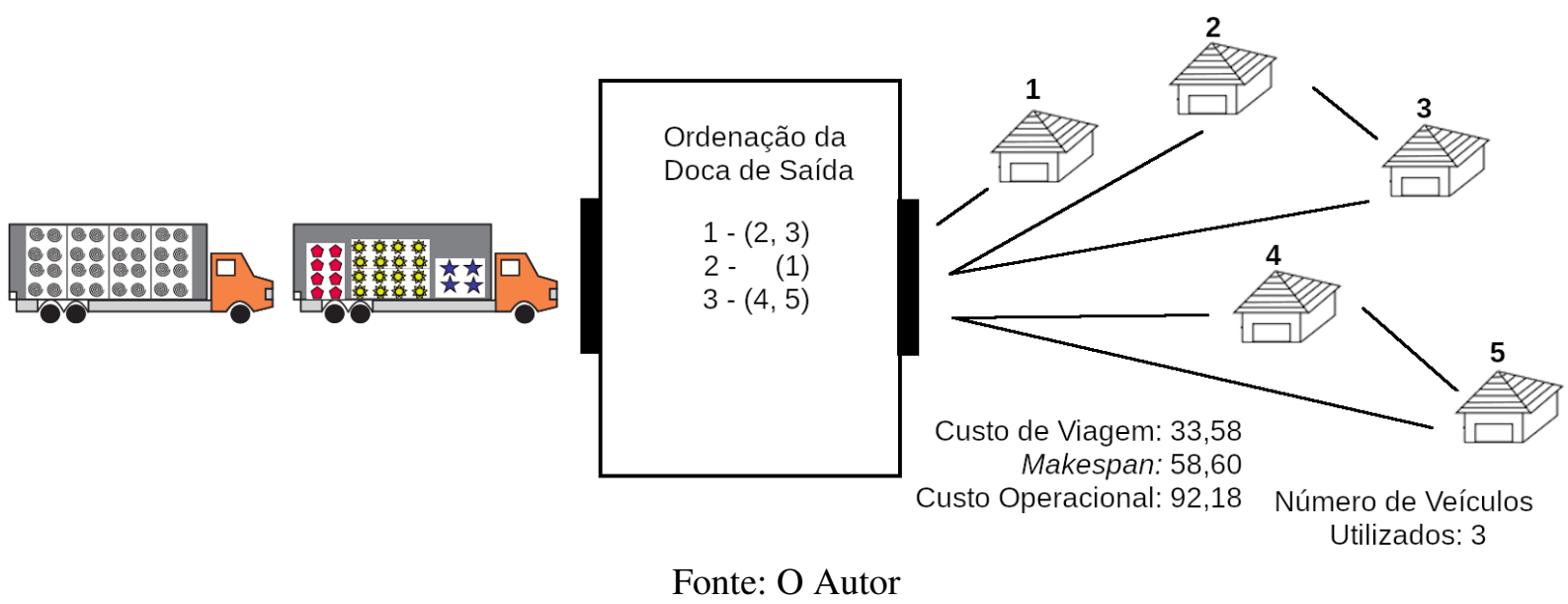

Fonte: O Autor

$2->3->0$ e $0->4->5->0$. Tais rotas totalizam um custo de transporte de 33,58 unidades monetárias. O custo total associado ao makespan do cross-dock é de 58,60 unidades monetárias. Para o presente resultado, por não possui atrasos ou adiantamentos, não há custo associado a estas parcelas da função objetivo.

Com o problema teste é possível notar a integração nas decisões operacionais do crossdocking. A primeira rota a ser atendida é a rota dos clientes 2 e 3 , porém para isto há necessidade de se concretizar a desconsolidação do veículo de entrega 1. Caso a desconsolidação do veículo 2 precedesse 1 não seria possível realizar a entrega para os clientes 2 e 3 e tampouco para o cliente 1 , que demanda produtos do veículo 1 . Sendo assim, é possível verificar o impacto das decisões de recebimento na operação de consolidação das cargas.

Também é possível notar que, ao visar apenas o custo operacional, há uma utilização 
Figura 6 - Solução do Problema Teste com Objetivo de Número de Veículos.

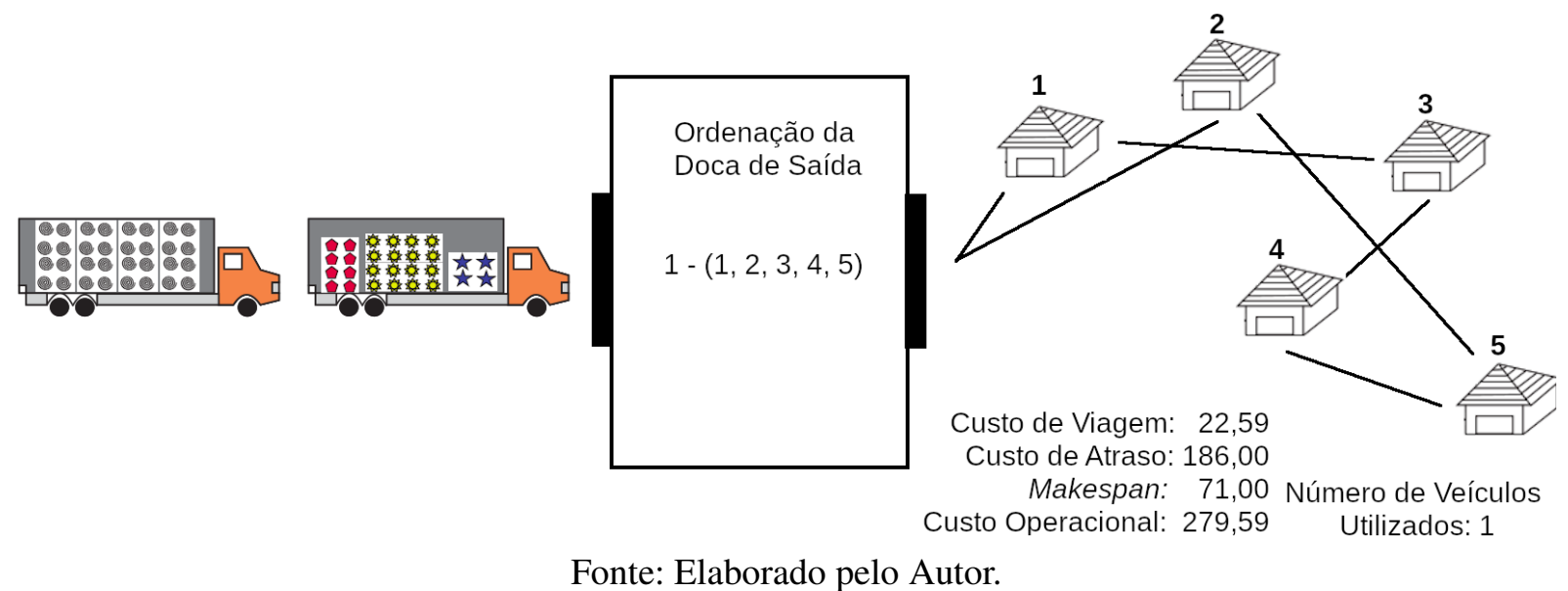

Fonte: Elaborado pelo Autor.

adicional de dois veículos, uma vez que todas as entregas poderiam ser realizadas com apenas um veículo, como observado no problema com objetivo de reduzir o número de veículos, apresentado na Figura 6. Entretanto, nota-se o aumento de aproximadamente três vezes nos custos operacionais. Isto se dá devido ao custo associado aos atrasos nas entregas dos clientes. Sendo assim, ao observar o problema em relação o ambos os objetivos isoladamente é possível notar um trade-off entre os mesmos. Para reduzir o custo operacional é necessário a utilização de um número maior de veículos, bem como o contrário.

\subsection{Considerações}

Na literatura, modelos para o problema de roteamento de veículos com programação do cross-dock englobam aspectos importantes do problema, como: decisões das cargas de entrada, decisões das cargas de saída, roteamento dos veículos e conexões entre rotas e cargas. No entanto, outros aspectos relevantes do problema devem ser estudados, como o número de veículos utilizados na operação. Desse modo, o modelo apresentado considera como um dos objetivos, a redução do número de veículos utilizados na entrega.

No Capítulo 4, apresentamos estratégias para a resolução do problema estudado. Como temos um problema bi-objetivo, utilizamos diferentes abordagens para sua resolução. 


\section{ABORDAGENS DE RESOLUÇÃO}

Conforme apresentado no Capítulo 3, o problema estudado possui objetivos conflitantes do ponto de vista do custo operacional e do número de veículos utilizados. Sendo assim, se mostra necessário utilizar abordagens bi-objetivo para resolução do mesmo. No presente trabalho, foram consideradas as abordagens por somas ponderadas, preempção e metas para resolução do problema bi-objetivo. Assim, sejam $C O$ e $N V$, respectivamente, a função objetivo (3.1) que visa minimizar os custos operacionais e a função objetivo (3.26) que visa minimizar o número de veículos.

No presente capítulo são apresentadas as abordagens bi-objetivos consideradas para resolução do problema.

\subsection{Abordagem por Somas Ponderadas}

Inicialmente, buscou-se utilizar uma Abordagem por Somas Ponderadas (ASP), na qual os objetivos são ponderados na função objetivo. Inicialmente, foi observado que os objetivos $C O$ e $N V$ possuíam uma ordem de grandeza muito distinta. Desta maneira, a função objetivo foi reescrita como:

$$
\min (1-\alpha) C O+\alpha \eta N V
$$

Na qual: $\alpha \in[0,1]$ é um parâmetro utilizado para ponderar os objetivos. Desta maneira, quando $\alpha=0$ unicamente o custo operacional é relevante, e para $\alpha=1$ é considerado apenas o número de veículos. O parâmetro $\eta \in \mathbb{R}_{*}^{+}$é definido como um valor real a fim de trazer os objetivos a mesma ordem de grandeza para valores de $\alpha \in[0,1]$.

Observou-se que, para obter uma solução de boa qualidade utilizando a ASP, seria necessário conhecer os valores da abordagem quando $\alpha=0$ e $\alpha=1$, isto é, conhecer os valores 
ao minimizar os objetivos isoladamente. Sendo assim, é proposta uma função objetivo sem a utilização do parâmetro $\eta$, que é dada por:

$$
\min (1-\alpha) \frac{C O}{C O_{b e s t}}+\alpha \frac{N V}{N V_{b e s t}}
$$

Em que: $C O_{b e s t}$ é o valor da função objetivo quando $\alpha=0$ e $N V_{b e s t}$ o valor da função objetivo quando $\alpha=1$. Desta maneira, abordamos a soma dos objetivos normalizados. É possível notar que a função assume valor 1 quando ambos os objetivos assumem os melhores valores conhecidos. Porém, quando não é possível obter valores ótimos, ao resolver o problema pode-se obter valores ainda melhores.

Para o presente trabalho, verificou-se o comportamento da abordagem bi-objetivo para os valores de $\alpha \in\{0 ; 0,05 ; 0,1 ; 0,15 ; 0,2 ; 0,25 ; 0,5 ; 0,75 ; 1\}$.

\subsection{Abordagem por Preempção}

A Abordagem por Preempção (APP) estabelece os objetivos por ordem de importância adicionando diferentes coeficientes à parcela dos objetivos na função objetivo. Desta maneira, é possível indicar a prioridade de cada objetivo para o modelo, no qual o foco estará no objetivo principal, porém indicando a necessidade de considerar os demais objetivos na função objetivo. De modo que a função objetivo pode ser descrita como:

$$
\min \sum_{o \in \mathscr{O}} P_{o} f\left(x_{o}\right)
$$

Em que: $o$ é o índice dos objetivos e $P_{o}$ seu peso na função objetivo. Nesta abordagem, é necessário que $P_{1}>>>P_{2}>>>\ldots>>>P_{o}$. O conjunto $\mathscr{O}$ e $f\left(x_{o}\right)$ são descritos na Seção 4.3. Esta abordagem indica, na função objetivo, a ordem com a qual os objetivos devem ser atendidos.

\subsection{Abordagem por Metas}

A Abordagem por Metas (APM) tem por objetivo estabelecer metas a serem atendidas pelo modelo, a função objetivo busca minimizar a variação da solução em torno da meta estabelecida. Sendo assim, faz-se necessário a utilização de variáveis e parâmetros auxiliares ao modelo. Seja $\mathscr{O}$ o conjunto de objetivos do modelo, $d_{o}^{-} \geq 0$ e $d_{o}^{+} \geq 0$, respectivamente, as variações abaixo e acima da meta estabelecida. Portanto, a função objetivo que visa minimizar a soma dos desvios em relação as metas é dada por: 


$$
\min \sum_{o \in \mathscr{O}} d_{o}^{+}
$$

e as restrições (4.5) são acrescentadas ao modelo.

$$
d_{o}^{+}-d_{o}^{-}=\frac{f\left(x_{o}\right)}{g_{o}}-1 \quad \forall o \in \mathscr{O}
$$

Em que: a variável $d_{o}^{-}$representa o desvio abaixo da meta, enquanto a variável $d_{o}^{+}$ representa o desvio acima da meta. $f\left(x_{o}\right)$ é o valor objetivo $o$ e $g_{o}$ é o valor de sua meta. Para o problema estudado temos dois objetivos, ou seja, o conjunto de objetivos $\mathscr{O} \in\{$ Custo, Veiculos $\}$,

$f\left(x_{\text {Custo }}\right)$ e $f\left(x_{\text {Veiculo }}\right)$ que equivalem, respectivamente, a soma dos custos operacionais e a quantidade de veículos e $g_{o}$ é o melhor valor conhecido para o objetivo $o$. Como o problema estudado é um problema de minimização, os resultados abaixo da meta não devem ser penalizados, logo considera-se apenas a variação positiva.

\subsection{Experimentos Computacionais}

Os experimentos computacionais para determinar qual das abordagens bi-objetivo analisadas é a mais adequada para o problema estudado foram realizados utilizando as instâncias de Bernardes (2019) em um computador com sistema operacional Ubuntu 12.04.2 LTS com $16 \mathrm{~Gb}$ de memória RAM e processador Intel Xeon CPU E5-2620 2.00GHz com 4 threads. A implementação foi feita em C++ e foi utilizado o solver Gurobi 9.0 em sua configuração padrão, com tempo limite de 1800 segundos para processamento de cada instância.

Devido à complexidade de resolução do problema, foram utilizadas as instâncias com apenas 15 clientes para os dois cenários estudados por Bernardes (2019). No primeiro cenário, a quantidade de paletes necessários para organizar o pedido do cliente varia entre $25 \%$ a $100 \%$ da capacidade do veículo, enquanto no segundo, o valor é definido de $12 \%$ a $50 \%$ da capacidade do veículo. Desta forma, é possível notar que no Cenário 2 pode haver mais clientes na rota de um veículo de entrega. As instâncias também são dividas em três grupos em termos do número de tipos de produtos demandados pelos clientes. O número de tipos de produtos demandados por um cliente varia de 1 a $20 \%$ do total de tipos de produtos para as instâncias do Grupo A, de 1 a $40 \%$ para o Grupo B e de 1 a $100 \%$ para o Grupo C.

Na Figura 7, verifica-se o comportamento da Abordagem por Somas Ponderadas (ASP). Embora sejam apresentados os resultados apenas das instâncias R101-A, R101-B e R101-C, as demais instâncias possuem um comportamento semelhante. Na Figura 8, é possível verificar o comportamento médio da ASP para as instâncias de 15 clientes, os resultados para cada instância seguem a mesma tendência da média, como verificado na Figura 7. Os resultados para todas as instâncias estão disponíveis no Apêndice A. Como esperado, é possível notar que, em ambos 
Figura 7 - Resultados de Algumas Instâncias de 15 Clientes para ASP.

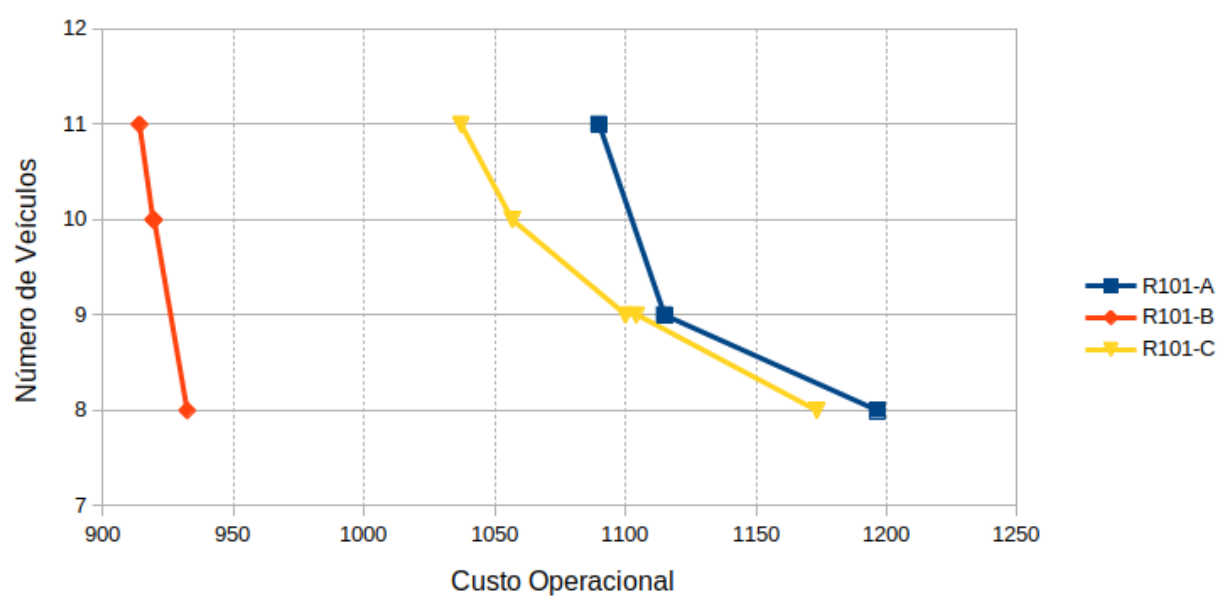

(a) Resultados das Instâncias R101 para ASP Cenário 1.

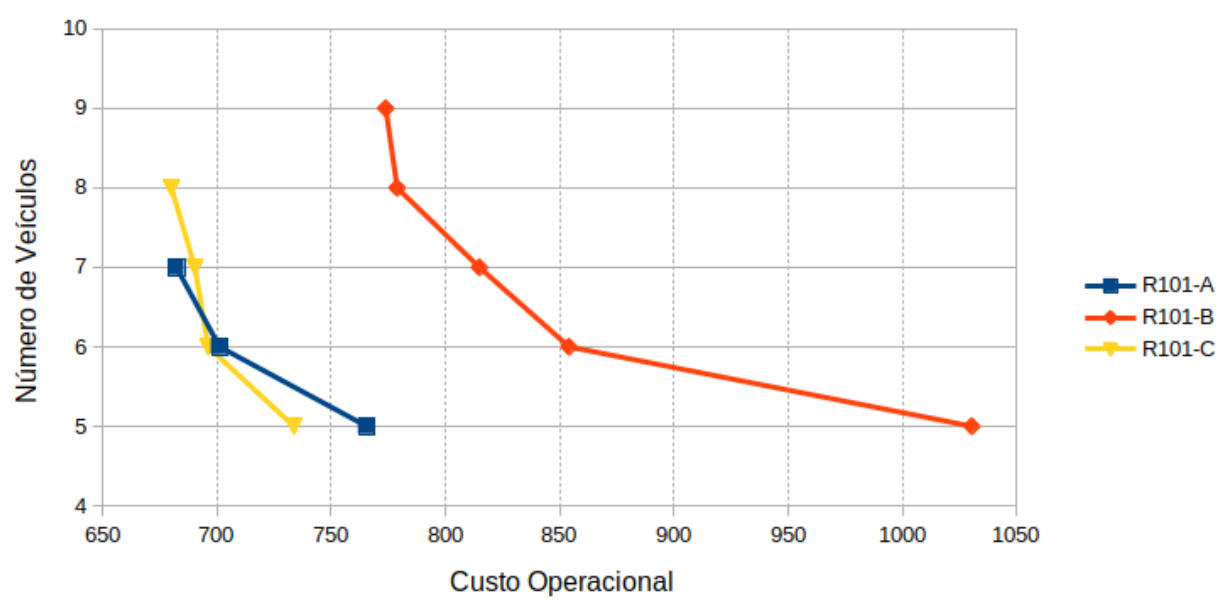

(b) Resultados das Instâncias R101 para ASP Cenário 2.

Fonte: Elaborado pelo Autor.

os cenários, há um grande aumento no custo operacional à medida que o valor de $\alpha$ tende a 1 . Também é possível observar a necessidade de tratar o problema de maneira bi-objetivo, uma vez que ao considerar apenas o número de veículos, o custo operacional aumenta, em relação a considerar apenas o custo operacional, em 58\% para o Cenário 1 e $108 \%$ para o Cenário 2. Entretanto, é possível notar a possibilidade de ter um redução de cerca de $10 \%$ no número de veículos a um aumento nos custos operacionais de 3,3\% $(\alpha=0,5)$ no Cenário 1 e uma redução de quase $20 \%$ a um aumento de $7 \%$ nos custos operacionais $(\alpha=0,75)$ no Cenário 2.

A ASP se mostra eficiente, uma vez que ao ponderar o número de veículos na função objetivo, é possível obter sua redução com um aumento ínfimo nos custos operacionais. No Cenário 1 isto é observado para $\alpha=0,25$, no qual há uma redução média de aproximadamente $7 \%$ no número de veículos utilizados a um acréscimo de $1 \%$ nos custos operacionais. Vale destacar que o valor de $\alpha$ deve ser pequeno, sinalizando uma ordem de relevância para os 
Figura 8 - Resultados Médios das Instâncias de 15 Clientes para ASP.

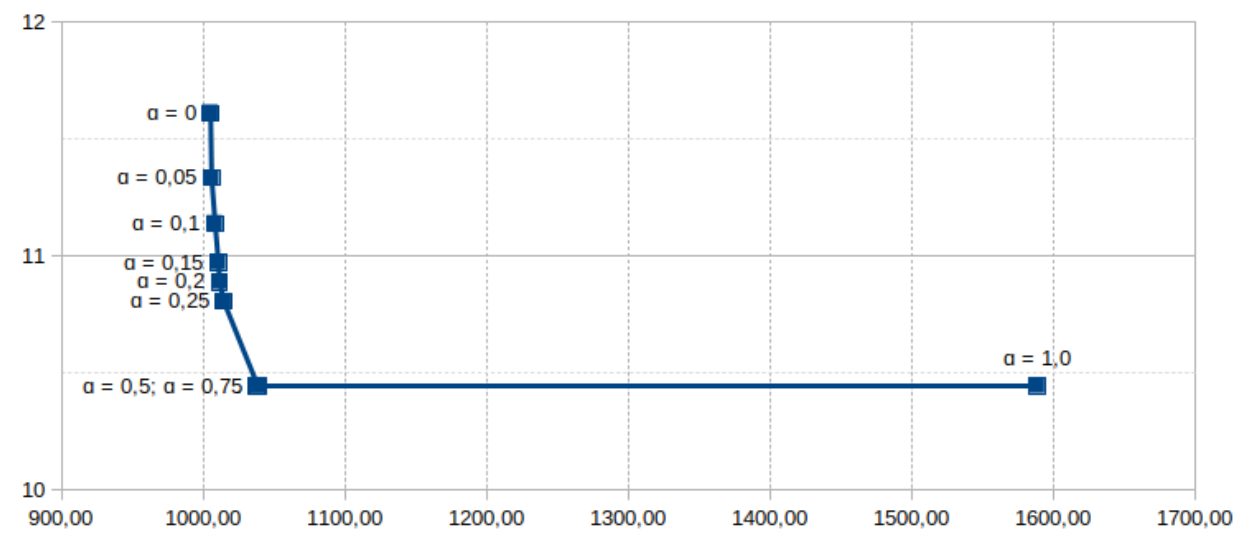

(a) Resultados da ASP para o Cenário 1.

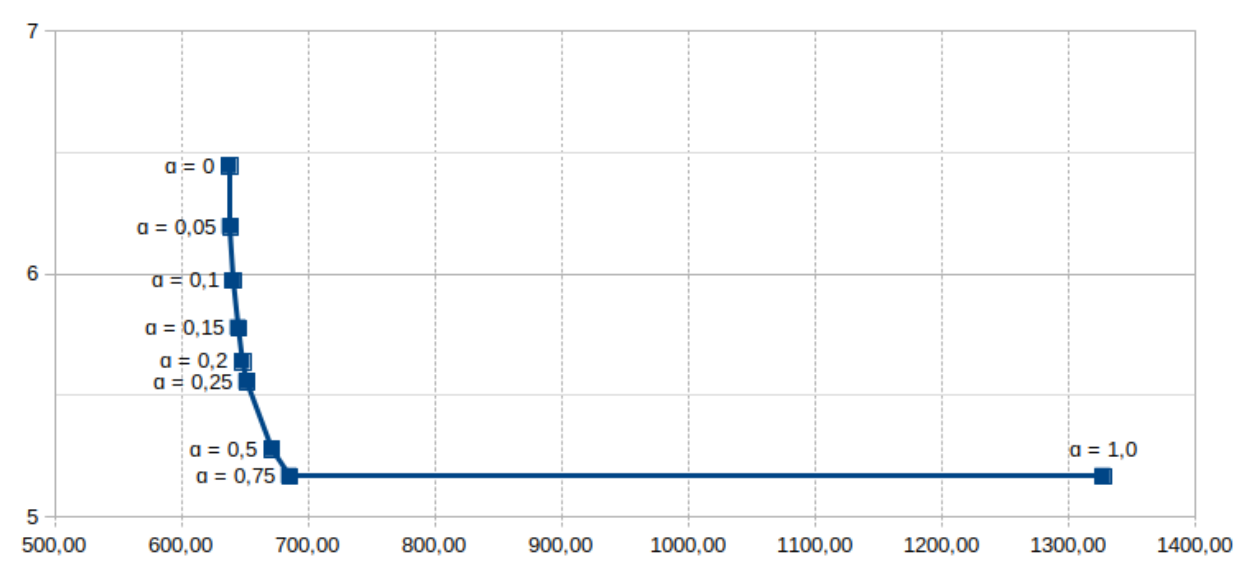

(b) Resultados da ASP para o Cenário 2.

Fonte: Elaborado pelo Autor.

objetivos estudados.

A Abordagem por Preempção (APP) permite definir a ordem de prioridade dos objetivos a serem otimizados. Desta maneira, foram considerados dois experimentos: $i$ ) o primeiro objetivo é considerado como custo operacional e o segundo como o número de veículos (APP1); e ii) a prioridade entre os objetivos é invertida (APP2). Os coeficientes utilizados na função objetivo (4.3) possuem uma diferença na ordem de grandeza de $10^{6}$ unidades, por exemplo, caso o custo operacional estivesse na ordem de grandeza $10^{4}$ e o número de veículos $10^{1}$, então uma opção é $P 1=1$ e $P 2=10^{-2}$.

Os resultados médios apresentados na Tabela 3 mostram que ao considerar APP1 é possível obter resultados muito semelhantes ao modelo mono-objetivo que visa reduzir o custo operacional. A APP2 apresenta resultados com uma redução no número de veículos de $10 \%$ para o Cenário 1 e 19,87\% para o Cenário 2, em relação à abordagem mono-objetivo. Conforme esperado, há um aumento no custo operacional médio de 3,19\% no Cenário 1 e 7,43\% no Cenário 2. Por meio dos resultados completos presentes no Apêndice A, é possível observar uma maior 
Tabela 3 - Resultados Médios para APP e APM.

\begin{tabular}{cccrc}
\hline & \multicolumn{2}{c}{ Cenário 1 } & \multicolumn{2}{c}{ Cenário 2 } \\
\hline & CO & NV & CO & NV \\
\hline Bernardes (2019) & 1005,21 & 11,61 & 637,73 & 6,44 \\
APP1 & 1005,48 & 11,66 & 638,13 & 6,42 \\
APP2 & 1037,36 & 10,44 & 685,11 & 5,16 \\
APM & 1037,36 & 10,44 & 667,41 & 5,25 \\
$\alpha=1$ & 1588,63 & 10,44 & 1327,89 & 5,16 \\
\hline
\end{tabular}

Fonte: Elaborado pelo Autor.

dificuldade ao resolver as instâncias do Cenário 2, para todas as abordagens. Isto se dá, pois no Cenário 2 é possível ter mais clientes por rota, o que torna o roteamento do problema mais complexo.

\subsubsection{Testes Estatísticos}

Dentre as abordagens estudadas, pode-se notar uma competitividade entre as abordagens ASP, APP2 e APM, as quais obtiveram resultados semelhantes para ambos os objetivos. Assim, utilizou-se o teste de Wilcoxon, utilizando a ferramenta estatística $\mathrm{R}$, para verificar se há diferenças estatísticas entre as abordagens estudadas. O teste utiliza da soma dos postos para verificar, de maneira não paramétrica, a semelhança estatística entre as abordagens. Os testes estatísticos foram realizados utilizando as informações de todas as instâncias avaliadas. O nível de confiança utilizado no teste bicaudal foi de $95 \%$. A hipótese nula $\left(H_{0}\right)$ considerada no teste é que a média das populações (soluções) verificadas são idênticas e a hipótese alternativa $\left(H_{1}\right)$ é que as populações são diferentes. Os testes foram avaliados por meio do $p$-valor. Desta maneira, caso $p-$ valor $\geq 0,025$ aceita-se $H_{0}$, caso contrário é aceito $H_{1}$. Vale destacar que o teste de Wilcoxon utiliza a soma dos postos para identificar semelhanças estatísticas, entretanto, o teste desconsidera as soluções que possuam o mesmo valor. Desta maneira, o teste de Wilcoxon pode encontrar resultados inconclusivos ao considerar o número de veículos, uma vez que duas abordagens podem encontrar o mesmo número de veículos para uma mesma instância e, neste caso, estes valores são desconsiderados. Porém, optou-se por seguir com o teste de Wilcoxon, uma vez que, mesmo com uma amostra pequena, foi possível identificar algumas semelhanças entre as abordagens em relação ao número de veículos.

Uma vez que as abordagens ASP, APP2 e APM tiveram os resultados mais equilibrados entre custo operacional e número de veículos, na Tabela 4 são apresentados os resultados dos testes de Wilcoxon para tais abordagens, em negrito estão os $p$-valores que indicam semelhança estatística, e caso não tenha sido possível determinar um $p$-valor o resultado é apresentado por NA. Os resultados completos para todas as abordagens podem ser verificados no Apêndice B. Para o Cenário 1, em relação ao custo operacional, a APM apresentou semelhanças estatísticas 
Tabela 4 - Resultados do Teste de Wilcoxon para ASP, APM e APP2.

\begin{tabular}{|c|c|c|c|c|c|c|}
\hline & & & $\alpha$ & & & \\
\hline & & 0,5 & 0,75 & 1,0 & APM & APP2 \\
\hline & 0,5 & - & & & & \\
\hline$\alpha$ & 0,75 & 1,000 & - & & & \\
\hline & 1,0 & 0,000 & 0,000 & - & & \\
\hline & APM & 1,000 & 1,000 & 0,000 & - & \\
\hline & APP2 & $\mathbf{0 , 0 9 8}$ & $\mathbf{0 , 0 9 8}$ & 0,000 & $\mathbf{0 , 0 9 8}$ & - \\
\hline
\end{tabular}

(a) Custo Operacional - Cenário 1.

\begin{tabular}{|c|c|c|c|c|c|c|c|}
\hline \multicolumn{8}{|c|}{$\alpha$} \\
\hline & & 0,5 & 0,75 & 1,0 & APM & 1 APP2 & \\
\hline \multirow{5}{*}{$\alpha$} & 0,5 & - & & & & & \\
\hline & 0,75 & NA & - & & & & \\
\hline & 1,0 & NA & NA & - & & & \\
\hline & APM & NA & NA & NA & - & & \\
\hline & APP2 & NA & NA & NA & NA & - & \\
\hline \multicolumn{8}{|c|}{ (c) Número de Veículos - Cenário 1.} \\
\hline \multicolumn{8}{|c|}{$\alpha$} \\
\hline & & 0,5 & 0,75 & & 1,0 & APM & APP2 \\
\hline \multirow{5}{*}{$\alpha$} & 0,5 & - & & & & & \\
\hline & 0,75 & 0,727 & - & & & & \\
\hline & 1,0 & 0,000 & 0,000 & & - & & \\
\hline & APM & 0,123 & 0,660 & & 0,000 & - & \\
\hline & APP2 & 0,088 & $\mathbf{0 , 1 0 4}$ & & 0,000 & 0,220 & - \\
\hline
\end{tabular}

(e) Tempo de Processamento - Cenário 1.

\begin{tabular}{|c|c|c|c|c|c|c|}
\hline \multicolumn{7}{|c|}{$\alpha$} \\
\hline & & 0,5 & 0,75 & 1,0 & APM & APP2 \\
\hline \multirow{5}{*}{$\alpha$} & 0,5 & - & & & & \\
\hline & 0,75 & 0,421 & - & & & \\
\hline & 1,0 & 0,000 & 0,000 & - & & \\
\hline & APM & 0,191 & 0,014 & 0,000 & - & \\
\hline & APP2 & 0,251 & 0,925 & 0,000 & 0,011 & - \\
\hline
\end{tabular}

(b) Custo Operacional - Cenário 2.

\begin{tabular}{|c|c|c|c|c|c|c|}
\hline \multicolumn{7}{|c|}{$\alpha$} \\
\hline & & 0,5 & 0,75 & 1,0 & APM & APP2 \\
\hline \multirow{5}{*}{$\alpha$} & 0,5 & - & & & & \\
\hline & 0,75 & $\mathbf{0 , 0 7 2}$ & - & & & \\
\hline & 1,0 & $\mathbf{0 , 0 7 2}$ & NA & - & & \\
\hline & APM & $\mathbf{0 , 7 7 3}$ & 0,149 & 0,149 & - & \\
\hline & APP2 & $\mathbf{0 , 0 7 2}$ & NA & NA & 0,149 & - \\
\hline
\end{tabular}

(d) Número de Veículos - Cenário 2.

\begin{tabular}{|c|c|c|c|c|c|c|}
\hline & & & $\alpha$ & & & \\
\hline & & 0,5 & 0,75 & 1,0 & APM & APP2 \\
\hline & 0,5 & - & & & & \\
\hline$\alpha$ & 0,75 & 0,201 & - & & & \\
\hline & 1,0 & 0,000 & 0,000 & - & & \\
\hline & APM & 0,005 & 0,003 & 0,000 & - & \\
\hline & APP2 & 0,235 & 0,474 & 0,000 & 0,000 & - \\
\hline
\end{tabular}

(f) Tempo de Processamento - Cenário 2.

Fonte: Elaborado pelo Autor.

com a abordagem APP2. Desta maneira, podemos observar que, para o Cenário 1, ambas as abordagens APP2 e APM possuem um desempenho muito semelhante em termos de custo operacional, isto também pode ser verificado na Tabela 3, uma vez que as duas abordagens possuem a mesma média de custo operacional. A APP2 também apresenta semelhanças com ASP para $\alpha \in\{0,5 ; 0,75\}$. Em relação ao número de veículos, no Cenário 1 , os testes foram inconclusivos entre as abordagens APP2 e APM. Os testes também foram inconclusivos entre as abordagens ASP para $\alpha \in\{0,75 ; 1,0\}$ e as abordagens APP2 e APM. Desta maneira, para as instâncias de 15 clientes no Cenário 1, pode-se verificar uma equivalência entre as abordagens APP2, APM e ASP (com $\alpha \in\{0,5 ; 0,75\})$.

Em relação aos custos operacionais do Cenário 2, foi possível identificar semelhanças estatísticas entre as abordagens APP2, APM e ASP para $\alpha \in\{0,5 ; 0,75\}$. Em relação ao número de veículos, embora os testes foram inconclusivos para APP2 e ASP para $\alpha \in\{0,5 ; 0,75\}$, foi possível identificar semelhanças estatísticas entre APM e ASP para $\alpha \in\{0,5 ; 0,75\}$. Desta maneira, também pode-se notar uma equivalência entre tais abordagens para o Cenário 2. Contudo, foi possível identificar uma diferença estatística no tempo de processamento da APM e 
as demais abordagens. Sendo assim, como o tempo de processamento médio da APM é menor que as demais, considera-se que a abordagem possui um desempenho melhor que APP2 e ASP.

\subsection{Considerações}

O presente capítulo apresentou algumas abordagens para resolução do VRSP bi-objetivo. Foi possível observar que as abordagens possuem pontos fortes e fracos. A ASP mostrou-se muito intuitiva e com poucos parâmetros para calibração, também observou-se que mesmo para valores mais baixos de $\alpha$ é possível obter soluções que reduzam o número de veículos sem grandes prejuízos ao custo operacional.

As abordagens ASP, APP2 e APM apresentaram os melhores resultados, encontrando soluções próximas em relação aos dois objetivos. Para APP2 e APM, o custo operacional médio no Cenário 1 permaneceu em 3,19\% acima da média das soluções ao considerar o problema mono-objetivo do custo operacional, enquanto obteve o mesmo número de veículos médio que o problema mono-objetivo para minimizar o número de veículos. Para o Cenário 2, a APP2 obteve, a um acréscimo de 7,42\% em relação a abordagem mono-objetivo de custos operacional e o mesmo número médio de veículos que a abordagem mono-objetivo de número de veículos. Já a abordagem APM obteve um custo operacional médio de 4,65\% e uma utilização adicional de $1,74 \%$ em relação às abordagens mono-objetivo de custo operacional e número de veículos, respectivamente.

Com o teste de Wilcoxon foi possível notar que as abordagens APP2 e APM possuem semelhanças estatísticas no Cenário 1, porém há uma leve superioridade da APM ao considerar o Cenário 2. De modo que, para o conjunto de instâncias considerado, por possuir um custo operacional médio menor que APP2, o mesmo número de veículos estatisticamente e um menor tempo de processamento, a APM é considerada a melhor abordagem para o Cenário 2.

As análises apresentadas no presente capítulo utilizando instâncias com 15 clientes, mostram o benefício de tratar o problema como bi-objetivo. Porém, para instâncias maiores, o método exato não se mostrou eficiente, uma vez que, após testes preliminares e conforme apresentado em Bernardes (2019), é necessário tempo de processamento muito elevado para que sejam obtidas soluções viáveis. Desta maneira, no Capítulo 5, é detalhada a matheurística desenvolvida para resolução do problema bi-objetivo aqui estudado. 


\section{MATHEURÍSTICA BI-OBJETIVO}

O problema estudado é de difícil resolução e testes computacionais preliminares mostraram que não foi possível obter solução factível para instâncias com 40 clientes ou mais em duas horas através de um solver comercial, como utilizado no Capítulo 4. Logo, a fim de poder tratar instâncias com mais clientes, apresentamos uma matheurística neste capítulo para tratar o problema. Bernardes (2019) mostra que a matheurística Proximity Search foi usada com sucesso para a versão mono-objetivo deste problema. Portanto, aqui vamos investigar sua aplicação ao problema bi-objetivo.

A matheurística Proximity Seach foi proposta por Fischetti e Monaci (2014) para tratar problemas inteiros binários. A ideia do método é buscar sucessivamente soluções de melhor qualidade próxima da solução atual. A proximidade entre soluções é medida por meio da distância de Hamming e para garantir que seja encontrada uma solução de melhor qualidade é adicionada ao modelo uma restrição que impõe que o valor da nova solução objetivo seja pelo menos $\theta$ melhor que a anterior. Em Berthold, Lodi e Salvagnin (2019), é observado que a matheurística Proximity Search possui uma combinação de características de busca local com a matheurística Feasibility Pump.

A seguir, é apresentada a estrutura geral da matheurística Proximity Search, bem como suas adptações para o problema estudado e, posteriormente, são reportados e analisados os resultados de experimentos computacionais realizados.

\subsection{Matheurística Proximity Search}

No Algoritmo 1, apresentamos um pseudocódigo da matheurística Proximity Search. Destacamos que ele está fortemente baseado em Bernardes (2019). O algoritmo consiste em, a partir de uma solução inicial $\bar{X}$ obter uma nova solução $X$ de modo que $f(X)<f(\bar{X})-\theta$, sendo $\theta \in \mathscr{R}_{*}^{+}$e $f$ é a função objetivo do problema, ou seja, é acrescentada esta restrição ao problema 
para buscar soluções de melhor qualidade. Desta maneira, é possível notar que há uma obrigação de monotonia no método, ou seja, o valor da função objetivo original deve ser reduzido a cada iteração. Entretanto, há possibilidade do modelo acrescido da restrição de melhoria do custo, aqui denominado Modelo Auxiliar (MA), não obter uma solução viável, devido à inexistência de uma solução que satisfaça esta condição. Neste caso, o valor de $\theta$ é reduzido em busca da melhoria da solução atual. O procedimento é repetido até que o critério de parada do método seja satisfeito.

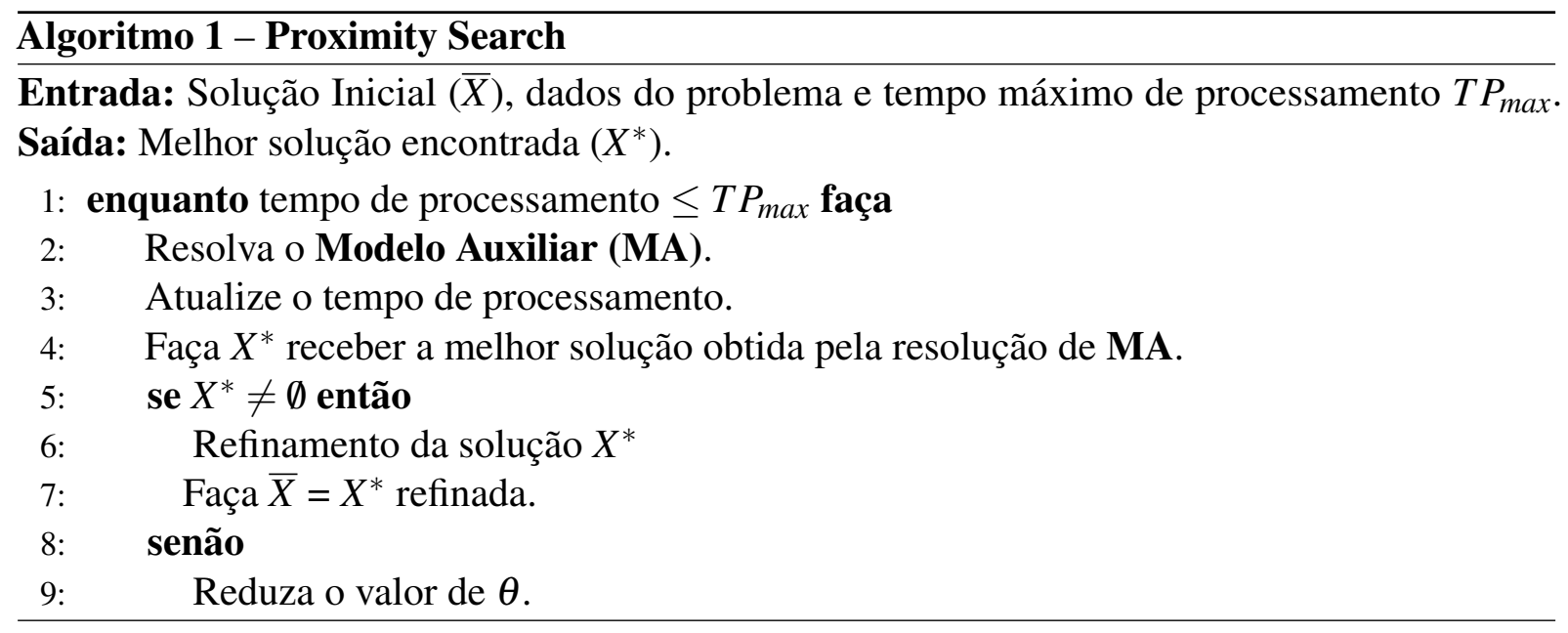

A seguir são descritas, de maneira mais detalhada, as etapas do Algoritmo 1. Na Seção 5.2, é detalhada a heurística utilizada para obter uma solução inicial para a Proximity Search. Em seguida, a construção do Modelo Auxiliar é apresentada na Seção 5.3

\subsection{Solução Inicial}

Inicialmente, foram realizados testes computacionais para obter uma solução inicial com base no modelo descrito no Capítulo 3. No entanto, os resultados mostraram que para instâncias com 40 clientes ou mais era necessário mais de uma hora apenas para obter esta solução. Portanto, optou-se por utilizar um método heurístico para encontrar uma solução inicial para a Proximity Search em tempo computacional aceitável.

A solução inicial foi obtida utilizando como base a heurística construtiva de Bernardes (2019). O algoritmo consiste em determinar critérios de prioridade e de compatibilidade entre os clientes. $\mathrm{O}$ início das rotas é definido pelo critério de prioridade, indicando quais clientes devem ser atendidos com mais agilidade, ou seja, considerando a janela de tempo do cliente para determinar sua prioridade. O critério de compatibilidade busca determinar quais são os clientes mais propensos a serem acrescidos à rota em construção. Esse critério também considera a janela de tempo de atendimento do cliente, verificando se o mesmo tem a possibilidade de ser atendido dentro da mesma. Os veículos oriundos dos fornecedores são alocados às docas de entrada à medida que as rotas de entrega são construídas, sendo alocados na primeira doca livre. O mesmo 
se repete na definição das docas de saída, as cargas de saída são alocadas na primeira doca de saída disponível. O Algoritmo 2 resume o pseudocódigo da heurística construtiva de Bernardes (2019).

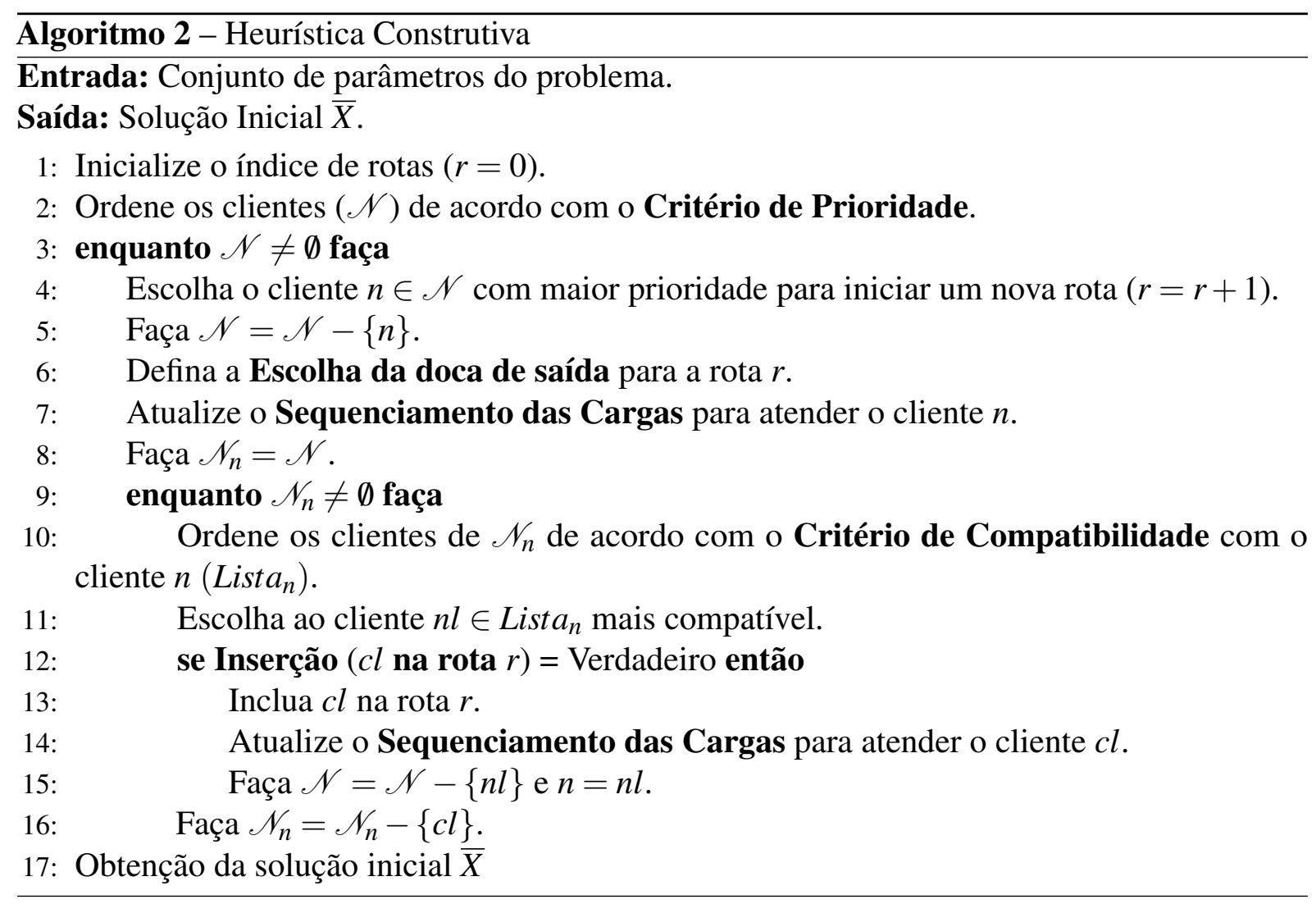

\subsubsection{Critério de Prioridade}

Como abordado anteriormente, o critério de prioridade utiliza informações referentes à janela de tempo de atendimento do cliente para definir sua prioridade. É considerado o instante mínimo que o cliente poderá ser atendido e o término da sua janela de tempo. $\mathrm{O}$ instante mínimo para que um cliente $i$ possa ser atendido é dado pela soma dos tempos para que suas cargas sejam recebidas no cross-dock com o tempo mínimo para que suas cargas sejam transferidas entre docas, carregadas no veículo e entregues. Desta maneira, calcula-se o limitante inferior $\left(l b_{i}\right)$ do tempo mínimo para o atendimento de cada cliente $i$ como:

$$
l b_{i}=U T_{\alpha_{i}^{*}}+\tau_{i}^{*}+Q_{i} L T+T T_{0 i}
$$

em que:

- $U T_{\alpha_{i}^{*}}$ : é o instante máximo de término de processamento dos produtos do cliente $i$, considerando que eles são processados o mais rapidamente possível $\left(\alpha_{i}^{*}=\underset{l \in \bar{L}_{i}}{\operatorname{argmax}}\left\{U T_{l}\right\}\right)$; 
- $\tau^{*}$ : é o instante mínimo para transferir os produtos da carga $\alpha_{i}^{*}$ do cliente $i$ entre docas;

- $Q_{i} L T$ : é o tempo de carregamento dos produtos do cliente $i$ para o interior do veículo;

- $T T_{0 i}$ : é o tempo de viagem do veículo partindo do cross-dock diretamente para o cliente $i$.

Para calcular de $U T_{\alpha_{i}^{*}}$, é feita uma simulação das cargas de entrada que contém produtos do cliente $i$, alocando-as na primeira doca disponível e em ordem descrente em relação aos tempos de processamento das mesmas, desta maneira, $\bar{L}_{i}$ é o conjunto de cargas de entrada que possuem produtos demandados pelo cliente $i$ e $\alpha_{i}^{*}$ é a última carga deste conjunto a ser processada.

A prioridade $\left(p r_{i}\right)$ é definida subtraindo $l b_{i}$ do fim da janela de tempo do cliente $i$, ou seja, $p r_{i}=B_{i}-l b_{i}$. Sendo assim, quanto menor for o valor de $p r_{i}$, maior será a prioridade do cliente $i$, uma vez que há maior tempo hábil para atender o cliente sem infringir sua janela de tempo. No Algoritmo 2, a ordenação dos clientes em relação à prioridade se dá de maneira crescente.

Bernardes (2019) apresenta duas abordagens para construção do critério de prioridade. A primeira se dá de maneira estática, quando o critério é calculado apenas uma vez no início do algoritmo. A segunda abordagem é dinâmica, tendo o critério atualizado antes da inicialização de uma nova rota e levando em consideração as cargas já alocadas. Após testes computacionais, Bernardes (2019) indica que o critério de prioridade estático possui melhor desempenho que o dinâmico, por isso, optou-se por utilizar o critério de prioridade estático neste trabalho.

\subsubsection{Critério de Compatibilidade}

O critério de compatibilidade definido por Bernardes (2019) busca determinar o melhor cliente para ser acrescentado a uma rota, respeitando sua janela de tempo. O critério de compatibilidade entre dois clientes $i$ e $j$, denominado $c o m p p_{i j}$, é determinado por:

$$
\text { comp }_{i j}=\left\{\begin{array}{cl}
\infty & , \text { se } A_{i}+Q_{i} S T+T T_{i j}>B_{j} \\
T T_{i j}+T_{j}^{v} & , \text { caso contrário }
\end{array}\right.
$$

em que $A_{i}$ é o início da janela de tempo do cliente $i, Q_{i} S T$ é o tempo para descarregamento dos produtos no cliente $i, T T_{i j}$ é o tempo de viagem entre os clientes $i$ e $j$ e $T_{j}^{v}$ o pior caso para atendimento do cliente $j$ caso ele seja adicionado na sequência do cliente $i$. Sendo assim, dois clientes $i$ e $j$ são considerados incompatíveis se mesmo que o veículo chegasse em $i$ no início de sua janela de tempo não fosse possível chegar em $j$ antes do término de sua janela de tempo $\left(B_{j}\right)$. Caso contrário, é calculada a compatibilidade $T_{j}^{v}=\max \{$ Antes, Depois $\}$. Caso a carga chegue ao cliente $j$ antes do começo da sua janela de tempo, Antes $=\max \left\{0, A_{j}-\left(\frac{A_{i}+B_{i}}{2}+Q_{i} S T+T T_{i j}\right)\right\}$, ou seja, supõe-se que o cliente $i$ foi visitado no instante igual à metade da sua janela de tempo e contabiliza-se os tempos para efetuar o descarregamento de mercadorias e de viagem para o cliente $j$. Caso o veículo chegue no cliente $j$ após o término da sua janela de tempo, 
então Depois $=\max \left\{0,\left(\frac{A_{i}+B_{i}}{2}+Q_{i} S T+T T_{i j}\right)-B_{j}\right\}$. Desta forma, são estimados o atraso ou adiantamento ao atender o cliente $j$, supondo que o veículo chegue no cliente $i$ no meio de sua janela de tempo.

Bernardes (2019) também propõe uma abordagem para o critério de compatibilidade ser determinado de maneira dinâmica, na qual não é utilizada a média da janela de tempo, mas o instante de chegada ao cliente $i$ para determinar a chegada ao cliente $j$, ou seja, modifica-se $\frac{A_{i}+B_{i}}{2}$ pelo instante de chegada ao cliente $i$. O autor indica que a abordagem estática apresenta melhores resultados para instâncias menores, enquanto a abordagem dinâmica apresenta um melhor desempenho para instâncias maiores. Como a vantagem da abordagem estática é pequena em relação à dinâmica para instâncias menores, optou-se por utilizar a abordagem dinâmica em todos os testes.

\subsubsection{Obtenção de $\bar{X}$}

Esta heurística construtiva pode gerar soluções infactíveis em relação ao tempo máximo de operação do cross-dock. Sendo assim, para a Proximity Search, foi permitida a infactibilidade, contudo é utilizada uma variável linear auxiliar denominada $F T_{\max }$ para penalizar a infactibilidade. De modo que a função objetivo, para obtenção de $\bar{X}$, é reescrita como:

$$
\min C O+\operatorname{Big}_{F T_{\max }} F T_{\max }
$$

em que: $B i g M_{F T_{\max }}$ é uma constante de valor suficientemente grande. Adicionalmente, a restrição (3.25) é reescrita como:

$$
t_{N+1} \leq T^{\max }+F T_{\max }
$$

Assim, é permitido que $\bar{X}$ seja uma solução inviável, ou seja, viole o tempo máximo de operação no cross-dock.

Uma vez definidas as rotas, alocações das cargas às docas e o sequenciamento das rotas e cargas, ou seja, todas as variáveis inteiras do problema, ele é reduzido a um problema linear que é resolvido utilizando um solver de otimização.

\subsubsection{Estratégias de Refinamento da Solução Inicial}

Neste trabalho, estudamos a possibilidade de refinar a solução inicial de Bernardes (2019). A partir disto, realizaram-se alguns testes com a solução inicial buscando refinar sua qualidade, em termos de função objetivo, da solução heurística. Na primeira abordagem, utilizou-se a solução da heurística como ponto de partida para o solver, não fixando nenhuma variável inteira 
e disponibilizando 120 segundos para a busca de uma nova solução, a função objetivo visa apenas minimizar os custos operacionais do cross-dock, sem considerar a penalidade de $F T_{\text {max }}$. A segunda, também não fixa as variáveis inteiras e utiliza como função objetivo minimizar $F T_{\text {max }}$, afim de iniciar a Proximity Search com uma solução factível. Como esperado, em ambas as abordagens foi possível obter uma solução inicial mais refinada que Bernardes (2019), uma vez que Bernardes (2019) utiliza a solução oriunda da heurística e as abordagens consideradas refinam tal solução, porém ao utilizar tais soluções como ponto de partida para a PS, as soluções finais obtidas tiveram qualidade inferior à utilizar a solução inicial de Bernardes (2019). Sendo assim, no presente trabalho, utiliza-se a solução inicial de Bernardes (2019).

\subsection{Modelo Auxiliar}

O Modelo Auxiliar (MA) utilizado na Proximity Search consiste em modificar a função objetivo original para uma função de proximidade. Para o presente problema, de acordo com Bernardes (2019), é possível escrever o MA a partir de uma solução $\bar{X}=\left(\bar{x}, \overline{z^{\text {in }}}, \overline{z^{\text {out }}}, \overline{w^{\text {in }}}, \overline{w^{\text {out }}}, \overline{e t}, \overline{l t}\right.$, $\overline{d t^{m a x}}$ ), sem a necessidade de $\bar{y}$, que indica se pelo menos um tipo de produto é transferido entre uma doca de entrada para uma determinada doca de saída, uma vez que o valor da variável é obtido a partir dos valores das demais variáveis.

A função objetivo do MA é dada pela distância de Hamming entre a solução $\bar{X}$ atual e uma nova solução para o problema. Desta maneira, a função objetivo $(\Delta)$ do MA é dada por:

$$
\begin{array}{r}
\min \Delta=\Delta(x, \bar{x})+\Delta\left(z^{\text {in }}, \overline{z^{\text {in }}}\right)+\Delta\left(z^{\text {out }}, \overline{z^{\text {out }}}\right)+\Delta\left(w^{\text {in }}, \overline{w^{\text {in }}}\right)+\Delta\left(w^{\text {out }}, \overline{w^{\text {out }}}\right)+ \\
\text { BigM } \zeta+B i g M_{F T_{\max }} F T_{\max } .
\end{array}
$$

De modo que $\Delta(x, \bar{x})$ é definido como:

$$
\Delta(x, \bar{x})=\sum_{i \in \mathscr{N} \cup\{0\}} \sum_{j \in \mathscr{N} \cup\{N+1\} \mid i \neq j, \overline{x_{i j}}=0} x_{i j}+\sum_{i \in \mathscr{N} \cup\{0\}} \sum_{j \in \mathscr{N} \cup\{N+1\} \mid i \neq j, \overline{x_{i j}}=1}\left(1-x_{i j}\right)
$$

Ou seja, são contabilizados todas as variáveis relacionadas ao roteamento que tiveram seus valores alterados em relação a solução $\bar{X}$. Analogamente, são contabilizadas as alterações das demais variáveis binárias. Também é possível notar a utilização de uma variável auxiliar $\zeta \in[0,1]$ que tem por objetivo permitir que a solução $\bar{X}$ seja considerada factível se seu custo não atender a melhoria imposta, como expresso em (5.6). Logo, a solução $\bar{X}$ é factível e pode ser utilizada como ponto de partida para o modelo atual.

$$
f\left(x, e t, l t, d t^{\max }\right) \leq f\left(\bar{x}, \overline{e t}, \overline{l t}, \overline{d t^{\max }}\right)-\theta(1-\zeta)
$$


Sendo assim, é possível notar que a medida que $\zeta$ tende a 0 , a redução no valor da função objetivo original é de $\theta$ e quando $\zeta$ tende a 1 , a redução se aproxima de 0 . Destacamos que como $\bar{X}$ é uma solução viável de MA e o objetivo é buscar soluções melhores, a variável $\zeta$ é penalizada na função objetivo pelo peso BigM, forçando a busca por outra solução melhor. Foi utilizado BigM= $3 \times(N+2) \times(N+2)+L \times F+N \times H+L \times L$, o qual garante um número significativamente maior de $\Delta$, e utilizou-se $B i g M_{F T_{\max }}=10 \times B i g M$, assim priorizando a factibilidade durante a Proximity Search. Uma vez que é encontrada uma solução na qual $F T_{\max }=0$, fixa-se o valor da mesma em 0.

Os testes computacionais realizados mostraram que após algumas iterações da Proximity Search o valor $\theta$ permanece inalterado, contudo a função objetivo não apresentava melhoria igual a $\theta$, pois o valor de $\zeta$ se aproxima de 1 . Também foi observado que, embora a Proximity Search tenha por objetivo encontrar a solução mais próxima a $\bar{X}$, devido aos critérios de parada utilizados e a complexidade do problema, o MA busca apenas uma solução factível que respeite (5.6). Sendo assim, foram exploradas adaptações para a Proximity Search.

\subsubsection{Critérios de Parada do Modelo Auxiliar}

Uma das etapas principais da Proximity Search é a resolução do Modelo Auxiliar (MA). No entanto, devido à complexidade do problema estudado sua resolução demanda muito tempo computacional, uma vez que o MA é um problema linear inteiro misto, o que pode tornar a matheurística ineficiente. Desta maneira, há necessidade de considerar critérios de parada para resolução do modelo. Neste trabalho, são considerados os três critérios de parada de Bernardes (2019). O primeiro consiste em limitar o tempo de processamento do solver ao tratar o problema, levando a obtenção de uma solução factível, mas descartando a imposição de parada por otimalidade. O segundo critério de parada consiste em utilizar o gap de otimalidade. Segundo Bernardes (2019), quando um gap de otimalidade de $99 \%$ é atingido isto implica que a solução $X$ possui uma redução no valor da função objetivo original em relação à $\bar{X}$. O último critério de parada consiste em limitar o número de soluções factíveis encontradas. Esse critério é utilizado apenas quando $\theta$ atinge o menor valor estabelecido. Quando o limite de soluções factíveis é alcançado, caso haja tempo computacional, reinicia-se a PS com a última solução factível obtida.

Na definição de MA, foram utilizados os mesmos parâmetros de Bernardes (2019), ou seja, $\theta=\lambda f(\bar{X})$ e $\lambda \in\{0,25 ; 0,2 ; 0,15 ; 0,1 ; 0,05 ; 0,001\}$. Inicialmente, utiliza-se valores mais agressivos de $\theta$ para o corte (5.6), uma vez que nas primeiras iterações do método é possível encontrar soluções que satisfaçam essa completamente esta restrição $(\zeta=0)$. O tempo limite para o processamento do MA inicia-se em 120 segundos para os valores de $\lambda \in\{0,25 ; 0,2 ; 0,15 ; 0,1\}$ e decaí em 20 segundos para cada redução de $\lambda$ até o mínimo de 60 segundos. Caso $\lambda$ atinja seu valor mínimo de $\lambda=0,001$, o tempo limite é fixado no tempo restante disponível de processamento. Neste caso, também é imposto o critério de limite por número de soluções viáveis igual a 3. Caso a terceira solução viável não possua melhorias em relação à $\bar{X}$, a 
Proximity Search é reiniciada com a última solução viável obtida, o tempo limite é atualizado para o tempo restante de processamento e o critério de parada referente ao número de soluções viáveis é aumentado em 1 , neste caso passa a ser 4 . O procedimento se repete até que uma solução viável melhor seja encontrada e, neste caso, o critério de parada para soluções viáveis retorna a 3 .

Novos testes computacionais foram realizados e observou-se que para valores maiores de $\lambda$ o solver encontra soluções factíveis rapidamente, mas a medida que os valores de $\lambda$ diminuem há mais dificuldades em encontrar soluções factíveis. Sendo assim, foi analisada uma estratégia inversa a de Bernardes (2019). Para valores de $\lambda \in\{0,25 ; 0,2 ; 0,15 ; 0,1\}$ utilizou-se um tempo de processamento para o MA de 60 segundos e acrecia-se 20 segundos para cada $\lambda$ subsequente até um máximo de 120 segundos, intensificando a busca por soluções melhores. Entretanto, a estratégia de Bernardes (2019) mostrou-se superior.

\subsection{Adaptações da Proximity Search}

Em uma primeira abordagem, buscou-se retirar a variável $\zeta$ do modelo, porém, como destacado anteriormente, ao remover a mesma, a solução $\bar{X}$ não é uma solução inicial para o MA. Desta maneira, a função objetivo foi modificada para maximizar $\theta$, com o objetivo de obter uma solução que permitia o maior ganho no valor da função objetivo original. Porém tal abordagem resultou em um método que possui grandes ganhos nas primeiras iterações, mas que converge rapidamente para um mínimo local, tendo seus resultados inferiores à abordagem de Bernardes (2019). A segunda proposta foi utilizar uma abordagem híbrida, ou seja, a partir

de $\bar{X}$, determinou-se o maior valor possível de $\theta$, denomina-se esta solução $\bar{X}_{\theta}$, em seguida, o valor de $\theta$ obtido era imposto na restrição de corte, como originalmente proposto na Proximity Search. Então, inicia-se o procedimento de busca por uma solução próxima à $\bar{X}$. Desta maneira, a solução $\bar{X}_{\theta}$ é dada como ponto de partida para determinar uma solução próxima de $\bar{X}$. Entretanto, tal abordagem apresentou dificuldades em encontrar uma solução próxima de $\bar{X}$ a qual fosse melhor que $\bar{X}_{\theta}$, gerando resultados muito semelhantes a $\bar{X}$. Na terceira proposta de adaptação, utilizou-se a restrição (5.6) com $\theta$ definido como na segunda proposta, mas permitindo sua redução. Foram testados valores de folga de $1 \%$ à $5 \%$, porém sem grandes ganhos em relação as abordagens anteriores. Sendo assim, optou-se por utilizar a abordagem de Bernardes (2019) para resolução do problema bi-objetivo.

\subsection{Refinamento da Solução}

Uma vez encontrada uma solução $X^{*}$ melhor que $\bar{X}$, a solução $X^{*}$ passa por uma etapa de refinamento. Nesta etapa, os valores inteiros são fixados e determina-se os melhores valores para as variáveis lineares. Notou-se que as diferenças entre $X^{*}$ e $\bar{X}$, em diversas iterações, estavam relacionadas apenas à ordenação das cargas de entrada e de saída, demandando diversas 
iterações da Proximity Search até que o roteamento dos veículos fosse alterado. Desta maneira, foram fixadas apenas as variáveis relacionadas ao roteamento de veículos durante o processo de refinamento da solução. Durante o procedimento, utilizou-se um tempo limite de 30 segundos para efetuar o refinamento. Foi possível observar que tal abordagem é competitiva com a abordagem de Bernardes (2019). Entretanto, encontrou-se uma dificuldade ao tratar o problema bi-objetivo, uma vez que um dos objetivos é reduzir o número de veículos, que está diretamente relacionado as variáveis de roteamento. Assim, ao considerar a Proximity Search bi-objetivo, realizou-se testes computacionais sem fixar as variáveis inteiras na etapa de refinamento. Os testes preliminares indicaram que mesmo a estratégia de não fixar as variáveis inteiras era competitiva com Bernardes (2019). Logo, foram avaliadas a abordagem de Bernardes (2019) e a abordagem modificada, com nenhuma variável inteira fixada na etapa de refinamento.

\subsection{Experimentos Computacionais}

Os experimentos computacionais foram realizados no computador descrito na Seção 4.4, utilizando as instâncias de Bernardes (2019). Foi utilizado o solver Gurobi 9.0 na configuração padrão, na linguagem de programação $\mathrm{C}++$. O tempo máximo de processamento dos métodos matheurísticos foi de 1.800 segundos, incluindo o tempo para determinar a solução inicial. Para os presentes testes computacionais, foram utilizadas as instâncias de 15 e 40 clientes. As instâncias de 15 permitem avaliar a competitividade do método, enquanto as instâncias maiores indicam a robustez da matheurística Proximity Search.

Conforme discutido anteriormente, foram realizados testes computacionais referentes à Proximity Search de Bernardes (2019) (PSB) e à Proximity Search Modificada (PSM). Ambas utilizam o modelo de Bernardes (2019) adaptado para tratar o problema bi-objetivo, por meio da abordagem de Programação por Metas. Desta maneira, a matheurística Proximity Search busca determinar a menor variação entre as metas estabelecidas para cada objetivo. Como destacado anteriormente, a diferença entre as abordagens PSB e PSM consiste na etapa de refinamento da Proximity Search, na PSB as variáveis inteiras são fixadas, reduzindo a etapa de refinamento à resolução de um problema de programação linear. Enquanto a abordagem modificada não fixa as variáveis inteiras do problema, portanto, na etapa de refinamento resolve-se um problema de programação inteira mista.

\subsubsection{Análise da Competitividade da Proximity Search}

Os resultados referentes ao Custo Operacional (CO) e ao Número de Veículos (NV) para as instâncias de 15 clientes no Cenário 1 são apresentados na Tabela 5. Também apresentados os resultados obtidos utilizando a Abordagem por Metas (APM), apresentada no Capítulo 4. As abordagens matheurísticas apresentaram resultados semelhantes aos resultados obtidos ao utilizar a APM. Ambas obtiveram custos operacionais médios menores que APM, a redução no 
custo operacional médio foi de 0,26\% para PSM e de 0,24\% para PSB. Em relação ao número de veículos utilizados, PSM e PSB obtiveram um número de veículos médios 0,28\% maiores que APM. Vale ressaltar que para algumas instâncias, os resultados via método exato não estão na otimalidade, sendo assim, é possível que as abordagens PSM e PSB obtenham soluções melhores que o método exato.

A Tabela 6 apresenta os $p$-valores obtidos ao realizar o teste de Wilcoxon para os custos operacionais de APM, PSM e PSB nas instâncias de 15 clientes no Cenário 1. Ressalta-se que, por se tratar de um problema bi-caudal, é estabelecido que caso $p-v a l o r \geq 0,025$ não é possível identificar diferenças estatísticas entre as abordagens. É possível notar que, em termos de custo operacional, a abordagem PSB possui semelhança estatística com as demais abordagens. $\mathrm{O}$ fato de APM e PSM, de acordo com o $p$-valor obtido, não possuírem semelhanças estatísticas pode ser justificado devido aos diversos valores semelhantes obtidos nas instâncias, os quais são desconsiderados no teste. Desta maneira, a amostragem se torna muito pequena, tornando difícil a obtenção do $p$ - valor correto. O mesmo pode ser observado em relação ao número de veículos nas três abordagens.

A Tabela 7 apresenta os resultados para as instâncias de 15 clientes no Cenário 2. Pode-se notar que PSB, em relação à PSM, possui um resultado médio ligeiramente menor em relação ao custo operacional, porém um pouco maior em relação ao número de veículos. Assim como no Cenário 1, ambas determinam soluções próximas a APM. O custo operacional médio de PSM e PSB foram, respectivamente, $1,08 \%$ maior e $0,20 \%$ menor que o custo operacional da APM. Entretanto, PSM teve uma redução média no número de veículos utilizados de $0,57 \%$, enquanto PSB teve um aumento médio de $0,57 \%$ em relação ao número de veículos da APM. A Tabela 8 resume os resultados para o teste de Wilcoxon para as instâncias de 15 clientes no Cenário 2. É possível notar, que PSM e PSB são estatisticamente iguais em ambos os objetivos, e PSB é considerada estatisticamente igual a APM em relação ao custo operacional. Não pode-se afirmar que PSM e APM são estatisticamente iguais pelo $p$-valor, contudo, conforme discutido anteriormente, devido à incidência de diversos valores iguais, tanto para o custo operacional quanto para número de veículos, o $p$-valor pode estar incorreto.

Sendo assim pode-se notar que, para as instâncias com 15 clientes, ambas as abordagens são competitivas em relação a abordagem bi-objetivo de Programação por Metas (APM).

\subsubsection{Análise da Robustez da Proximity Search}

Conforme discutido anteriormente, para instâncias maiores, devido à complexidade do problema, não é possível obter soluções viáveis em um tempo computacional razoável utilizando o método exato como apresentado no Capítulo 4. Conforme apresentado em Bernardes (2019), ao utilizar o modelo exato, em ambos os cenários, o tempo de processamento de 7200 segundos foi insuficiente para encontrar a otimalidade de várias instâncias, e para algumas instâncias maiores, com 40 clientes, não foi possível determinar uma solução factível no tempo limite estabelecido. 
Tabela 5 - Resultados da Matheurística PS para Instâncias de 15 Clientes - Cenário 1.

\begin{tabular}{|c|c|c|c|c|c|c|}
\hline & \multicolumn{2}{|c|}{ APM } & \multicolumn{2}{|c|}{ PSM } & \multicolumn{2}{|c|}{ PSB } \\
\hline Instância & $\mathrm{CO}$ & NV & $\mathrm{CO}$ & $\mathrm{NV}$ & $\mathrm{CO}$ & NV \\
\hline R101-A & 1196,56 & 8 & 1196,56 & 8 & 1204,09 & \\
\hline R102-A & 1090,10 & 12 & 1090,10 & 12 & 1090,10 & 12 \\
\hline R103-A & 1076,36 & 11 & 1076,36 & 11 & 1076,36 & 11 \\
\hline R104-A & 922,54 & 9 & 922,54 & 9 & 922,54 & \\
\hline R105-A & 1165,26 & 11 & 1165,26 & 11 & 1165,26 & 11 \\
\hline R106-A & 982,23 & 11 & 982,23 & 11 & 982,23 & 11 \\
\hline R107-A & 1062,88 & 11 & 1062,88 & 11 & 1062,88 & 11 \\
\hline R108-A & 788,88 & 9 & 788,88 & 9 & 788,88 & \\
\hline R109-A & 894,86 & 9 & 894,86 & 9 & 894,86 & \\
\hline R110-A & 121,83 & 11 & 1121,83 & 11 & 1121,83 & 11 \\
\hline R111-A & 46,02 & 12 & 1046,02 & 12 & 1046,02 & 12 \\
\hline R112-A & 954,90 & 11 & 954,90 & 11 & 954,90 & 11 \\
\hline $\begin{array}{c}\text { Média } \\
\text { Grupo A }\end{array}$ & 1025,20 & 10,42 & 1025,20 & 10,42 & 1025,83 & 10,42 \\
\hline $\mathrm{R} 1$ & 2,45 & 8 & 932,45 & 8 & 932,45 & \\
\hline & 93,70 & 12 & 1193,70 & 12 & 1193,70 & 12 \\
\hline R103-B & 1048,38 & 11 & 1048,38 & 11 & 1048,38 & 11 \\
\hline R104-B & 914,17 & 9 & 914,17 & 9 & 914,17 & \\
\hline R105-B & 45,27 & 11 & 1145,27 & 11 & 1146,27 & 11 \\
\hline R106-B & 07,13 & & 1007,13 & 11 & 1007,13 & 11 \\
\hline $\mathrm{R} 10^{\circ}$ & 24,16 & 11 & 1024,16 & 11 & 1024,16 & 11 \\
\hline R108-B & 806,79 & 9 & 806,79 & 9 & 806,79 & \\
\hline $\mathrm{R}$ & 0,70 & 9 & 900,70 & 9 & 900,70 & \\
\hline R110 & 2,70 & 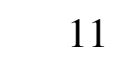 & 1052,70 & 11 & 1052,70 & 11 \\
\hline R111-B & 74,82 & & 1074,82 & 13 & 1074,82 & 13 \\
\hline R112-B & 1100,82 & & 1100,82 & 11 & 1100,82 & 11 \\
\hline $\begin{array}{c}\text { Média } \\
\text { Grupo B }\end{array}$ & 1016,76 & 10,50 & 1016,76 & 10,50 & 1016,84 & 10,50 \\
\hline & & & & 8 &, 74 & \\
\hline R102-C & 75,43 & 12 & 1175,43 & 12 & 1175,43 & 12 \\
\hline & 1088,88 & 11 & 1088,88 & 11 & 1088,88 & 11 \\
\hline R104-C & 897,41 & 9 & 897,41 & 9 & 897,41 & \\
\hline R105-C & 1513,50 & 11 & 1410,31 & 12 & 1410,31 & 12 \\
\hline R106-C & 11,28 & . & 1211,28 & 11 & 1212,01 & 1 \\
\hline R107-C & 1020,93 & 11 & 1020,93 & 11 & 1020,93 & 11 \\
\hline & 823,46 & 9 & 823,46 & 9 & 823,46 & \\
\hline R109-C & 915,06 & 9 & 915,06 & 9 & 915,06 & \\
\hline R110-C & 989,92 & 11 & 993,24 & 11 & 989,92 & 11 \\
\hline R111-C & & 12 & 1035,79 & 12 & 1035,79 & 12 \\
\hline R112-C & 1007,59 & 11 & 1007,59 & 11 & 1007,59 & 11 \\
\hline $\begin{array}{l}\text { Méc } \\
\text { Grup }\end{array}$ & 1070,13 & 10 & 1061,81 & 10,50 & 10 & (5, \\
\hline dia Ger & 1037,36 & 10,44 & 1034,59 & 10,47 & 1034,85 & 10,47 \\
\hline
\end{tabular}


Tabela 6 - Resultados do Teste de Wilcoxon para as Instâncias de 15 Clientes - Cenário 1.

\begin{tabular}{lccc}
\hline & APM & PSM & PSB \\
\hline APM & - & 1,0000 & 0,5896 \\
PSM & 1,0000 & - & 0,2807 \\
PSB & 0,5896 & 0,2807 & - \\
\hline
\end{tabular}

(a) Resultados para Custo Operacional.

\begin{tabular}{lccc}
\hline & APM & PSM & PSB \\
\hline APM & - & 1,0000 & 1,0000 \\
PSM & 1,0000 & - & - \\
PSB & 1,0000 & - & - \\
\hline
\end{tabular}

(b) Resultados para Número de Veículos.

Fonte: Elaborado pelo Autor.

Sendo assim, para estabelecer as metas para PSM e PSB, foram utilizadas as próprias abordagens de maneira mono-objetivo. Assim, considera-se PSBCO a abordagem PSB mono-objetivo para o custo operacional e PSBNV a abordagem PSB mono-objetivo para o número de veículos. De maneira análoga, defini-se PSMCO a abordagem mono-objetivo para o custo operacional e PSMNV a abordagem mono-objetivo para o número de veículos. Vale ressaltar que na etapa de refinamento de PSMCO, são fixadas as variáveis associadas ao roteamento de veículos, diferentemente de PSM e PSMNV nas quais nenhuma variável inteira é fixada na etapa de refinamento.

Na Tabela 9, são apresentados os resultados para as abordagens PSM, PSMCO e PSMNV para as instâncias de 40 clientes no Cenário 1. Pode-se notar, como esperado, que a abordagem PSM tem resultados com valores intermediários às abordagens mono-objetivo. A PSM obteve um custo operacional médio 1,66\% maior que PSMCO, porém com uma redução de 4,41\% em relação ao número de veículos médios utilizados. Ao comparar PSM e PSMNV, o número de veículos médios utilizados tem um aumento de $2,32 \%$, entretanto há uma redução do custo operacional médio de $41,31 \%$.

Os resultados para as instâncias de 40 clientes no Cenário 1 para PSB, PSBCO e PSBNV são apresentados na Tabela 10. Assim como a PSM, PSB obteve resultados médios intermediários aos resultados das abordagens mono-objetivo. Com PSB é possível obter uma redução de 4,35\% no número médio de veículos, a um acréscimo de $1,54 \%$ dos custos operacionais médios em relação à PSBCO. Também é possível notar com a PSB, em relação à PSBNV, um aumento no número médio de veículos de 2,51\%, porém com uma redução de 40,83\% nos custos operacionais médios.

Assim, é possível notar que as duas abordagens apresentam resultados relevantes em comparação aos resultados das abordagens mono-objetivo. Embora os resultados de PSB sejam ligeiramente melhores que PSM, as abordagens podem ser consideradas estatisticamente iguais. O teste de Wilcoxon apresentou $p$-valores de 0,8706 e 0,7897 para, respectivamente, o custo operacional e o número de veículos. Sendo assim, para o Cenário 1, pode-se considerar que as abordagens são equivalentes.

A Tabela 11 apresenta os resultados de PSM, PSMCO e PSMNV para as instâncias de 
Tabela 7 - Resultados da Matheurística PS para Instâncias de 15 Clientes - Cenário 2.

\begin{tabular}{|c|c|c|c|c|c|c|}
\hline & \multicolumn{2}{|c|}{ APM } & \multicolumn{2}{|c|}{ PSM } & \multicolumn{2}{|c|}{ PSB } \\
\hline Instância & $\mathrm{CO}$ & NV & $\mathrm{CO}$ & NV & $\mathrm{CO}$ & NV \\
\hline R101-A & 765,59 & 5 & 774,13 & 5 & 767,56 & 5 \\
\hline R102-A & 633,70 & 5 & 639,35 & 5 & 624,77 & 5 \\
\hline R103-A & 666,30 & 5 & 666,30 & 5 & 666,30 & 5 \\
\hline R104-A & 647,31 & 5 & 642,99 & 5 & 642,99 & 5 \\
\hline R105-A & 799,66 & 6 & 799,66 & 6 & 806,04 & 6 \\
\hline R106-A & 632,62 & 5 & 632,62 & 5 & 632,62 & 5 \\
\hline R107-A & 573,08 & 5 & 570,69 & 5 & 572,69 & 5 \\
\hline R108-A & 585,65 & 5 & 582,61 & 5 & 585,65 & 5 \\
\hline R109-A & 695,45 & 5 & 695,45 & 5 & 695,45 & 5 \\
\hline R110-A & 552,24 & 5 & 552,24 & 5 & 552,24 & 5 \\
\hline R111-A & 650,55 & 6 & 654,08 & 6 & 650,55 & 6 \\
\hline R112-A & 570,81 & 5 & 570,81 & 5 & 570,81 & 5 \\
\hline $\begin{array}{c}\text { Média } \\
\text { Grupo A }\end{array}$ & 647,75 & 5,17 & 648,41 & 5,17 & 647,31 & 5,17 \\
\hline R101-B & 977,51 & 5 & 977,51 & 5 & 880,17 & 6 \\
\hline R102-B & 577,45 & 5 & 600,15 & 5 & 615,08 & 5 \\
\hline R103-B & 581,52 & 5 & 584,58 & 5 & 584,58 & 5 \\
\hline R104-B & 704,34 & 5 & 706,25 & 5 & 714,70 & 5 \\
\hline R105-B & 855,97 & 6 & 861,13 & 6 & 855,97 & 6 \\
\hline R106-B & 777,18 & 5 & 777,18 & 5 & 777,18 & 5 \\
\hline R107-B & 591,17 & 5 & 591,17 & 5 & 595,58 & 5 \\
\hline R108-B & 605,82 & 5 & 618,79 & 5 & 605,82 & 5 \\
\hline R109-B & 1203,76 & 8 & 1202,95 & 8 & 1209,39 & 8 \\
\hline R110-B & 537,75 & 5 & 556,34 & 5 & 537,75 & 5 \\
\hline R111-B & 666,48 & 6 & 666,48 & 6 & 656,61 & 6 \\
\hline R112-B & 599,05 & 5 & 596,15 & 5 & 597,82 & 5 \\
\hline $\begin{array}{c}\text { Média } \\
\text { Grupo B }\end{array}$ & 723,17 & 5,42 & 728,22 & 5,42 & 719,22 & 5,50 \\
\hline R101-C & 733,73 & 5 & 757,43 & 5 & 733,73 & 5 \\
\hline R102-C & 600,57 & 5 & 600,53 & 5 & 600,53 & 5 \\
\hline R103-C & 597,04 & 5 & 597,04 & 5 & 597,04 & 5 \\
\hline R104-C & 636,11 & 5 & 641,10 & 5 & 636,11 & 5 \\
\hline R105-C & 699,24 & 6 & 839,36 & 5 & 693,28 & 6 \\
\hline R106-C & 627,91 & 5 & 627,91 & 5 & 627,91 & 5 \\
\hline R107-C & 571,41 & 5 & 570,99 & 5 & 570,99 & 5 \\
\hline R108-C & 561,16 & 5 & 561,16 & 5 & 561,16 & 5 \\
\hline R109-C & 771,98 & 5 & 786,68 & 5 & 779,60 & 5 \\
\hline R110-C & 558,18 & 5 & 558,18 & 5 & 558,18 & 5 \\
\hline R111-C & 639,58 & 6 & 647,06 & 6 & 641,83 & 6 \\
\hline R112-C & 579,21 & 5 & 579,21 & 5 & 579,21 & 5 \\
\hline $\begin{array}{c}\text { Média } \\
\text { Grupo C }\end{array}$ & 631,34 & 5,17 & 647,22 & 5,08 & 631,63 & 5,17 \\
\hline Média Gera & 667,42 & 5,25 & 674,62 & 5,22 & 666,05 & 5,28 \\
\hline
\end{tabular}


Tabela 8 - Resultados do Teste de Wilcoxon para as Instâncias de 15 Clientes - Cenário 2.

\begin{tabular}{cccc}
\hline & APM & PSM & PSB \\
\hline APM & - & 0,0049 & 0,6951 \\
PSM & 0,0049 & - & 0,0559 \\
PSB & 0,6951 & 0,0559 & - \\
\hline
\end{tabular}

(a) Resultados para Custo Operacional.

\begin{tabular}{lccc}
\hline & APM & PSM & PSB \\
\hline APM & - & 1,0000 & 1,0000 \\
PSM & 1,0000 & - & 0,3478 \\
PSB & 1,0000 & 0,3478 & - \\
\hline
\end{tabular}

(b) Resultados para Número de Veículos.

Fonte: Elaborado pelo Autor.

40 clientes no Cenário 2. A PSM obteve o mesmo número médio de veículos que PSMCO a uma redução média de $0,36 \%$ nos custos operacionais, superando a abordagem PSMCO para tal objetivo. Em relação a PSMNV, foram utilizados, em média, 16,91\% veículos adicionais, porém há uma redução de 49,61\% nos custos operacionais. Sendo assim, para o Cenário 2, pode-se notar que os resultados da abordagem PSM obtiveram uma direcionamento maior para redução nos custos operacionais que ao número de veículos utilizados.

Para PSB, PSBCO e PSBNV, os resultados das instâncias de 40 clientes para o Cenário 2 podem ser verificados na Tabela 12. Assim como PSM, a PSB também obteve resultados melhores que a abordagem mono-objetivo de custo operacional. Com PSB, em relação à PSBCO, foi possível obter uma redução de 1,24\% nos custos operacionais e de $8,93 \%$ no número de veículos. Sendo assim, os resultados médios obtidos com PSB são superiores à PSBCO e ligeiramente superiores à PSM. Em relação à PSBNV, PSB obteve um acréscimo de 7,17\% no número de veículos utilizados, porém também obteve uma redução de 49,95\% no custo operacional médio.

Assim como no Cenário 1, a PSB obteve resultados superiores à PSM no Cenário 2. Contudo o teste de Wilcoxon indica que as abordagens são estatisticamente iguais em relação ao custo operacional médio ( $p-$ valor $=0,1763)$, porém diferentes em relação ao número de veículos utilizados $(p-$ valor $<0,0001)$. Desta maneira, pode-se concluir que a PSB apresenta melhor desempenho com relação ao número de veículos e resultados equivalentes com relação ao custo operacional.

\subsection{Considerações}

Após o estudo realizado foi possível observar a necessidade de utilizar um método heurístico para resolução do VRSP. A Proximity Search desenvolvida se mostrou eficiente na resolução do VRSP, obtendo soluções factíveis em tempo hábil e com qualidade. Embora tenham sido realizados testes em relação à solução inicial e a etapa de refinamento da PS, a abordagem de Bernardes (2019) apresentou os melhores resultados.

Os resultados aqui obtidos corroboram as vantagens de tratar o VRSP bi-objetivo. Utili- 
Tabela 9 - Resultados da PSM para Instâncias de 40 Clientes - Cenário 1.

\begin{tabular}{|c|c|c|c|c|c|c|}
\hline & \multicolumn{2}{|c|}{ PSMCO } & \multicolumn{2}{|c|}{ PSM } & \multicolumn{2}{|c|}{ PSMNV } \\
\hline Instância & $\mathrm{CO}$ & NV & $\mathrm{CO}$ & NV & $\mathrm{CO}$ & NV \\
\hline R101-A & 2161,68 & 29 & 2247,01 & 27 & 5009,83 & 25 \\
\hline R102-A & 341,61 & 31 & 2348,98 & & 4509,71 & 31 \\
\hline R103-A & 1986,54 & 27 & 2011,58 & 26 & 3631,44 & 26 \\
\hline R104-A & 2079,46 & 29 & 2076,67 & 29 & 2847,37 & 29 \\
\hline R105-A & 2306,94 & 31 & 2379,70 & 29 & 4714,15 & 28 \\
\hline R106-A & 2336,63 & 32 & 2381,17 & 30 & 4047,42 & 30 \\
\hline R107-A & 1933,63 & 26 & 1980,38 & 25 & 3364,61 & 25 \\
\hline R108-A & 1886,79 & 26 & 1917,30 & 25 & 2724,20 & 24 \\
\hline R109-A & 2108,96 & 31 & 2120,06 & 30 & 4249,70 & 30 \\
\hline R110-A & 349,12 & & 1846,75 & 25 & 3489,64 & 25 \\
\hline R111-A & 2069,20 & 29 & 2045,13 & 28 & 3391,64 & 27 \\
\hline R112-A & 2079,36 & 29 & 2067,24 & 9 & 3024,75 & 29 \\
\hline $\begin{array}{c}\text { Média } \\
\text { Grupo A }\end{array}$ & 2094,99 & 28,83 & 2118,50 & 27,83 & 3750,37 & 27,42 \\
\hline $\mathrm{R} 1 \mathrm{C}$ & 2207 & 3( & 23 & & & \\
\hline & 70,77 & 31 & 2413,72 & 31 & 4451,58 & 31 \\
\hline R103-B & 2080,78 & 28 & 2042,87 & 27 & 3500,10 & 26 \\
\hline R104-B & 2090,38 & 30 & 2091,33 & 29 & 2922,57 & 29 \\
\hline R105 & 55,21 & 3 & 2508,02 & 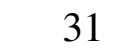 & 4781,06 & 28 \\
\hline R106-B & 2343,34 & & 2403,29 & 1 & 4117,36 & 30 \\
\hline $\mathrm{R} 10^{\circ}$ & 1901,60 & 2 & 1956,25 & 2 & 3385,22 & 25 \\
\hline R108-B & 1896,34 & & 1904,06 & & 2663,90 & 24 \\
\hline $\mathrm{R} 1$ & 2136,85 & 3( & 2436,18 & 2 & 4145,65 & 30 \\
\hline R110-B & 82,15 & 2 & 1962,87 & & 3432,10 & 25 \\
\hline $\mathrm{R} 1$ & 2078,82 & 3 & 2137,14 & 28 & 3574,40 & 28 \\
\hline R112-B & 2094,55 & & 2092,54 & 29 & 3128,17 & 29 \\
\hline $\begin{array}{c}\text { Média } \\
\text { Grupo B }\end{array}$ & 2138,17 & 29,25 & 2190,87 & 28,25 & 3759,45 & 27,50 \\
\hline & & & & & & 2 \\
\hline R102-C & $.78,35$ & 32 & 2476,80 & 1 & 4438,11 & 31 \\
\hline R103-C & 2123,27 & 0 & 2160,87 & & 3524,56 & 27 \\
\hline R104-C & 2088,42 & 3 & 2098,27 & 29 & 2713,02 & 29 \\
\hline & 2617,47 & & 2700,46 & 30 & 4700,47 & 28 \\
\hline R106-C & 2423,16 & 3 & 2550,68 & 31 & 4058,19 & 30 \\
\hline R107-C & 1965,33 & 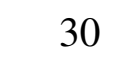 & 1973,20 & 26 & 3248,68 & 25 \\
\hline & 1932,26 & 2 & 1918,28 & 25 & 2501,72 & 24 \\
\hline R109-C & 2711,09 & 3 & 2656,53 & 32 & 4402,82 & 30 \\
\hline R110-C & 1894,65 & 97 & 1941,25 & 25 & 3475,66 & 25 \\
\hline R111-C & 2082,06 & 2 & 2085,97 & 28 & 3462,21 & 28 \\
\hline R112-C & 2061,86 & 29 & 2084,52 & 29 & 2999,03 & 29 \\
\hline $\begin{array}{c}\text { Média } \\
\text { Grupo C }\end{array}$ & 2245,73 & 30 & $22^{\prime}$ & 2 & 67 & ? \\
\hline dia Ger & 2159,63 & 29,44 & 2195,50 & 28,14 & 3740,83 & 27,50 \\
\hline
\end{tabular}


Tabela 10 - Resultados da PSB para Instâncias de 40 Clientes - Cenário 1.

\begin{tabular}{|c|c|c|c|c|c|c|}
\hline & \multicolumn{2}{|c|}{ PSBCO } & \multicolumn{2}{|c|}{ PSB } & \multicolumn{2}{|c|}{ PSBNV } \\
\hline Instância & $\mathrm{CO}$ & $\mathrm{NV}$ & $\mathrm{CO}$ & $\mathrm{NV}$ & $\mathrm{CO}$ & NV \\
\hline R10 & 2202,47 & 29 & 2384,88 & 26 & 4979,79 & 25 \\
\hline R102-A & 301,18 & 31 & 2306,52 & 31 & 4360,28 & 31 \\
\hline R103-A & 967,17 & 27 & 2021,15 & 26 & 3522,60 & 26 \\
\hline R104-A & 2079,46 & 29 & 2075,95 & 29 & 2678,89 & 29 \\
\hline R105-A & 339,06 & 32 & 2249,43 & 30 & 4752,54 & 28 \\
\hline R106-A & 237,72 & 32 & 2277,41 & 31 & 4165,38 & 30 \\
\hline R107-A & 1971,40 & 26 & 2022,07 & 25 & 3352,64 & 25 \\
\hline R108-A & 01,87 & 25 & 1900,20 & 25 & 2660,33 & 25 \\
\hline R109-A & 138,38 & 32 & 2215,66 & 30 & 4310,58 & 30 \\
\hline R110-A & 59,11 & 26 & 1882,58 & 25 & 3389,76 & 25 \\
\hline R111 & 45,40 & 28 & 2092,30 & 27 & 3329,62 & 27 \\
\hline R112-A & 2080,19 & 29 & 2082,24 & 29 & 2993,18 & 29 \\
\hline $\begin{array}{c}\text { Média } \\
\text { Grupo A }\end{array}$ & 2093,62 & 28,83 & 2125,87 & 27,83 & 3707,97 & 27,50 \\
\hline $\mathrm{R}$ & 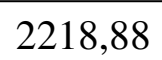 & ) & 8 & $r$ & & 25 \\
\hline $\mathrm{R} 1 \mathrm{C}$ & 94,79 & 33 & 2462,82 & 31 & 4413,36 & 31 \\
\hline $\mathrm{R} 10$ & 2059,33 & 28 & 2095,03 & 26 & 3384,48 & 26 \\
\hline $\mathrm{R} 1$ & 95,71 & 30 & 2101,98 & 29 & 2865,79 & 29 \\
\hline $\mathrm{R} 10$ & 2504,85 & 33 & 2422,68 & 30 & 4854,79 & 28 \\
\hline $\mathrm{R} 1 \mathrm{C}$ & 78,95 & 31 & 2368,73 & 31 & 4067,55 & 30 \\
\hline $\mathrm{R} 1$ & 01,31 & 27 & 1908,19 & & 3337,67 & 25 \\
\hline & & & & & & 4 \\
\hline $\mathrm{R} 1$ & 84,49 & 32 & 2140,94 & 1 & 4166,44 & 30 \\
\hline $\mathrm{R} 11$ & 96,34 & 26 & & & 3387,83 & 25 \\
\hline & 3 & 29 & 2091,66 & 8 & 3440,76 & 27 \\
\hline R112-B & 2084,80 & 29 & 2084,44 & 29 & 3070,63 & 29 \\
\hline $\begin{array}{c}\text { Média } \\
\text { Grupo B }\end{array}$ & 2133,17 & 29,42 & 2156,55 & 28,08 & 3714,25 & 27 \\
\hline & & & & & 5222,11 & 25 \\
\hline $\mathrm{R}$ & 73,41 & $J 2$ & 2511,00 & 31 & 4336,30 & 31 \\
\hline & 42,39 & 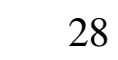 & 2153,87 & & 3556,07 & 26 \\
\hline & & 0 & & & & 2 \\
\hline R105-C & 2645,82 & 36 & 2719,87 & 31 & 4778,75 & 28 \\
\hline $\mathrm{R} 1 \mathrm{C}$ & 2402 & 32 & 2462,65 & 31 & 3914,56 & 31 \\
\hline $\mathrm{R} 1 \mathrm{C}$ & 1935,93 & 27 & 1937,42 & 26 & 3190,36 & 25 \\
\hline & 1933,09 & 25 & 1909,06 & 25 & 2501,72 & 24 \\
\hline R109-C & 2775,38 & 34 & 2853,24 & 32 & 4224,21 & 30 \\
\hline & 1875,00 & 26 & 1880,90 & 25 & 3456,96 & 25 \\
\hline R111-C & 2101,66 & 29 & 2100,06 & 28 & 3122,05 & 25 \\
\hline R112-C & 2065,02 & 29 & 2064,87 & 29 & 3068,64 & 20 \\
\hline $\begin{array}{c}\text { Média } \\
\text { Grupo C }\end{array}$ & 2244,08 & 29,92 & 2287,99 & 28,42 & 3682,22 & 27 , \\
\hline 年 & 2156,95 & 29,39 & 2190,14 & 28,11 & 3701,48 & 27,42 \\
\hline
\end{tabular}


Tabela 11 - Resultados da PSM para Instâncias de 40 Clientes - Cenário 2.

\begin{tabular}{|c|c|c|c|c|c|c|}
\hline & \multicolumn{2}{|c|}{ PSMCO } & \multicolumn{2}{|c|}{ PSM } & \multicolumn{2}{|c|}{ PSMNV } \\
\hline Instância & $\mathrm{CO}$ & $\mathrm{NV}$ & $\mathrm{CO}$ & $\mathrm{NV}$ & $\mathrm{CO}$ & NV \\
\hline R101-A & 1675,76 & 21 & 1726,40 & 21 & 4114,54 & 14 \\
\hline R102-A & 53,48 & 18 & 51,58 & & 3245,92 & 13 \\
\hline R103-A & 402,45 & 16 & 1391,05 & 16 & 2668,82 & 14 \\
\hline R104-A & 1313,74 & 15 & 1292,96 & 15 & 1932,46 & 14 \\
\hline R105-A & 1463,52 & 18 & 1549,22 & 18 & 3995,72 & 13 \\
\hline R106-A & 1350,52 & 15 & 1298,13 & 15 & 2894,1 & 13 \\
\hline R107-A & 1304,23 & 14 & 1275,77 & 14 & 2459,47 & 13 \\
\hline R108-A & 1466,77 & 16 & 1466,77 & 16 & 2261,69 & 15 \\
\hline R109-A & 22,61 & 16 & 1337,19 & 16 & 3623,24 & 14 \\
\hline R110-A & 23,52 & 14 & 1325,51 & 14 & 2570,38 & 13 \\
\hline R111-A & 17,06 & 13 & 1217,06 & 13 & 2185,26 & 12 \\
\hline R112-A & 1136,41 & 13 & 1136,41 & 13 & 1769,76 & 13 \\
\hline $\begin{array}{c}\text { Média } \\
\text { Grupo A }\end{array}$ & 1360,84 & 15,75 & 1372,34 & 15,75 & 2810,11 & 13,42 \\
\hline $\mathrm{R} 1$ & 7 & 20 & 7 & & 4147,49 & 14 \\
\hline & 05 & 18 & 1569,57 & 1 & 3558,98 & 13 \\
\hline R103 & 53,19 & 18 & 1551,37 & 1 & 2595,67 & 14 \\
\hline R104-B & 73,59 & 15 & 1373,59 & 1 & 1938,05 & 14 \\
\hline R105 & 45,95 & 16 & 1545,95 & 1 & 3471,19 & 13 \\
\hline R106 & 57,55 & & 1467,55 & & 2992,48 & 10 \\
\hline R1 & 89,26 & 1 & 58,93 & 14 & 2367,58 & 12 \\
\hline R108-B & 1168,83 & 1 & 1190,11 & & 1627,07 & 13 \\
\hline & 56,71 & 1 & 1367,07 & 1 & 2925,36 & 13 \\
\hline $\mathrm{R} 1$ & 42,77 & & 1257,60 & & 2784,91 & 13 \\
\hline $\mathrm{R}$ & 55,43 & 2 & 1164,26 & 1 & 2064,25 & 11 \\
\hline R112-B & 1243,52 & & 1199,87 & & 1841,37 & 13 \\
\hline $\begin{array}{c}\text { Média } \\
\text { Grupo B }\end{array}$ & 1394,65 & 15,42 & 1398,90 & 15,42 & 2692,87 & 3,00 \\
\hline & & & & & 45 & 15 \\
\hline $\mathrm{R} 1$ & 82,93 & 18 & 1592,54 & 1 & 3399,09 & 13 \\
\hline & 1480,19 & 1 & 1431,62 & & 2691,4 & 15 \\
\hline R104-C & 1375,35 & 1 & 1338,09 & 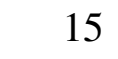 & 2050,76 & 1 \\
\hline & 19,36 & 15 & 1501,01 & & 3783,62 & 14 \\
\hline & 30,49 & 1 & 1492,08 & 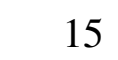 & 3090,27 & 13 \\
\hline R107-C & 1309,21 & 14 & 1271,89 & 9 & 2385,8 & 13 \\
\hline & 1198,73 & & 1164,04 & 1 & 1629,48 & 11 \\
\hline R109-C & 1400,38 & 4 & 1376,52 & 14 & 3121,61 & 13 \\
\hline R110-C & 1322,93 & 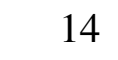 & 1293,74 & 14 & 2540,16 & 13 \\
\hline R111-C & & 11 & 1234,36 & 12 & 2155,66 & 11 \\
\hline R112-C & 1264,78 & 13 & 1278,70 & 13 & 1895,84 & 13 \\
\hline $\begin{array}{l}\text { Méc } \\
\text { Grup }\end{array}$ & 1422,32 & 15 , & 1391,48 & 15 &, 84 & 17 \\
\hline dia Ger & 1392,60 & 15,42 & 1387,57 & 15,42 & 2753,61 & 13,19 \\
\hline
\end{tabular}


Tabela 12 - Resultados da PSB para Instâncias de 40 Clientes - Cenário 2.

\begin{tabular}{|c|c|c|c|c|c|c|}
\hline & \multicolumn{2}{|c|}{ PSBCO } & \multicolumn{2}{|c|}{ PSB } & \multicolumn{2}{|c|}{ PSBNV } \\
\hline Instância & $\mathrm{CO}$ & $\mathrm{NV}$ & $\mathrm{CO}$ & $\mathrm{NV}$ & $\mathrm{CO}$ & NV \\
\hline R101-A & 1704,38 & 21 & 1580,38 & 16 & 4114,54 & 14 \\
\hline R102-A & 1511,89 & 17 & 1476,51 & 15 & 3245,92 & 13 \\
\hline R103-A & 1343,28 & 16 & 1359,29 & 15 & 2668,82 & 14 \\
\hline R104-A & 1295,38 & 15 & 1391,40 & 16 & 1892,47 & 14 \\
\hline R105-A & 1455,08 & 18 & 1492,96 & 15 & 3995,72 & 13 \\
\hline R106-A & 1335,94 & 15 & 1344,71 & 14 & 2894,1 & 13 \\
\hline R107-A & 1268,43 & 15 & 1262,98 & 13 & 2459,47 & 13 \\
\hline R108-A & 1443,17 & 16 & 1548,31 & 16 & 2255,65 & 17 \\
\hline R109-A & 1310,80 & 15 & 1326,81 & 14 & 3623,24 & 14 \\
\hline R110-A & 1272,08 & 14 & 1243,12 & 14 & 2570,38 & 13 \\
\hline R111-A & 1114,43 & 13 & 1116,19 & 12 & 2185,26 & 12 \\
\hline R112-A & 1160,89 & 13 & 1158,37 & 13 & 1769,76 & 13 \\
\hline $\begin{array}{c}\text { Média } \\
\text { Grupo A }\end{array}$ & 1351,31 & 15,67 & 1358,42 & 14,42 & 2806,28 & 13,58 \\
\hline $\mathrm{R} 1$ & 27 & 2 & 25 & 16 & 111 & 14 \\
\hline $\mathrm{R} 1 \mathrm{C}$ & 86,49 & 17 & 1685,05 & 14 & 3558,98 & 13 \\
\hline $\mathrm{R} 10$ & 1486,45 & 17 & 1432,18 & 5 & 2595,67 & 14 \\
\hline $\mathrm{R} 1$ & 1449,50 & 15 & 1345,26 & 15 & 1938,05 & 14 \\
\hline R10 & 1544,30 & 16 & 1487,28 & 14 & 3471,19 & 13 \\
\hline $\mathrm{R} 1 \mathrm{C}$ & 70,41 & 16 & 1337,99 & 14 & 2992,48 & 13 \\
\hline $\mathrm{R} 1 \mathrm{C}$ & 24,93 & 14 & 1360,77 & 13 & 2367,58 & 12 \\
\hline $\mathrm{R} 10$ & 68,16 & 12 & 1205,43 & 2 & 1627,07 & 3 \\
\hline $\mathrm{R} 1$ & 28,78 & 16 & 1374,66 & 5 & 2925,36 & 13 \\
\hline R110-B & 1255,92 & 14 & 1252,15 & & 2784,91 & 13 \\
\hline & 96,77 & 12 & 1145,12 & 2 & 2064,25 & 11 \\
\hline R112-B & 1276,26 & 13 & 1230,42 & 13 & 1841,37 & 13 \\
\hline $\begin{array}{c}\text { Média } \\
\text { Grupo B }\end{array}$ & 1391,35 & 15,25 & 1382,30 & 13,92 & 2692,87 & 13,00 \\
\hline & & & & & נד, דנJ & 15 \\
\hline $\mathrm{R} 1$ & 79 & 1 & 90 & 15 & 3399,09 & 13 \\
\hline & 62,64 & 20 & 1550,83 & 16 & 2691,4 & 15 \\
\hline R104-C & 1352,77 & 15 & 1348,75 & 14 & 2050,76 & 14 \\
\hline R105-C & 1555,23 & 16 & 1488,39 & 15 & 3708,88 & 13 \\
\hline & & 16 & 1435 & 14 & 3090,27 & 13 \\
\hline $\mathrm{R} 10$ & 1327,82 & 15 & 1247,04 & 13 & 2385,8 & 13 \\
\hline R108-C & 1177,79 & 12 & 1098,95 & 12 & 1629,48 & 11 \\
\hline R109-C & 1382,83 & 15 & 1337,71 & 15 & 3121,61 & 13 \\
\hline & 1323,13 & 14 & 1280,42 & 14 & 2540,16 & 13 \\
\hline R111-C & 1351,11 & 13 & 1201,04 & 12 & 2155,66 & 11 \\
\hline R112-C & 29,81 & 13 & 1228,88 & 13 & 1895,84 & 13 \\
\hline $\begin{array}{l}\text { Méc } \\
\text { Grup }\end{array}$ & 1438,54 & 15,75 & 1388,61 & 4,17 & 751,62 & 13 , \\
\hline 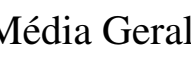 & 1393,74 & 15,56 & 1376,44 & 14,17 & 2750,25 & 13,22 \\
\hline
\end{tabular}


zando a PSM para 15 clientes no Cenário 2, foi possível reduzir o número de veículos em 23,38\% a um aumento de 5,78\% nos custos operacionais, enquanto a redução no número de veículos foi de $21,97 \%$ a um acréscimo de $4,44 \%$ para a PSB. Embora ambas possuam estatisticamente o mesmo desempenho em termos de custo operacional, para as instâncias de 40 clientes no Cenário 2 foi possível verificar um melhor desempenho da PSB, com a qual obteve-se, respectivamente, soluções para custo operacional e número de veículos em média de 1,24\% e 8,93\% em relação à abordagem mono-objetivo dos custos operacionais. A PSB também obteve acréscimo do número de veículos médio de 7,17\% em relação à abordagem mono-objetivo do número de veículos, porém houve uma redução de $49,95 \%$ no custo operacional médio.

Sendo assim, conclui-se que a matheurística Proximity Search é indicada para abordar o problema bi-objetivo, aproximando-se de ambos os objetivos, caso seja possível. Também mostra-se a necessidade de estudar o problema em dimensões maiores, com um maior número de clientes e com a possibilidade de haver mais clientes por rota. 



\section{CONCLUSÕES E TRABALHOS FUTUROS}

Neste trabalho, estudou-se o problema bi-objetivos de Roteamento de Veículos e Programação do Cross-Dock com integração entre as decisões operacionais do sistema. A relevância do problema mono-objetivo, ou seja, tratando a minimização dos custos operacionais do sistema, foi apontada por diferentes autores Agustina, Lee e Piplani (2014), Rahbari et al. (2019), Bernardes (2019) e Liao (2020). No entanto, embora já tenha sido enfatizada a relevância da redução no número de veículos na literatura de roteamento de veículos, este objetivo ainda não havia sido abordado no contexto de cross-dock. Como a minimização dos custos de distribuição e do número de veículos são objetivos conflitantes, foi desenvolvido um modelo bi-objetivo para representar o problema.

Três abordagens bi-objetivo foram avaliadas para resolução do problema estudado. Inicialmente, a Abordagem por Somas Ponderadas foi analisada. No entanto, houve a necessidade de utilizar parâmetros adicionais afim de normalizar os objetivos devido a diferença na ordem de grandeza dos mesmos. A segunda abordagem utilizada foi Preempção (APP) para qual a calibração de parâmetros é facilmente obtida, apenas determinando a ordem de importância dos objetivos. A terceira abordagem foi a Programação por Metas (APM) que busca reduzir a variação em torno dos objetivos quando considerados separadamente. Considerar apenas a variação positiva da meta se mostrou eficaz, uma vez que algumas soluções obtiveram soluções com valores de custo operacional melhores que as metas estabelecidas. A Abordagem por Metas apresentou resultados muito semelhantes à Abordagem por Preempção com objetivo principal de redução do número de veículos. Em diversos casos, as abordagens puderam ser consideradas estatisticamente iguais. Porém, devido ao tempo de processamento inferior, a Abordagem por Metas mostrou-se a mais adequada, dentre as estudadas, para resolução do problema bi-objetivo.

Considerando o problema mono-objetivo que visa minimizar os custos operacionais, os resultados obtidos pela abordagem bi-objetivo apresentaram em média um acréscimo nos custos operacionais de $25 \%$, em contra partida, ao considerar apenas o número de veículos, o 
aumento no custo operacional, em relação à abordagem mono-objetivo dos custos operacionais é de 108,22\%. Estes valores foram obtidos para instâncias com 15 clientes no Cenário 2, o qual permite um maior número de cliente por rota. Ao tratar o problema de maneira bi-objetivo, conforme mostrado nos experimentos realizados, é possível determinar soluções próximas à ambos os objetivos.

A resolução das instâncias utilizando o modelo bi-objetivo e a Abordagem por Metas, mostrou bons resultados para as instâncias de 15 clientes, contudo, a mesma é inviável para instâncias maiores. Desta forma, foi desenvolvida uma matheurística Proximity Search baseada na Abordagem por Metas para resolução do problema bi-objetivo para instâncias de dimensões maiores. A matheurística desenvolvida está fortemente baseada na Proximity Search proposta por Bernardes (2019) para resolver o problema mono-objetivo, ou seja, em que apenas os custos operacionais são considerados.

A matheurística Proximity Search de Bernardes (2019) (PSB) possui a etapa de refinamento com as variáveis inteiras fixadas, reduzindo o problema a ser resolvido na etapa a um problema linear. Neste trabalho também foi proposta uma matheurística Proximity Search Modificada (PSM), a qual não fixa as variáveis inteiras na etapa de refinamento. Com as instâncias de 15 clientes, foi possível observar que as matheurísticas Proximity Search bi-objetivo obtiveram resultados muito semelhantes a Abordagem por Metas. Para o Cenário 1, em uma das matheurísticas, houve uma redução no custo operacional médio de $0,26 \%$ em relação à APM com um aumento de $0,28 \%$ no número de veículos utilizados. No Cenário 2, a maior variação em torno do custo operacional da APM foi de 1,08\%, e 0,57\% para o número de veículos.

Os resultados das matheurísticas para as instâncias de 40 clientes mostraram que as duas abordagens apresentam melhoria em relação à abordagem mono-objetivo. Foi possível notar uma superioridade na matheurística Proximity Search de Bernardes (2019) que, para o Cenário 2, obteve resultados médios melhores que a abordagem mono-objetivo de custo operacional, com reduções de $1,24 \%$ e de $8,93 \%$, respectivamente, nos custos operacionais e no número de veículos médios. Sendo assim, com as abordagens matheurísticas bi-objetivo, foi possível obter resultados competitivos em relação às abordagens mono-objetivos para as instâncias de 40 clientes.

A matheurística desenvolvida mostrou-se eficiente na resolução das instâncias apresentadas, no entanto, pode-se observar que a cada iteração do método há pouca variação nas decisões de roteamento, porém, há mudanças quanto ao sequenciamento das cargas, tanto nas docas de entrada quanto de saída. Neste sentido, explorar estas características na matheurística pode levar a melhoria dos resultados obtidos, como utilizar outros métodos na etapa de refinamento da Proximity Search. Além disso, há outros pontos já estudados na literatura de roteamento de veículos que podem ser incorporados ao problema estudado na busca de melhoria dos custos, como permitir spliting de carga, em especial, em instâncias como as do Cenário 1. Também seria possível considerar a interligação de vários cross-docks. 


\section{REFERÊNCIAS}

AGUSTINA, D.; LEE, C.; PIPLANI, R. Vehicle scheduling and routing at a cross docking center for food supply chains. International Journal of Production Economics, v. 152, p. 29 - 41, 2014. Citado nas páginas 22, 25, 26, 29, 32, 37, 38 e 77.

ALVAREZ-PÉREZ, G. A.; GONZÁLEZ-VELARDE, J. L.; FOWLER, J. W. Crossdocking Just in Time scheduling: An alternative solution approach. Journal of the Operational Research Society, v. 60, n. 4, p. 554-564, 2009. Citado na página 28.

APTE, U. M.; VISWANATHAN, S. Effective cross docking for improving distribution efficiencies. International Journal of Logistics Research and Applications, v. 3, n. 3, p. 291-302, 2000. Citado nas páginas 21 e 25.

ASEFI, H.; SHAHPARVARI, S.; CHETTRI, P.; LIM, S. Variable fleet size and mix VRP with fleet heterogeneity in Integrated Solid Waste Management. Journal of Cleaner Production, v. 230, p. 1376-1395, 2019. Citado na página 34.

BANIAMERIAN, A.; BASHIRI, M.; TAVAKKOLI-MOGHADDAM, R. Modified variable neighborhood search and genetic algorithm for profitable heterogeneous vehicle routing problem with cross-docking. Applied Soft Computing Journal, Elsevier B.V., v. 75, p. 441-460, 2019. Citado na página 31.

BANIAMERIAN, A.; BASHIRI, M.; ZABIHI, F. Two phase genetic algorithm for vehicle routing and scheduling problem with cross-docking and time windows considering customer satisfaction. Journal of Industrial Engineering International, Springer Berlin Heidelberg, v. 14, n. 1, p. 15-30, 2018. Citado na página 31.

BELFIORE, P. P.; FÁVERO, L. P. L. Scatter search for the fleet size and mix vehicle routing problem with time windows. Central European Journal of Operations Research, v. 15, n. 4, p. 351-368, 2007. Citado na página 34.

BERNARDES, E. D. Planejamento operacional integrado cross-docking e roteamento de veículos para um sistema de distribuição. Tese (Doutorado) - Instituto de Ciências Matemáticas e Computação, Universidade de São Paulo, São Carlos - SP, 2019. P. 153. Citado nas páginas $17,22,25,26,28,30,32,37,38,39,40,42,45,51,54,56,57,58,59,60,61,62,63$, $64,65,66,70,77,78,86,89,95,96$ e 97.

BERTHOLD, T.; LODI, A.; SALVAGNIN, D. Ten years of feasibility pump, and counting. EURO Journal on Computational Optimization, Springer, v. 7, n. 1, p. 1-14, 2019. Citado na página 57.

BOWMAN, E. H. The schedule-sequencing problem. Operations Research, INFORMS, v. 7, n. 5, p. 621-624, 1959. Citado na página 28.

BOYSEN, N.; FLIEDNER, M. Cross dock scheduling: Classification, literature review and research agenda. Omega, v. 38, n. 6, p. 413 - 422, 2010. Citado nas páginas 21, 25, 26, 27 e 35. 
BRÄYSY, O.; DULLAERT, W.; HASLE, G.; MESTER, D.; GENDREAU, M. An effective multirestart deterministic annealing metaheuristic for the fleet size and mix vehicle-routing problem with time windows. Transportation Science, v. 42, n. 3, p. 371-386, 2008. Citado na página 34.

BRÄYSY, O.; PORKKA, P. P.; DULLAERT, W.; REPOUSSIS, P. P.; TARANTILIS, C. D. A well-scalable metaheuristic for the fleet size and mix vehicle routing problem with time windows. Expert Systems with Applications, v. 36, n. 4, p. 8460-8475, 2009. Citado na página 34.

BUAKUM, D.; WISITTIPANICH, W. Stochastic internal task scheduling in cross docking using chance-constrained programming. International Journal of Management Science and Engineering Management, Taylor Francis, v. 15, n. 4, p. 258-264, 2020. Citado na página 29.

BUIJS, P.; VIS, I. F. A.; CARLO, H. J. Synchronization in cross-docking networks: A research classification and framework. European Journal of Operational Research, v. 239, n. 3, p. 593 - 608, 2014. Citado nas páginas 21, 25 e 35.

CHEN, F.; LEE, C. Y. Minimizing the makespan in a two-machine cross-docking flow shop problem. European Journal of Operational Research, v. 193, n. 1, p. 59-72, 2009. Citado na página 28.

DELL'AMICO, M.; MONACI, M.; PAGANI, C.; VIGO, D. Heuristic approaches for the fleet size and mix vehicle routing problem with time windows. Transportation Science, v. 41, n. 4, p. 516-526, 2007. Citado na página 34.

DESROCHERS, M.; VERHOOG, T. W. A new heuristic for the fleet size and mix vehicle routing problem. Computers and Operations Research, v. 18, n. 3, p. 263-274, 1991. Citado na página 33.

DONDO, R.; CERDÁ, J. A sweep-heuristic based formulation for the vehicle routing problem with cross-docking. Computers and Chemical Engineering, v. 48, p. 293-311, 2013. Citado na página 31 .

A monolithic approach to vehicle routing and operations scheduling of a cross-dock system with multiple dock doors. Computers and Chemical Engineering, Elsevier Ltd, v. 63, p. 184-205, 2014. Citado na página 31.

. The heterogeneous vehicle routing and truck scheduling problem in a multi-door crossdock system. Computers and Chemical Engineering, Elsevier Ltd, v. 76, p. 42-62, 2015. Citado na página 31.

DONDO, R.; MEŃDEZ, C. A.; CERDÁ, J. Managing distribution in supply chain networks. Industrial and Engineering Chemistry Research, v. 48, n. 22, p. 9961-9978, 2009. Citado na página 31.

DONDO, R.; MÉNDEZ, C. A.; CERDÁ, J. The multi-echelon vehicle routing problem with cross docking in supply chain management. Computers and Chemical Engineering, Elsevier Ltd, v. 35, n. 12, p. 3002-3024, 2011. Citado na página 31.

DULLAERT, W.; JANSSENS, G. K.; SIRENSEN, K.; VERNIMMEN, B. New heuristics for the fleet size and mix vehicle routing problem with time windows. Journal of the Operational Research Society, v. 53, n. 11, p. 1232-1238, 2002. Citado na página 34. 
FISCHETTI, M.; MONACI, M. Proximity search for 0-1 mixed-integer convex programming. Journal of Heuristics, Springer, v. 20, n. 6, p. 709-731, 2014. Citado na página 57.

Freight Transport Association. The Logistics Report 2014. 2014. 68 p. Citado na página 35.

GENDREAU, M.; LAPORTE, G.; MUSARAGANYI, C.; TAILLARD, D. A tabu search heuristic for the heterogeneous fleet vehicle routing problem. Computers and Operations Research, v. 26, n. 12, p. 1153-1173, 1999. Citado na página 33.

GHEYSENS, F.; GOLDEN, B.; ASSAD, A. A Comparison of Techniques for Solving the Fleet Size and Mix Vehicle Routing Problem. OR Spektrum, v. 6, p. 207-216, 1984. Citado na página 33.

GLOVER, F. Heuristics for integer programming using surrogate constraints. Decision sciences, Wiley Online Library, v. 8, n. 1, p. 156-166, 1977. Citado na página 34.

A template for scatter search and path relinking. Lecture notes in computer science, Berlin: Springer-Verlag, 1973-, v. 1363, p. 13-54, 1998. Citado na página 34.

GOLDEN, B.; ASSAD, A.; LEVY, L.; GHEYSENS, F. The fleet size and mix vehicle routing problem. Computers \& Operations Research, v. 11, n. 1, p. 49-66, 1984. Citado nas páginas 33 e 34 .

Hasani Goodarzi, A.; TAVAKKOLI-MOGHADDAM, R.; AMINI, A. A new bi-objective vehicle routing-scheduling problem with cross-docking: Mathematical model and algorithms. Computers Industrial Engineering, v. 149, p. 106832, 2020. Citado na página 31.

KARAKOSTAS, P.; SIFALERAS, A.; GEORGIADIS, M. C. Adaptive variable neighborhood search solution methods for the fleet size and mix pollution location-inventory-routing problem. Expert Systems with Applications, Elsevier Ltd, v. 153, 2020. Citado na página 35.

KOÇ, Ç.; BEKTAş, T.; JABALI, O.; LAPORTE, G. The fleet size and mix location-routing problem with time windows: Formulations and a heuristic algorithm. European Journal of Operational Research, v. 248, n. 1, p. 33-51, 2016. Citado na página 34.

LADIER, A.-L.; ALPAN, G. Crossdock truck scheduling with time windows: earliness, tardiness and storage policies. Journal of Intelligent Manufacturing, Springer US, v. 29, n. 3, p. 569583, 2014. Citado na página 28.

LADIER, A. L.; ALPAN, G. Cross-docking operations: Current research versus industry practice. Omega (United Kingdom), Elsevier, v. 62, p. 145-162, 2016. Citado nas páginas 27 e 28.

LEE, Y. H.; JUNG, J. W.; LEE, K. M. Vehicle routing scheduling for cross-docking in the supply chain. Computers \& Industrial Engineering, v. 51, n. 2, p. 247 - 256, 2006. Citado na página 29.

Liao, T. W. Integrated outbound vehicle routing and scheduling problem at a multi-door crossdock terminal. IEEE Transactions on Intelligent Transportation Systems, p. 1-14, 2020. Citado nas páginas 22, 32, 37 e 77.

LIU, F. H.; SHEN, S. Y. The fleet size and mix vehicle routing problem with time windows. Journal of the Operational Research Society, v. 50, n. 7, p. 721-732, 1999. Citado na página 34. 
MAKNOON, Y.; LAPORTE, G. Vehicle routing with cross-dock selection. Computers \& Operations Research, v. 77, p. 254 - 266, 2017. Citado na página 30.

MANNE, A. S. On the job-shop scheduling problem. Operations Research, INFORMS, v. 8, n. 2, p. 219-223, 1960. Citado na página 28.

MAVI, R. K.; GOH, M.; MAVI, N. K.; JIE, F.; BROWN, K.; BIERMANN, S.; KHANFAR, A. A. Cross-docking: A systematic literature review. Sustainability, Multidisciplinary Digital Publishing Institute, v. 12, n. 11, p. 4789, 2020. Citado na página 31.

MOGHADAM, S. S.; GHOMI, S. F.; KARIMI, B. Vehicle routing scheduling problem with cross docking and split deliveries. Computers \& Chemical Engineering, v. 69, p. 98 - 107, 2014. Citado na página 30.

MORAIS, V. W.; MATEUS, G. R.; NORONHA, T. F. Iterated local search heuristics for the vehicle routing problem with cross-docking. Expert Systems with Applications, v. 41, n. 16, p. 7495 - 7506, 2014. Citado na página 30.

NOGUEIRA, T. H.; COUTINHO, F. P.; RIBEIRO, R. P.; RAVETTI, M. G. Parallel-machine scheduling methodology for a multi-dock truck sequencing problem in a cross-docking center. Computers Industrial Engineering, v. 143, p. 106391, 2020. Citado na página 28.

PAN, C. H. A study of integer programming formulations for scheduling problems. International Journal of Systems Science, v. 28, n. 1, p. 33-41, 1997. Citado na página 28.

RAHBARI, A.; NASIRI, M. M.; WERNER, F.; MUSAVI, M.; JOLAI, F. The vehicle routing and scheduling problem with cross-docking for perishable products under uncertainty: Two robust bi-objective models. Applied Mathematical Modelling, v. 70, p. 605 - 625, 2019. Citado nas páginas 22, 32, 37 e 77 .

REPOUSSIS, P. P.; TARANTILIS, C. D. Solving the fleet size and mix vehicle routing problem with time windows via adaptive memory programming. Transportation Research Part C: Emerging Technologies, Elsevier Ltd, v. 18, n. 5, p. 695-712, 2010. Citado na página 34.

ROCHAT, Y.; TAILLARD, É. D. Probabilistic diversification and intensification in local search for vehicle routing. Journal of Heuristics, v. 1, n. 1, p. 147-167, 1995. Citado na página 33.

RONEN, D. Allocation of trips to trucks operating from a single terminal. Computers and Operations Research, v. 19, n. 5, p. 445-451, 1992. Citado na página 33.

SALHI, S.; RAND, G. K. Incorporating vehicle routing into the vehicle fleet composition problem. European Journal of Operational Research, v. 66, n. 3, p. 313-330, 1993. Citado na página 33 .

SALHI, S.; SARI, M.; SAIDI, D.; TOUATI, N. Adaptation of some vehicle fleet mix heuristics. Omega, v. 20, n. 5-6, p. 653-660, 1992. Citado na página 33.

SANTOS, F. A.; MATEUS, G. R.; CUNHA, A. S. d. The pickup and delivery problem with cross-docking. Computers \& Operations Research, v. 40, n. 4, p. 1085 - 1093, 2013. Citado na página 30.

SHAHMARDAN, A.; SAJADIEH, M. S. Truck scheduling in a multi-door cross-docking center with partial unloading - reinforcement learning-based simulated annealing approaches.

Computers Industrial Engineering, v. 139, p. 106134, 2020. Citado na página 29. 
SOLOMON, M. M. Algorithms for the vehicle routing and scheduling problems with time window constraints. Operations Research, v. 35, n. 2, p. 254-265, 1987. Citado na página 34.

SPERANZA, M. G. Trends in transportation and logistics. European Journal of Operational Research, v. 264, n. 3, p. 830 - 836, 2018. Citado na página 21.

STEPHAN, K.; BOYSEN, N. Cross-docking. Journal of Management Control, v. 22, n. 1, p. 129, 2011. Citado nas páginas 22 e 25.

TAILLARD, É. D. A heuristic column generation method for the heterogeneous fleet vrp. RAIRO-Operations Research-Recherche Opérationnelle, v. 33, n. 1, p. 1-14, 1999. Citado nas páginas 33 e 34 .

TARANTILIS, C. D. Adaptive multi-restart tabu search algorithm for the vehicle routing problem with cross-docking. Optimization Letters, v. 7, n. 7, p. 1583-1596, 2013. Citado na página 30.

TARANTILIS, C. D.; KIRANOUDIS, C. T.; VASSILIADIS, V. S. A threshold accepting metaheuristic for the heterogeneous fixed fleet vehicle routing problem. European Journal of Operational Research, v. 152, n. 1, p. 148-158, 2004. Citado na página 34.

THEEB, N. A.; AL-ARAIDAH, O.; ALJARRAH, M. H. Optimization of the heterogeneous vehicle routing problem with cross docking logistic system. Logistics Research, v. 12, n. 1, p. 0-22, 2019. Citado na página 31.

Van Belle, J.; VALCKENAERS, P.; CATTRYSSE, D. Cross-docking: State of the art. Omega, Elsevier, v. 40, n. 6, p. 827-846, 2012. Citado na página 27.

WAGNER, H. M. An integer linear-programming model for machine scheduling. Naval Research Logistics Quarterly, Wiley Online Library, v. 6, n. 2, p. 131-140, 1959. Citado na página 28.

WASSAN, N. A.; OSMAN, I. H. Tabu search variants for the mix fleet vehicle routing problem. Journal of the Operational Research Society, v. 53, n. 7, p. 768-782, 2002. Citado na página 33.

WEN, M.; LARSEN, J.; CLAUSEN, J.; CORDEAU, J.-F.; LAPORTE, G. Vehicle routing with cross-docking. Journal of the Operational Research Society, v. 60, n. 12, p. 1708-1718, 2009. Citado nas páginas 29 e 30.

YAN, H.; TANG, S. long. Pre-distribution and post-distribution cross-docking operations. Transportation Research Part E: Logistics and Transportation Review, Elsevier Ltd, v. 45, n. 6, p. 843-859, 2009. Citado na página 27.

YIN, P.-Y.; LYU, S.-R.; CHUANG, Y.-L. Cooperative coevolutionary approach for integrated vehicle routing and scheduling using cross-dock buffering. Engineering Applications of Artificial Intelligence, v. 52, p. 40 - 53, 2016. Citado nas páginas 30 e 35.

YU, V. F.; JEWPANYA, P.; REDI, A. P. Open vehicle routing problem with cross-docking. Computers \& Industrial Engineering, v. 94, p. 6 - 17, 2016. Citado na página 22. 

APÊNDICE

\section{A}

\section{EXPERIMENTOS COMPUTACIONAIS DAS ABORDAGENS BI-OBJETIVO}

No presente apêndice, são detalhados os resultados refentes às abordagens bi-objetivo do Capítulo 4. São apresentadas as tabelas com informações referentes ao custo operacional (CO), número de veículos (NV) e tempo de processamento (TP) em segundos para as instâncias de 15 clientes. As Tabelas 13, 14 e 15 mostram os resultados para a ASP no Cenário 1, já as Tabelas 16, 17 e 18 apresentam os resultados para o Cenário 2. É possível verificar que para a ASP em ambos os cenários há uma tendência de aumento no custo operacional e redução no número de veículos a medida que o parâmetro $\alpha$ se aproxima de 1 . Também é possível notar que, para as instâncias utilizadas, há uma grande redução no seu tempo de processamento médio ao considerar o problema de minimizar apenas o número de veículos $(\alpha=1)$.

As Tabelas 19 e 20 apresentam os resultados para as abordagens APP e APM para o Cenários 1 e 2, respectivamente. É possível notar que tais abordagens resultam, conforme discutido no Capítulo 4, nas melhores soluções dentre as abordagens bi-objetivo escolhidas. 
Tabela 13 - Resultados para ASP 15 Clientes Cenário 1 - Parte 1.

\begin{tabular}{|c|c|c|c|c|c|c|c|c|c|}
\hline & \multicolumn{3}{|c|}{ Bernardes (2019) } & \multicolumn{3}{|c|}{$\alpha=0,05$} & \multicolumn{3}{|c|}{$\alpha=0,1$} \\
\hline Instância & $\mathrm{CO}$ & NV & $\mathrm{TP}$ & $\mathrm{CO}$ & NR & $\mathrm{TP}$ & $\mathrm{CO}$ & NR & $\mathrm{TP}$ \\
\hline R101-A & 1090,02 & 11 & 3,31 & 1090,02 & 11 & 31,03 & 1115,08 & 9 & 52,87 \\
\hline R102-A & 1089,78 & 13 & 8,92 & 1090,10 & 12 & & $10 s$ & 12 & 4,5 \\
\hline R103-A & 999,31 & 12 & 8,23 & 999,31 & 12 & 26,00 & 999,31 & 12 & 17,54 \\
\hline R104-A & 905,42 & 10 & 2,71 & 905,42 & 10 & 3,80 & 905,42 & 10 & 4,03 \\
\hline R105-A & 1119,25 & 13 & 1477,98 & 1122,21 & 12 & 838,95 & 1122,21 & 12 & 112,58 \\
\hline R106-A & 982,23 & 11 & 7,42 & 982,23 & 11 & 5,33 & 982,23 & 11 & 8,34 \\
\hline R107-A & 1062,85 & 12 & 3,65 & 1062,88 & 11 & 7,09 & 1062,88 & 11 & 4,57 \\
\hline R108-A & 788,88 & 9 & 121,65 & 788,88 & 9 & 190,92 & 788,88 & 9 & 177,04 \\
\hline R109-A & 855,47 & 11 & 180,68 & 855,47 & 11 & 397,09 & 860,96 & 10 & 698,04 \\
\hline R110-A & 1058,35 & 12 & 1,70 & 1058,35 & 12 & 1,51 & 1058,35 & 12 & 5,43 \\
\hline R111-A & 1042,62 & 13 & 108,76 & 1046,02 & 12 & 477,87 & 1046,02 & 12 & 211,20 \\
\hline R112-A & 943,24 & 12 & 655,09 & 943,24 & 12 & 964,05 & 943,24 & 12 & 370 \\
\hline $\begin{array}{c}\text { Média } \\
\text { Grupo A }\end{array}$ & 994,79 & 158 & 216,68 & 995,34 & 1125 & 245,75 & 997,89 & 11,00 & 1 \\
\hline $\mathrm{R}$ & the & 1 & 0 & 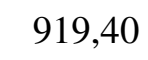 & 10 & 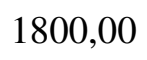 & & 10 & 00,00 \\
\hline R102 & 1173,71 & 13 & 2,50 & 117 & 13 & 10,28 & 117 & 13 & 3,41 \\
\hline R103-B & 994,59 & 12 & 65,37 & 994 & 12 & 67,23 & & 12 & 77,00 \\
\hline R104-B & 880,36 & 11 & 29,74 & 880 & 10 & 25,32 & 88 & 10 & 21,14 \\
\hline R105-B & 1048,44 & 14 & 9,00 & 1048,46 & & 6,61 & 104 & 13 & 8, \\
\hline R106-B & 982,64 & 12 & 2 & & 12 & 6,67 & & 12 & 6,1 \\
\hline R107-B & 1024,16 & 11 & 79,02 & 1024 & 11 & 70,66 & 1024,16 & 11 & 68,81 \\
\hline R108-B & 06,79 & 9 & 1340,53 & 806,79 & 9 & 826,21 & & 9 & 1044,74 \\
\hline R109-B & 896,66 & 10 & 0,00 & 14 & 10 & 1800,00 & 900,70 & 9 & 1800,00 \\
\hline R110-B & 1042,17 & 12 & 1800,00 & 1042, & 2 & 1800,00 & 1052 & 11 & 1800,00 \\
\hline $\mathrm{R} 1$ & 66,40 & 14 & 6 & 10 & 4 & 37,66 & 107 & 13 & 184,64 \\
\hline R112-B & 1032,80 & 12 & 339,47 & 103 & 12 & 110,96 & 1032,80 & 12 & 65,26 \\
\hline $\begin{array}{c}\text { Média } \\
\text { Grupo B }\end{array}$ & 988,58 & 11,75 & 606,93 & 989,10 & 11,50 & 546,80 & 990,99 & 11,25 & 573,32 \\
\hline R101-C & 2717 & 1 & & & - & & & 10 & 1800,0 \\
\hline R102-C & 54,44 & 1 & 800,99 & & 1 & 1249,54 & & 13 & 1800,00 \\
\hline R103-C & 1005,89 & 12 & 3 & 100 & 1 & 25,05 & 100 & 12 & 21,0 \\
\hline R104-C & 878,86 & 10 & 547,04 & 8 & 10 & 912,08 & 87 & 10 & 1781,35 \\
\hline R105-C & 1359,96 & 14 & 1800,00 & 1365,72 & 13 & 1800,00 & 1368,13 & 13 & 1800,00 \\
\hline R106-C & 1173,67 & 12 & 561,62 & 1173,67 & 12 & 677,34 & 1173,67 & 12 & 699,4 \\
\hline R107-C & 1019,82 & 12 & & 1020,93 & 11 & 982,32 & 1020,93 & 11 & 374 \\
\hline R108-C & 823,46 & 9 & 1800,00 & & 9 & 1800 & & 9 & 1800,00 \\
\hline R109-C & 915,06 & 9 & 70,38 & 915,06 & 9 & 94,78 & 915,06 & 9 & 56,6 \\
\hline R110-C & 985,26 & 12 & 1800,00 & 989,92 & 11 & 1800,00 & 989,92 & 11 & 1800,00 \\
\hline R111-C & 1035,79 & 12 & 1800,00 & 1035,79 & 12 & 1800,00 & 1035,79 & 12 & 1800,00 \\
\hline R112-C & 997,96 & 12 & 1800,00 & 998,71 & 12 & 1800,00 & 998,71 & 12 & 1800,00 \\
\hline $\begin{array}{c}\text { Média } \\
\text { Grupo C }\end{array}$ & 1032,28 & 11,50 & 1104,04 & 1033,42 & 11,25 & 1228,43 & 1036,39 & 11,17 & 1294,45 \\
\hline Tédia Geral & 1005,21 & 11,61 & 642,55 & 1005,96 & 11,33 & 673,66 & 1008,42 & 11,14 & 000 \\
\hline
\end{tabular}


Tabela 14 - Resultados para ASP 15 Clientes Cenário 1- Parte 2.

\begin{tabular}{|c|c|c|c|c|c|c|c|c|c|}
\hline \multirow[b]{2}{*}{ Instância } & \multicolumn{3}{|c|}{$\alpha=0,15$} & \multicolumn{3}{|c|}{$\alpha=0,2$} & \multicolumn{3}{|c|}{$\alpha=0,25$} \\
\hline & $\mathrm{CO}$ & NV & $\mathrm{TP}$ & $\mathrm{CO}$ & NR & $\mathrm{TP}$ & $\mathrm{CO}$ & NR & $\mathrm{TP}$ \\
\hline R101-A & 1115,08 & 9 & 114,18 & 1115,08 & 9 & 26,81 & 1115,08 & 9 & 11,27 \\
\hline R102-A & 1090,10 & 12 & 0,32 & 1090,10 & 12 & 0,32 & 1090,10 & 12 & 0,16 \\
\hline R103-A & 999,31 & 12 & 0,97 & 999,31 & 12 & 0,54 & 999,31 & 12 & 0,19 \\
\hline R104-A & 922,54 & 9 & 0,52 & 922,54 & 9 & 0,47 & 922,54 & 9 & 0,31 \\
\hline R105-A & 1122,21 & 12 & 0,43 & 1122,21 & 12 & 0,43 & 1122,21 & 12 & 0,21 \\
\hline R106-A & 982,23 & 11 & 0,16 & 982,23 & 11 & 0,18 & 982,23 & 11 & 0,17 \\
\hline R107-A & 1062,88 & 11 & 0,26 & 1062,88 & 11 & 0,23 & 1062,88 & 11 & 0,24 \\
\hline R108-A & 788,88 & 9 & 0,59 & 788,88 & 9 & 0,66 & 788,88 & 9 & 0,55 \\
\hline R109-A & 860,96 & 10 & 1,64 & 860,96 & 10 & 1,20 & 860,96 & 10 & 1,56 \\
\hline R110-A & 1058,35 & 12 & 1,16 & 1058,35 & 12 & 0,67 & 1058,35 & 12 & 0,64 \\
\hline R111-A & 1046,02 & 12 & 0,15 & 1046,02 & 12 & 0,16 & 1046,02 & 12 & 0,17 \\
\hline R112-A & 954,90 & 11 & 0,17 & 954,90 & 11 & 0,18 & 954,90 & 11 & 0,18 \\
\hline $\begin{array}{c}\text { Média } \\
\text { Grupo A }\end{array}$ & 1000,29 & 10,83 & 10,05 & 1000,29 & 10,83 & 2,65 & 1000,29 & 10,83 & 1, \\
\hline R101-B & 32,45 & 8 & 35,70 & 932,45 & 8 & 9,07 & 932,45 & 8 & 1,00 \\
\hline R102-B & 1173,71 & 13 & 0,28 & 1193,70 & 12 & 0,16 & 1193,70 & 12 & 0,18 \\
\hline R103-B & 994,59 & 12 & 0,34 & 994,59 & 12 & 0,68 & 994,59 & 12 & 0,19 \\
\hline R104-B & 880,65 & 10 & 0,63 & 880,65 & 10 & 0,74 & 880,65 & 10 & 0,24 \\
\hline R105-B & 1048,46 & 13 & 1,13 & 1066,06 & 12 & 2,56 & 1066,06 & 12 & 0,46 \\
\hline R106 & 982,64 & 12 & & 982,64 & 12 & & 1007,13 & 11 & 0,27 \\
\hline R107-B & 1024,16 & 11 & 0,13 & 1024,16 & 11 & 0,14 & 1024,16 & 11 & 0,13 \\
\hline R108-B & 806,79 & 9 & 0,68 & 806,79 & 9 & 0,57 & 811,39 & 9 & 0,58 \\
\hline R109-B & 900,70 & 9 & & 900,70 & 9 & 2,07 & 900,70 & 9 & 1,58 \\
\hline R110-B & 1052,70 & 11 & 0,30 & 1052,70 & 11 & 0,31 & 1052,70 & 11 & 0,21 \\
\hline R111-B & 1074,82 & 13 & 0,75 & 1074,82 & 13 & 0,32 & 1074,82 & 13 & 0,56 \\
\hline R112-B & 1032,80 & 12 & 0,44 & 1032,80 & 12 & 0,21 & 1032,80 & 12 & 0,35 \\
\hline $\begin{array}{c}\text { Média } \\
\text { Grupo B }\end{array}$ & 992,04 & 11,08 & 0 & 995,17 & 10,92 & 1,42 & 997,60 & 10,83 & 0 , \\
\hline $\mathrm{R} 1 \mathrm{C}$ & 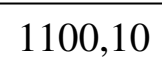 & 9 & 0 & & 10 & & & 9 & 2,45 \\
\hline R102-C & 1155,34 & 13 & 0,24 & 1175,43 & 12 & 0,21 & 1175,43 & 12 & 0,22 \\
\hline R103-C & 1005,89 & 12 & 0,58 & 1005,89 & 12 & 0,28 & 1005,89 & 12 & 0,52 \\
\hline R104-C & 878,86 & 10 & 1,54 & 897,41 & 9 & 0,40 & 897,41 & 9 & 0,39 \\
\hline R105-C & 1369,98 & 13 & 14,57 & 1369,98 & 13 & 3,29 & 1396,43 & 12 & 3,22 \\
\hline R106-C & 1173,67 & 12 & & 1173,67 & 12 & 0,87 & 1173,67 & 12 & 1,04 \\
\hline R107-C & 1020,93 & 11 & 0,21 & 1020,93 & 11 & 0,28 & 1020,93 & 11 & 0,21 \\
\hline R108-C & 823,46 & 9 & 0,70 & 823,46 & 9 & 0,73 & 823,46 & 9 & 0,69 \\
\hline R109-C & 915,06 & 9 & & 915,06 & 9 & & 915,06 & 9 & 0,27 \\
\hline R110-C & 989,92 & 11 & 0,51 & 989,92 & 11 & 0,91 & 989,92 & 11 & 0,33 \\
\hline R111-C & 1035,79 & 12 & 0,16 & 1035,79 & 12 & 0,16 & 1035,79 & 12 & 0,16 \\
\hline R112-C & 1007,59 & 11 & 2,85 & 1007,59 & 11 & 2,22 & 1007,59 & 11 & 1,89 \\
\hline $\begin{array}{c}\text { Média } \\
\text { Grupo C }\end{array}$ & 1039,72 & 11,00 & 151,89 & 1039,33 & 10,92 & 3,06 & 1045,49 & 10,75 & 0,95 \\
\hline Média Geral & 1010,68 & 10,97 & 55,17 & 1011,60 & 10,89 & 2,38 & 1014,46 & 10,81 & 0,93 \\
\hline
\end{tabular}


Tabela 15 - Resultados para ASP 15 Clientes Cenário 1 - Parte 3.

\begin{tabular}{|c|c|c|c|c|c|c|c|c|c|}
\hline \multirow[b]{2}{*}{ Instância } & \multicolumn{3}{|c|}{$\alpha=0,5$} & \multicolumn{3}{|c|}{$\alpha=0,75$} & \multicolumn{3}{|c|}{$\alpha=1,0$} \\
\hline & $\mathrm{CO}$ & NV & $\mathrm{TP}$ & $\mathrm{CO}$ & NV & $\mathrm{TP}$ & $\mathrm{CO}$ & NR & $\mathrm{TP}$ \\
\hline R101-A & 1196,56 & 8 & 0,63 & 1196,56 & 8 & 0,77 & 2276,90 & 8 & 0,90 \\
\hline R102-A & 1090,10 & 12 & 0,18 & 1090,10 & 12 & 0,24 & 1905,43 & 12 & 0,22 \\
\hline R103-A & 1076,36 & 11 & 0,20 & 1076,36 & 11 & 0,18 & 1350,62 & 11 & 0,20 \\
\hline R104-A & 922,54 & 9 & 0,28 & 922,54 & 9 & 0,31 & 1345,37 & 9 & 0,32 \\
\hline R105-A & 1165,26 & 11 & 0,27 & 1165,26 & 11 & 0,19 & 1935,47 & 11 & 0,19 \\
\hline R106-A & 982,23 & 11 & 0,17 & 982,23 & 11 & 0,16 & 1303,00 & 11 & 0,16 \\
\hline R107-A & 1062,88 & 11 & 0,16 & 1062,88 & 11 & 0,17 & 1433,92 & 11 & 0,18 \\
\hline R108-A & 788,88 & 9 & 0,52 & 788,88 & 9 & 0,54 & 1316,70 & 9 & 0,65 \\
\hline R109-A & 894,86 & 9 & 0,41 & 894,86 & 9 & 0,41 & 1614,20 & 9 & 0,40 \\
\hline R110-A & 1121,83 & 11 & & 1121,83 & 11 & & 1403,09 & 11 & 0,56 \\
\hline R111-A & 046,02 & 12 & 0,15 & 1046,02 & 12 & 0,16 & 1381,46 & 12 & 0,15 \\
\hline R112-A & 954,90 & 11 & 0,17 & 954,90 & 11 & & 1233,46 & 11 & 0,19 \\
\hline $\begin{array}{c}\text { Média } \\
\text { Grupo A }\end{array}$ & 1025,20 & 10,42 & 0,35 & 1025,20 & 10,42 & 0,38 & 1541,64 & 10,42 & 0,34 \\
\hline & & 8 & & & 8 & & & 8 & \\
\hline R102-B & 93,70 & 12 & 0,26 & 1193,70 & 12 & 0,18 & 1479,99 & 12 & 0,17 \\
\hline & 1048,38 & 11 & 0,17 & 1048,38 & 11 & & 1573,35 & 11 & 0,29 \\
\hline $\mathrm{R} 1$ & 914,17 & 9 & 0,25 & 914,17 & 9 & 0,28 & 1202,18 & 9 & 0,25 \\
\hline R105-B & 1145,27 & 11 & 0,27 & 1145,27 & 11 & 0,21 & 1601,47 & 11 & 0,22 \\
\hline R106-B & 07,13 & 11 & 0,28 & 1007,13 & 11 & 0,25 & 1410,31 & 11 & 0,23 \\
\hline $\mathrm{R} 1$ & 24,16 & 11 & 0,12 & 1024,16 & 11 & 0,12 & 1461,88 & 11 & 0,12 \\
\hline & & 9 & & & 9 & & & 9 & 0,60 \\
\hline R109-B & 900,70 & 9 & 0,52 & 900,70 & 9 & 0,39 & 1679,47 & 9 & 0,43 \\
\hline R110-B & 1052,70 & 11 & & 1052,70 & 11 & & 1724,82 & 11 & 0,21 \\
\hline R111-H & 4,82 & 13 & 0,86 & 1074,82 & 13 & 0,82 & 1476,69 & 13 & 0,43 \\
\hline R112-B & 1100,82 & 11 & 1,05 & 1100,82 & 11 & 0,46 & 1667,94 & 11 & 0,25 \\
\hline $\begin{array}{c}\text { Média } \\
\text { Grupo B }\end{array}$ & 1016,76 & 10,50 & 0,49 & 1016,76 & 10,50 & 0,40 & 1554,54 & 10,50 & 0,32 \\
\hline & & 8 & & & 8 & & & 8 & 0,55 \\
\hline $\mathrm{R}$ & 5,43 & 12 & 0,43 & 5,43 & 12 & 0 & 1621,09 & 12 & 0,20 \\
\hline & 88,88 & 11 & 0,52 & 1088,88 & 11 & & 1807,78 & 11 & 0,59 \\
\hline R104-C & 897,41 & 9 & 0,32 & 897,41 & 9 & 0,30 & 1567,86 & 9 & 0,37 \\
\hline R105-C & 1513,50 & 11 & 0,80 & 1513,50 & 11 & 0,64 & 2222,69 & 11 & 1,80 \\
\hline & & 11 & & & 11 & & 524,03 & 11 & 2,02 \\
\hline R107-C & 1020,93 & 11 & 0,21 & 1020,93 & 11 & 0,23 & 1505,88 & 11 & 0,30 \\
\hline R108-C & 823,46 & 9 & 0,74 & 823,46 & 9 & 0,76 & 1262,00 & 9 & 0,76 \\
\hline R109-C & 915,06 & 9 & 0,28 & 915,06 & 9 & 0,27 & 1798,51 & 9 & 0,27 \\
\hline R110-C & 989,92 & 11 & 0,32 & 989,92 & 11 & 0,32 & 1423,82 & 11 & 0,31 \\
\hline R111-C & 1035,79 & 12 & 0,15 & 1035,79 & 12 & 0,15 & 1357,43 & 12 & 0,15 \\
\hline R112-C & 1007,59 & 11 & 1,37 & 1007,59 & 11 & 1,95 & 1661,94 & 11 & 1,03 \\
\hline $\begin{array}{l}\text { Média } \\
\text { Grupo }\end{array}$ & 073,65 & 0,42 & 1 & 1071,05 & 42 & 0,60 & 1669,70 & 10,42 & 0, \\
\hline
\end{tabular}

$\begin{array}{llllllllll}\text { Média Geral } & 1038,54 & 10,44 & 0,48 & 1037,67 & 10,44 & 0,46 & 1588,63 & 10,44 & 0,45\end{array}$ 
Tabela 16 - Resultados para ASP 15 Clientes Cenário 2 - Parte 1.

\begin{tabular}{|c|c|c|c|c|c|c|c|c|c|}
\hline & \multicolumn{3}{|c|}{ Bernardes (2019) } & \multicolumn{3}{|c|}{$\alpha=0,05$} & \multicolumn{3}{|c|}{$\alpha=0,1$} \\
\hline Instância & $\mathrm{CO}$ & $\mathrm{NV}$ & $\mathrm{TP}$ & $\mathrm{CO}$ & NV & $\mathrm{TP}$ & $\mathrm{CO}$ & NV & $\mathrm{TP}$ \\
\hline R101-A & 682,35 & 7 & 149,21 & 682,35 & 7 & 700,17 & 682,35 & 7 & 1397,0 \\
\hline R102-A & 612,89 & 6 & 1800,00 & 612,89 & 6 & 1800,00 & 1 & 6 & 800,00 \\
\hline R103-A & 633,41 & 6 & 1800,00 & 633,41 & 6 & 1800,00 & 633,41 & 6 & 1800,00 \\
\hline R104-A & 634,70 & 6 & 1800,00 & 634,70 & 6 & 1800,00 & 649,70 & 5 & 1800,00 \\
\hline R105-A & 761,92 & 8 & 1403,58 & 769,73 & 7 & 1746,26 & 769,73 & 7 & 1800,00 \\
\hline R106-A & 594,44 & 6 & 1800,00 & 594,44 & 6 & 1800,00 & 594,44 & 6 & 1800,00 \\
\hline R107-A & 573,08 & 6 & 1800,00 & 570,69 & 5 & 1800,00 & 581 & 5 & 1800,00 \\
\hline R108-A & 579,56 & 6 & 1800,00 & 579 & 6 & 1800,00 & 587 & 5 & 1800,00 \\
\hline R109-A & 639,47 & 7 & 1346,77 & 639,52 & 6 & 1800,00 & 645 & 6 & 1800,00 \\
\hline R110-A & 552,24 & 5 & 429,81 & 552,24 & 5 & 615,14 & 552 & 5 & 1800,00 \\
\hline R111-A & 646,34 & 7 & 477,58 & 650 & 6 & 778 & & 6 & 661,70 \\
\hline R112-A & 570,81 & 5 & 1800,00 & 570,81 & 5 & 1800,00 & 570,81 & 5 & 1688,59 \\
\hline $\begin{array}{c}\text { Média } \\
\text { Grupo A }\end{array}$ & 623,43 & 6,25 & 1367,25 & 624,24 & 5,92 & 1519,99 & 627,34 & 5,75 & 662 \\
\hline $\mathrm{R} 1 \mathrm{C}$ & 773,92 & 9 & S & 778, & 8 & 18 & 778 & 8 & 1800,00 \\
\hline R102-B & 572,72 & 6 & 1800,00 & 572,72 & 6 & 1800,00 & 577 & 5 & 1800,00 \\
\hline R103-B & 567,78 & 6 & 1800,00 & 567,78 & 6 & 1800,00 & $56^{7}$ & 6 & 1800,00 \\
\hline $\mathrm{R} 10$ & 656,72 & 7 & 1800 & 656 & 7 & 1800,00 & 66 & 7 & 1800,00 \\
\hline R10s & 806,30 & 9 & 1800,00 & 805 & 8 & 1800,00 & 800 & 8 & 1800,00 \\
\hline $\mathrm{R} 106$ & 678,52 & 7 & 1800,00 & 683 & 6 & 1800,00 & & 6 & 1800,00 \\
\hline $\mathrm{R} 10$ & 591,17 & 5 & 506 & 591 & 5 & 130 & 59 & 5 & 1323,19 \\
\hline $\mathrm{R} 10$ & 592,55 & 6 & 1800,00 & 592 & 6 & 1800,00 & 592 & 6 & 1800,00 \\
\hline R109-B & 1080,82 & 12 & 1800,00 & 1075,57 & 11 & 1800,00 & 1080 & 11 & 1800,00 \\
\hline R110-B & 537,75 & 5 & 1800 & 75 & 5 & 1800,00 & & 5 & 1800,00 \\
\hline R111-B & 666,48 & 6 & 1800,00 & 666,48 & 6 & 1800,00 & 66 & 6 & 1800,00 \\
\hline R112-B & 599,05 & 6 & 1800,00 & 595,18 & 5 & 1800,00 & 599,77 & 5 & 1800,00 \\
\hline $\begin{array}{l}\text { Média } \\
\text { Grupo B }\end{array}$ & 676,98 & 7,00 & 1616,99 & 676,92 & 6,58 & 1758,82 & 678,23 & 6,50 & 1760,27 \\
\hline $\mathrm{R}$ & 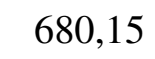 & & & 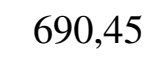 & 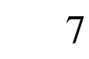 & & & 6 & 1800,00 \\
\hline R102-C & 9,90 & 6 & 1800 & 597 & 6 & 180 & 59 & 6 & 1800,00 \\
\hline R103-C & 9,14 & 6 & 1800,00 & 587,95 & 6 & 1800,00 & 59 & 5 & 1800,00 \\
\hline R104-C & 617,60 & 6 & 1800,00 & & 6 & 1800,00 & & 6 & 1800,00 \\
\hline R105-C & 680,55 & 7 & 1002,51 & 683,58 & 7 & 1800,00 & 695 & 6 & 1800,00 \\
\hline R106-C & 595,11 & 6 & 1800,00 & 601,30 & 6 & 1800,00 & 595 & 6 & 1800,00 \\
\hline & 567,11 & 6 & 1800,00 & 567,11 & 6 & 1800,00 & 570 & 5 & 1800,00 \\
\hline R108-C & 561,16 & 5 & 1800,00 & 566,22 & 6 & 1800,00 & 561 & 5 & 1800,00 \\
\hline R109-C & 685,43 & 7 & 1800,00 & 685,43 & 7 & 1800,00 & 685,43 & 7 & 1800,00 \\
\hline R110-C & 558,18 & 5 & 1800,00 & 558,18 & 5 & 1800,00 & 558 & 5 & 1800,00 \\
\hline R111-C & 639,58 & 6 & 1800,00 & 639,58 & 6 & 1800,00 & 639,58 & 6 & 1800,00 \\
\hline R112-C & 579,21 & 5 & 1800,00 & 579,21 & 5 & 1800,00 & 579,21 & 5 & 1233,67 \\
\hline $\begin{array}{l}\text { Média } \\
\text { Grupo C }\end{array}$ & 612,76 & 6,08 & 1733,54 & 614,33 & 6,08 & 1800,00 & 616,80 & 5,67 & 1 \\
\hline & & 等 & & 0, & 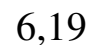 & רא, & TU, & 8 & 172 \\
\hline
\end{tabular}


Tabela 17 - Resultados para ASP 15 Clientes Cenário 2 - Parte 2.

\begin{tabular}{|c|c|c|c|c|c|c|c|c|c|}
\hline & \multicolumn{3}{|c|}{$\alpha=0,15$} & \multicolumn{3}{|c|}{$\alpha=0,2$} & \multicolumn{3}{|c|}{$\alpha=0,25$} \\
\hline Instância & $\mathrm{CO}$ & $\mathrm{NV}$ & $\mathrm{TP}$ & $\mathrm{CO}$ & $\mathrm{NV}$ & $\mathrm{TP}$ & $\mathrm{CO}$ & $\mathrm{NV}$ & $\mathrm{TP}$ \\
\hline R101-A & 701,22 & 6 & 1350,32 & 701,22 & 6 & 1800,00 & 701,22 & 6 & 1800,00 \\
\hline R102-A & 610,51 & 6 & 1800 & 633,70 & 5 & 1800,00 & 639,35 & 5 & 1800,00 \\
\hline R103-A & 633,41 & 6 & 1800,00 & 633,41 & 6 & 1800,00 & 633,41 & 6 & 1800,00 \\
\hline R104-A & 642,99 & 5 & 1800,00 & 642,99 & 5 & 1800,00 & 647,31 & 5 & 1800,00 \\
\hline R105-A & 799,66 & 6 & 1800,00 & 799,66 & 6 & 1800,00 & 799,66 & 6 & 1800,00 \\
\hline R106-A & 594,44 & 6 & 1800,00 & 594,44 & 6 & 1800,00 & 594,44 & 6 & 1800,00 \\
\hline R107-A & 574,18 & 5 & 1800,00 & 570,69 & 5 & 1800,00 & 574,18 & 5 & 1800,00 \\
\hline R108-A & 582,61 & 5 & 1800,00 & 585,65 & 5 & 1800,00 & 585,65 & 5 & 1800,00 \\
\hline R109- & 639,52 & 6 & 1800,00 & 639,52 & 6 & 1800,00 & 639,52 & 6 & 1800,00 \\
\hline R110-A & 552,24 & 5 & 1517,32 & 552,24 & 5 & 1280,49 & 552,24 & 5 & 1274,08 \\
\hline R111-A & 650,55 & 6 & 1092,73 & 650,55 & 6 & 1134,18 & 650,55 & 6 & 1150,77 \\
\hline R112-A & 570,81 & 5 & 1800,00 & 570,81 & 5 & 1800,00 & 570,81 & 5 & 1800,00 \\
\hline $\begin{array}{c}\text { Média } \\
\text { Grupo A }\end{array}$ & 629,35 & 5,58 & 1680,03 & 631,24 & 5,50 & 1701,22 & 632,36 & 5,50 & 1702,07 \\
\hline $\mathrm{R} 1 \mathrm{C}$ & 3 & 8 & 0 & 4 & 7 & 0 & 814,89 & 7 & 1800,00 \\
\hline R102 & 587,18 & 5 & 1800,00 & 577,45 & 5 & 1800,00 & 579,03 & 5 & 1800,00 \\
\hline R103-E & 581,52 & 5 & 1800,00 & 581,52 & 5 & 1800,00 & 581,52 & 5 & 1800,00 \\
\hline R104-F & 681,50 & 6 & 1800,00 & 675,99 & 6 & 1800,00 & 709,30 & 5 & 1800,00 \\
\hline $\mathrm{R} 1 \mathrm{C}$ & 805 , & 8 & 1800,00 & 836,09 & 7 & 1800,00 & 888,80 & 6 & 1800,00 \\
\hline R106- & 683,55 & 6 & 1800,00 & 690,23 & 6 & 1800,00 & 683,55 & 6 & 1800,00 \\
\hline R107-I & 591,17 & 5 & 605,17 & 591,17 & 5 & 1529,08 & 591,17 & 5 & 930,39 \\
\hline $\mathrm{R} 10$ & 605 & 5 & 1800,00 & 605,83 & 5 & 1800,00 & 605,83 & 5 & 1800,00 \\
\hline R109-B & 1109,01 & 10 & 1800,00 & 1109,01 & 10 & 1800,00 & 1147,48 & 9 & 1800,00 \\
\hline R110-B & 541,97 & 5 & 1800,00 & 537,75 & 5 & 1800,00 & 539,47 & 5 & 1800,00 \\
\hline $\mathrm{R} 11$ & 6,48 & 6 & 1800,00 & 666,48 & 6 & 1800,00 & 666,48 & 6 & 1800,00 \\
\hline R112-B & 595,18 & 5 & 1800,00 & 595,18 & 5 & 1800,00 & 599,77 & 5 & 1800,00 \\
\hline $\begin{array}{c}\text { Média } \\
\text { Grupo B }\end{array}$ & 685,60 & 6,17 & 1700,43 & 692,28 & 6,00 & 1777,42 & 700,61 & 5,75 & 1727,53 \\
\hline $\mathrm{R} 1$ & & . & 1800,00 & & 6 & & & 6 & 1800,00 \\
\hline R102-C & 600,53 & 5 & 1800,00 & 600,53 & 5 & 1800,00 & 600,53 & 5 & 1800,00 \\
\hline R103-C & 597,04 & 5 & 1800,00 & 597,04 & 5 & 1800,00 & 597,04 & 5 & 1800,00 \\
\hline R104-C & 617,60 & 6 & 1800,00 & 641,10 & 5 & 1800,00 & 641,10 & 5 & 1800,00 \\
\hline $\mathrm{R} 1$ & 8,62 & 6 & 1800,00 & 698,62 & 6 & 1800,00 & 698,62 & 6 & 1800,00 \\
\hline R106-C & 595,11 & 6 & 1800,00 & 595,11 & 6 & 1800,00 & 595,11 & 6 & 1800,00 \\
\hline R107-C & 571,41 & 5 & 1800,00 & 570,99 & 5 & 1800,00 & 571,41 & 5 & 1800,00 \\
\hline R108-C & 561,16 & 5 & 1800,00 & 561,16 & 5 & 1800,00 & 561,16 & 5 & 1800,00 \\
\hline R109-C & 685,43 & 7 & 1800,00 & 713,60 & 6 & 1800,00 & 711,35 & 6 & 1800,00 \\
\hline R110-C & 564,76 & 5 & 1800,00 & 558,18 & 5 & 1800,00 & 558,73 & 5 & 1800,00 \\
\hline & 641,83 & 6 & 1800,00 & 637,30 & 6 & 1800,00 & 639,58 & 6 & 1800,00 \\
\hline R112-C & 579,21 & 5 & 1276,54 & 579,21 & 5 & 1800,00 & 579,21 & 5 & 1539,15 \\
\hline $\begin{array}{c}\text { Média } \\
\text { Grupo C }\end{array}$ & 619,49 & 5,58 & 1756,38 & 620,75 & 5,42 & 1800,00 & 621,47 & 5,42 & 1778,2 \\
\hline
\end{tabular}

$\begin{array}{llllllllll}\text { Média Geral } & 644,81 & 5,78 & 1712,28 & 648,09 & 5,64 & 1759,55 & 651,48 & 5,56 & 1735,96\end{array}$ 
Tabela 18 - Resultados para ASP 15 Clientes Cenário 2 - Parte 3.

\begin{tabular}{|c|c|c|c|c|c|c|c|c|c|}
\hline & \multicolumn{3}{|c|}{$\alpha=0,5$} & \multicolumn{3}{|c|}{$\alpha=0,75$} & \multicolumn{3}{|c|}{$\alpha=1,0$} \\
\hline Instância & $\mathrm{CO}$ & $\mathrm{NV}$ & $\mathrm{TP}$ & $\mathrm{CO}$ & NV & $\mathrm{TP}$ & $\mathrm{CO}$ & NV & $\mathrm{TP}$ \\
\hline R101-A & 765,59 & 5 & 1800,00 & 765,59 & 5 & 1800,00 & 1711,34 & 5 & 0,84 \\
\hline R102-A & 640,61 & 5 & 1800,00 & 626,85 & 5 & 1800,00 & 1141,44 & 5 & 1,75 \\
\hline R103-A & 666,30 & 5 & 1800,00 & 666,30 & 5 & 1800,00 & 1336,01 & 5 & 10,08 \\
\hline R104-A & 642,99 & 5 & 1800,00 & 649,32 & 5 & 1800,00 & 1210,70 & 5 & 2,74 \\
\hline R105-A & 831,89 & 6 & 1800,00 & 982,05 & 5 & 1800,00 & 1754,94 & 5 & 10,93 \\
\hline R106-A & 632,62 & 5 & 1800,00 & 632,62 & 5 & 1800,00 & 1414,61 & 5 & 7,09 \\
\hline R107-A & 570,69 & 5 & 1800,00 & 574,18 & 5 & 1800,00 & 1177,86 & 5 & 2,26 \\
\hline R108-A & 582,61 & 5 & 1800,00 & 587,53 & 5 & 1800,00 & 1209,23 & 5 & 2,50 \\
\hline R109-A & 716,93 & 5 & 1800,00 & 700,76 & 5 & 1800,00 & 1400,94 & 5 & 2,60 \\
\hline R110-A & 552,24 & 5 & 738,01 & 553,99 & 5 & 1800,00 & 1151,28 & 5 & 1,63 \\
\hline R111-A & 650,55 & 6 & 975,80 & 650,55 & 6 & 1589,69 & 1180,15 & 6 & 1,79 \\
\hline R112-A & 570,81 & 5 & 1800,00 & 570,81 & 5 & 1800,00 & 1130,76 & 5 & 16,15 \\
\hline $\begin{array}{c}\text { Média } \\
\text { Grupo A }\end{array}$ & 651,99 & 5,17 & 1642,82 & 663,38 & 5,08 & 1782,47 & 1318,27 & 5,08 & 5,03 \\
\hline R101-B & 854,11 & 6 & 1800,00 & 1030,29 & 5 & 1800,00 & 1898,32 & 5 & 2,95 \\
\hline R102-B & 577,45 & 5 & 1800,00 & 577,45 & 5 & 1800,00 & 1134,75 & 5 & 2,07 \\
\hline R103-B & 581,52 & 5 & 1800,00 & 584,58 & 5 & 1800,00 & 1457,06 & 5 & 6,21 \\
\hline R104-B & 706,25 & 5 & 1800,00 & 709,30 & 5 & 1800,00 & 894,35 & 5 & 4,12 \\
\hline R105-B & 1056,74 & 5 & 1800,00 & 1056,74 & 5 & 1800,00 & 1670,35 & 5 & 59,01 \\
\hline R106-B & 777,18 & 5 & 1800,00 & 777,18 & 5 & 1800,00 & 1441,56 & 5 & 20,05 \\
\hline R107-B & 591,17 & 5 & 1021,12 & 591,17 & 5 & 659,87 & 1134,74 & 5 & 1,62 \\
\hline R108-B & 605,83 & 5 & 1800,00 & 605,83 & 5 & 1800,00 & 1197,65 & 5 & 2,54 \\
\hline R109-B & 1216,96 & 8 & 1800,00 & 1216,96 & 8 & 1800,00 & 1670,36 & 8 & 1800,00 \\
\hline R110-B & 539,47 & 5 & 1800,00 & 537,75 & 5 & 1800,00 & 1164,99 & 5 & 0,85 \\
\hline R111-B & 666,48 & 6 & 1800,00 & 666,48 & 6 & 1800,00 & 1409,83 & 6 & 1,71 \\
\hline R112-B & 595,18 & 5 & 1800,00 & 595,18 & 5 & 1800,00 & 1109,24 & 5 & 22,90 \\
\hline $\begin{array}{c}\text { Média } \\
\text { Grupo B }\end{array}$ & 730,69 & 5,42 & 1735,09 & 745,74 & 5,33 & 1704,99 & 1348,60 & 5,33 & 160,34 \\
\hline R101-C & 763,33 & 5 & 1800,00 & 733,73 & 5 & 1800,00 & 1734,20 & 5 & 16,49 \\
\hline R102-C & 622,30 & 5 & 1800,00 & 600,53 & 5 & 1800,00 & 1351,55 & 5 & 1,93 \\
\hline R103-C & 597,04 & 5 & 1800,00 & 597,04 & 5 & 1800,00 & 1213,06 & 5 & 2,10 \\
\hline R104-C & 641,10 & 5 & 1800,00 & 641,10 & 5 & 1800,00 & 1039,07 & 5 & 0,96 \\
\hline R105-C & 699,24 & 6 & 1800,00 & 839,36 & 5 & 1800,00 & 1485,33 & 5 & 5,99 \\
\hline R106-C & 627,91 & 5 & 1800,00 & 627,91 & 5 & 1800,00 & 1486,21 & 5 & 6,04 \\
\hline R107-C & 577,14 & 5 & 1800,00 & 569,61 & 5 & 1800,00 & 1117,90 & 5 & 5,75 \\
\hline R108-C & 561,16 & 5 & 1800,00 & 561,16 & 5 & 1800,00 & 1255,48 & 5 & 1,78 \\
\hline R109-C & 713,60 & 6 & 1800,00 & 813,60 & 5 & 1800,00 & 1623,42 & 5 & 7,80 \\
\hline R110-C & 558,18 & 5 & 1800,00 & 558,18 & 5 & 1800,00 & 1238,30 & 5 & 2,74 \\
\hline R111-C & 639,58 & 6 & 1800,00 & 637,30 & 6 & 1800,00 & 1308,70 & 6 & 2,90 \\
\hline R112-C & 579,21 & 5 & 1125,40 & 579,21 & 5 & 1714,99 & 948,23 & 5 & 1,67 \\
\hline $\begin{array}{c}\text { Média } \\
\text { Grupo C }\end{array}$ & 631,65 & 5,25 & 1743,78 & 646,56 & 5,08 & 1792,92 & 1316,79 & 5,08 & 4,68 \\
\hline
\end{tabular}

$\begin{array}{llllllllll}\text { Média Geral } & 671,44 & 5,28 & 1707,23 & 685,23 & 5,17 & 1760,13 & 1327,89 & 5,17 & 56,68\end{array}$ 
Tabela 19 - Resultados para as abordagens APP e APM 15 Clientes - Cenário 1.

\begin{tabular}{|c|c|c|c|c|c|c|c|c|c|}
\hline \multirow[b]{2}{*}{ Instância } & \multicolumn{3}{|c|}{ APP1 } & \multicolumn{3}{|c|}{ APP2 } & \multicolumn{3}{|c|}{ APM } \\
\hline & $\mathrm{CO}$ & NV & $\mathrm{TP}$ & $\mathrm{CO}$ & NV & $\mathrm{TP}$ & $\mathrm{CO}$ & NV & $\mathrm{TP}$ \\
\hline R101-A & 1090,02 & 11 & 180,40 & 1196,56 & 8 & 118,30 & 1196,56 & 0 & 128,55 \\
\hline R102-A & 1089,78 & 13 & 7,03 & 1090,10 & 12 & 5,67 & 1090,10 & 12 & 4,03 \\
\hline R103-A & 999,31 & 12 & 15,52 & 1076,36 & 11 & 2,02 & 1076,36 & 11 & 4,95 \\
\hline R104-A & 905,42 & 10 & 10,79 & 922,54 & 9 & 2,47 & 922,54 & 9 & 5,55 \\
\hline R105-A & 1119,25 & 13 & 208,70 & 1165,26 & 11 & 2,71 & 1165,26 & 11 & 3,86 \\
\hline R106-A & 982,23 & 11 & 1,92 & 982,23 & 11 & 2,48 & 982,23 & 11 & 3,08 \\
\hline R107-A & 1062,85 & 12 & 6,96 & 1062,88 & 11 & 12,77 & 1062,88 & 11 & 4,89 \\
\hline R108-A & 788,88 & 9 & 4,43 & 788,88 & 9 & 3,83 & 788,88 & 9 & 3,59 \\
\hline R109-A & 855,47 & 11 & 735,95 & 894,85 & 9 & 294,90 & 894,86 & 9 & 309,16 \\
\hline R110-A & 1058,35 & 12 & 4,93 & 1121,83 & 11 & 6,45 & 1121,83 & 11 & 3,26 \\
\hline R111-A & 1042,62 & 13 & 33,64 & 1046,02 & 12 & 58,32 & 1046,02 & 12 & 226,69 \\
\hline R112-A & 943,24 & 12 & 20,11 & 954,90 & 11 & 163,27 & 954,90 & 11 & 435,38 \\
\hline $\begin{array}{c}\text { Média } \\
\text { Grupo A }\end{array}$ & 994,79 & 11,58 & 102,53 & 1025,20 & 10,42 & 56,10 & 1025,20 & 10,42 & 94,42 \\
\hline R101-B & 916,92 & 11 & 1800,00 & 932,41 & 8 & 1800,00 & 932,45 & 8 & 1800,00 \\
\hline R102-B & 1173,71 & 13 & 4,58 & 1193,70 & 12 & 8,20 & 1193,70 & 12 & 7,52 \\
\hline R103-B & 994,59 & 12 & 16,44 & 1048,38 & 11 & 9,40 & 1048,38 & 11 & 10,62 \\
\hline R104-B & 880,36 & 11 & 399,24 & 914,17 & 9 & 16,35 & 914,17 & 9 & 22,52 \\
\hline R105-B & 1048,44 & 14 & 26,79 & 1145,27 & 11 & 4,25 & 1145,27 & 11 & 6,23 \\
\hline R106-B & 982,64 & 12 & 20,33 & 1007,13 & 11 & 11,53 & 1007,13 & 11 & 7,86 \\
\hline R107-B & 1024,16 & 11 & 15,40 & 1024,16 & 11 & 21,19 & 1024,16 & 11 & 2,07 \\
\hline R108-B & 806,79 & 9 & 396,97 & 806,79 & 9 & 29,43 & 806,79 & 9 & 166,20 \\
\hline R109-B & 896,66 & 10 & 1800,00 & 900,69 & 9 & 1800,00 & 900,70 & 9 & 1800,00 \\
\hline R110-B & 1042,17 & 12 & 865,22 & 1052,70 & 11 & 1089,38 & 1052,70 & 11 & 994,81 \\
\hline R111-B & 1066,40 & 14 & 28,54 & 1074,82 & 13 & 18,95 & 1074,82 & 13 & 11,97 \\
\hline R112-B & 1032,80 & 12 & 15,88 & 1100,82 & 11 & 102,67 & 1100,82 & 11 & 102,34 \\
\hline $\begin{array}{c}\text { Média } \\
\text { Grupo B }\end{array}$ & 988,80 & 11,75 & 449,12 & 1016,75 & 10,50 & 409,28 & 1016,76 & 10,50 & 411,01 \\
\hline R101-C & 1037,17 & 11 & 1800,00 & 1162,28 & 8 & 1800,00 & 1162,32 & 8 & 1800,00 \\
\hline R102-C & 1154,44 & 13 & 1800,00 & 1175,43 & 12 & 850,88 & 1175,43 & 12 & 1433,42 \\
\hline R103-C & 1005,89 & 12 & 15,57 & 1088,88 & 11 & 17,92 & 1088,88 & 11 & 15,40 \\
\hline R104-C & 878,86 & 10 & 117,67 & 897,41 & 9 & 398,13 & 897,41 & 9 & 1800,00 \\
\hline R105-C & 1367,15 & 14 & 1800,00 & 1513,50 & 11 & 1061,08 & 1513,50 & 11 & 1800,00 \\
\hline R106-C & 1174,23 & 12 & 1800,00 & 1211,28 & 11 & 897,83 & 1211,28 & 11 & 1800,00 \\
\hline R107-C & 1019,82 & 12 & 650,61 & 1020,93 & 11 & 347,95 & 1020,93 & 11 & 168,94 \\
\hline R108-C & 823,46 & 9 & 186,07 & 823,46 & 9 & 25,30 & 823,46 & 9 & 34,16 \\
\hline R109-C & 915,06 & 9 & 38,94 & 915,06 & 9 & 42,14 & 915,06 & 9 & 38,27 \\
\hline R110-C & 985,26 & 12 & 1800,00 & 989,92 & 11 & 1800,00 & 989,92 & 11 & 1800,00 \\
\hline R111-C & 1036,79 & 12 & 1800,00 & 1035,79 & 12 & 10,74 & 1035,79 & 12 & 119,68 \\
\hline R112-C & 998,71 & 12 & 936,29 & 1007,59 & 11 & 354,52 & 1007,59 & 11 & 298,91 \\
\hline $\begin{array}{c}\text { Média } \\
\text { Grupo C }\end{array}$ & 1033,07 & 11,50 & 1062,10 & 1070,13 & 10,42 & 633,87 & 1070,13 & 10,42 & 925,73 \\
\hline Média Geral & 1032,73 & 11,54 & 1000,60 & 1062,45 & 10,62 & 536,70 & 1062,45 & 10,62 & 852,88 \\
\hline
\end{tabular}


Tabela 20 - Resultados para as abordagens APP e APM 15 Clientes - Cenário 2.

\begin{tabular}{|c|c|c|c|c|c|c|c|c|c|}
\hline \multirow[b]{2}{*}{ Instância } & \multicolumn{3}{|c|}{ APP1 } & \multicolumn{3}{|c|}{ APP2 } & \multicolumn{3}{|c|}{ APM } \\
\hline & $\mathrm{CO}$ & NV & $\mathrm{TP}$ & $\mathrm{CO}$ & NV & $\mathrm{TP}$ & $\mathrm{CO}$ & NV & $\mathrm{TP}$ \\
\hline R101-A & 682,35 & 7 & 1800,00 & 767,56 & 5 & 1800,00 & 765,59 & 5 & 1800,00 \\
\hline R102-A & 612,89 & 6 & 1800,00 & 626,85 & 5 & 1800,00 & 633,70 & 5 & 1800,00 \\
\hline R103-A & 633,41 & 6 & 1800,00 & 666,30 & 5 & 1800,00 & 666,30 & 5 & 1800,00 \\
\hline R104-A & 634,70 & 6 & 1800,00 & 642,99 & 5 & 1800,00 & 647,31 & 5 & 1800,00 \\
\hline R105-A & 765,79 & 8 & 1800,00 & 982,05 & 5 & 1800,00 & 799,66 & 6 & 1800,00 \\
\hline R106-A & 594,44 & 6 & 1800,00 & 632,62 & 5 & 1800,00 & 632,62 & 5 & 1800,00 \\
\hline R107-A & 573,08 & 6 & 1800,00 & 573,08 & 5 & 106,17 & 573,08 & 5 & 80,7844 \\
\hline R108-A & 579,56 & 6 & 1800,00 & 599,92 & 5 & 1800,00 & 585,65 & 5 & 1800,00 \\
\hline R109-A & 639,52 & 6 & 1800,00 & 695,45 & 5 & 1800,00 & 695,45 & 5 & 1800,00 \\
\hline R110-A & 552,24 & 5 & 123,49 & 552,24 & 5 & 1145,21 & 552,24 & 5 & 1102,89 \\
\hline R111-A & 646,34 & 7 & 1800,00 & 650,55 & 6 & 1800,00 & 650,55 & 6 & 1800,00 \\
\hline R112-A & 570,81 & 5 & 13,64 & 570,81 & 5 & 88,72 & 570,81 & 5 & 7,98992 \\
\hline $\begin{array}{c}\text { Média } \\
\text { Grupo A }\end{array}$ & 623,76 & 6,17 & 1511,43 & 663,37 & 5,08 & 1461,68 & 647,75 & 5,17 & 1449,31 \\
\hline R101-B & 773,92 & 9 & 1800,00 & 1004,11 & 5 & 1800,00 & 977,51 & 5 & 1800,00 \\
\hline R102-B & 573,14 & 6 & 1800,00 & 577,45 & 5 & 1800,00 & 577,45 & 5 & 1800,00 \\
\hline R103-B & 567,78 & 6 & 1800,00 & 581,52 & 5 & 1800,00 & 581,52 & 5 & 1800,00 \\
\hline R104-B & 656,72 & 7 & 1800,00 & 706,25 & 5 & 1800,00 & 704,34 & 5 & 1800,00 \\
\hline R105-B & 806,30 & 8 & 1800,00 & 1103,32 & 5 & 1800,00 & 855,97 & 6 & 1800,00 \\
\hline R106-B & 678,52 & 7 & 1800,00 & 777,18 & 5 & 1800,00 & 777,18 & 5 & 1800,00 \\
\hline R107-B & 591,17 & 5 & 1800,00 & 591,17 & 5 & 547,52 & 591,17 & 5 & 110,453 \\
\hline R108-B & 592,55 & 6 & 1800,00 & 605,82 & 5 & 1800,00 & 605,82 & 5 & 1800,00 \\
\hline R109-B & 1080,82 & 12 & 1800,00 & 1206,73 & 8 & 1800,00 & 1203,76 & 8 & 1800,00 \\
\hline R110-B & 537,75 & 5 & 1290,55 & 537,75 & 5 & 877,11 & 537,75 & 5 & 76,5454 \\
\hline R111-B & 666,48 & 6 & 163,22 & 674,21 & 6 & 1800,00 & 666,48 & 6 & 59,9417 \\
\hline R112-B & 599,05 & 6 & 1800,00 & 599,05 & 5 & 23,04 & 599,05 & 5 & 150,834 \\
\hline $\begin{array}{c}\text { Média } \\
\text { Grupo B }\end{array}$ & 677,02 & 6,92 & 1621,15 & 747,05 & 5,33 & 1470,64 & 723,17 & 5,42 & 1233,15 \\
\hline R101-C & 685,54 & 7 & 1800,00 & 733,73 & 5 & 1800,00 & 733,73 & 5 & 1800,00 \\
\hline R102-C & 599,90 & 6 & 1800,00 & 617,90 & 5 & 1800,00 & 600,57 & 5 & 1800,00 \\
\hline R103-C & 589,14 & 6 & 1800,00 & 597,04 & 5 & 1800,00 & 597,04 & 5 & 1800,00 \\
\hline R104-C & 617,60 & 6 & 1800,00 & 641,10 & 5 & 1800,00 & 636,11 & 5 & 1800,00 \\
\hline R105-C & 683,50 & 8 & 1800,00 & 839,36 & 5 & 1800,00 & 699,24 & 6 & 1800,00 \\
\hline R106-C & 595,11 & 6 & 1800,00 & 627,91 & 5 & 1800,00 & 627,91 & 5 & 1800,00 \\
\hline R107-C & 568,87 & 6 & 1800,00 & 569,61 & 5 & 1800,00 & 571,41 & 5 & 1800,00 \\
\hline R108-C & 561,16 & 5 & 491,16 & 561,16 & 5 & 253,97 & 561,16 & 5 & 25,4473 \\
\hline R109-C & 685,43 & 8 & 1800,00 & 771,98 & 5 & 1800,00 & 771,98 & 5 & 1800,00 \\
\hline R110-C & 558,18 & 5 & 49,61 & 558,18 & 5 & 124,86 & 558,18 & 5 & 62,3259 \\
\hline R111-C & 639,58 & 6 & 84,80 & 641,83 & 6 & 1800,00 & 639,58 & 6 & 120,2 \\
\hline R112-C & 579,21 & 5 & 403,17 & 579,21 & 5 & 1800,00 & 579,21 & 5 & 185,343 \\
\hline $\begin{array}{c}\text { Média } \\
\text { Grupo C }\end{array}$ & 613,60 & 6,17 & 1285,73 & 644,92 & 5,08 & 1531,57 & 631,34 & 5,17 & 1232,78 \\
\hline Média Geral & 638,13 & 6,42 & 1472,77 & 685,11 & 5,17 & 1487,96 & 667,42 & 5,25 & 1305,08 \\
\hline
\end{tabular}



APÊNDICE

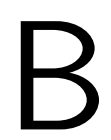

B

\section{RESULTADOS DOS TESTE DE WILCOXON}

O teste de Wilcoxon se mostra como uma opção para realizar testes não paramétricos em amostras pareadas. O teste utiliza da soma dos postos para identificar semelhanças entre as médias. Considera-se como hipótese nula $\left(H_{0}\right)$ que as médias são iguais e hipótese alternativa $\left(H_{1}\right)$ caso contrário. O resultado do teste é o $p$-valor e por se tratar de um teste bi-caudal com nível de confiança de $95 \%$, caso $p-$ valor $\geq 0,025$ aceita-se $H_{0}$, caso contrário é aceito $H_{1}$.

Os resultados referentes ao teste de Wilcoxon para as abordagens bi-objetivo apresentadas no Capítulo 4 são aqui detalhados. São reportados os $p$-valores ao comparar as abordagens em termos de custo operacional, número de veículos e tempo de processamento. Os valores destacados em negritos indicam as abordagens que possuem semelhança estatística. Para algumas combinações, principalmente ao analisar o número de veículos, não foi possível obter um $p-$ valor (indicadas por NA).

Tabela 21 - Resultados do Teste de Wilcoxon do Custo Operacional para Abordagens Bi-Objetivo Cenário 1.

\begin{tabular}{|c|c|c|c|c|c|c|c|c|c|c|c|c|c|}
\hline & & & & & & & & & & & & & \\
\hline & & Bernardes (2019) & 0,05 & 0,1 & 0,15 & 0,2 & 0,25 & 0,5 & 0,75 & 1,0 & APM & APP1 & APP2 \\
\hline & Bernardes (2019) & - & & & & & & & & & & & \\
\hline & 0,05 & 0,002 & - & & & & & & & & & & \\
\hline & 0,1 & 0,000 & 0,014 & - & & & & & & & & & \\
\hline & 0,15 & 0,000 & 0,003 & 0,022 & - & & & & & & & & \\
\hline & 0,2 & 0,000 & 0,001 & 0,025 & 0,590 & - & & & & & & & \\
\hline$\alpha$ & 0,25 & 0,000 & 0,000 & 0,003 & 0,014 & 0,100 & - & & & & & & \\
\hline & 0,5 & 0,000 & 0,000 & 0,000 & 0,000 & 0,001 & 0,001 & - & & & & & \\
\hline & 0,75 & 0,000 & 0,000 & 0,000 & 0,000 & 0,001 & 0,001 & 1,000 & - & & & & \\
\hline & 1,0 & 0,000 & 0,000 & 0,000 & 0,000 & 0,000 & 0,000 & 0,000 & 0,000 & - & & & \\
\hline & APM & 0,000 & 0,000 & 0,000 & 0,000 & 0,001 & 0,001 & 1,000 & 1,000 & 0,000 & - & & \\
\hline & APP1 & 0,100 & 0,006 & 0,001 & 0,000 & 0,000 & 0,000 & 0,000 & 0,000 & 0,000 & 0,000 & - & \\
\hline & APP2 & 0,000 & 0,000 & 0,000 & 0,000 & 0,001 & 0,001 & 0,098 & 0,098 & 0,000 & $\mathbf{0 , 0 9 8}$ & 0,000 & - \\
\hline
\end{tabular}


Tabela 22 - Resultados do Teste de Wilcoxon do Número de Veículos para Abordagens Bi-Objetivo Cenário 1.

\begin{tabular}{|c|c|c|c|c|c|c|c|c|c|c|c|c|c|}
\hline & & & & & & & & & & & & & \\
\hline & & Bernardes (2019) & 0,05 & 0,1 & 0,15 & 0,2 & 0,25 & 0,5 & 0,75 & 1,0 & APM & APP1 & APP2 \\
\hline & Bernardes (2019) & - & & & & & & & & & & & \\
\hline & 0,05 & 0,002 & - & & & & & & & & & & \\
\hline & 0,1 & 0,000 & 0,026 & - & & & & & & & & & \\
\hline & 0,15 & 0,000 & 0,004 & $\mathbf{0 , 0 4 8}$ & - & & & & & & & & \\
\hline & 0,2 & 0,000 & 0,000 & 0,008 & 0,233 & - & & & & & & & \\
\hline$\alpha$ & 0,25 & 0,000 & 0,000 & 0,002 & 0,020 & 0,149 & - & & & & & & \\
\hline & 0,5 & 0,000 & 0,000 & 0,000 & 0,000 & 0,000 & 0,000 & - & & & & & \\
\hline & 0,75 & 0,000 & 0,000 & 0,000 & 0,000 & 0,000 & 0,000 & NA & - & & & & \\
\hline & 1,0 & 0,000 & 0,000 & 0,000 & 0,000 & 0,000 & 0,000 & NA & NA & - & & & \\
\hline & APM & 0,000 & 0,000 & 0,000 & 0,000 & 0,000 & 0,000 & NA & NA & NA & - & & \\
\hline & APP1 & NA & 0,002 & 0,000 & 0,000 & 0,000 & 0,000 & 0,000 & 0,000 & 0,000 & 0,000 & - & \\
\hline & APP2 & 0,000 & 0,000 & 0,000 & 0,000 & 0,000 & 0,000 & NA & NA & NA & NA & 0,000 & - \\
\hline
\end{tabular}

Tabela 23 - Resultados do Teste de Wilcoxon do Tempo de Processamento para Abordagens Bi-Objetivo Cenário 1.

\begin{tabular}{|c|c|c|c|c|c|c|c|c|c|c|c|c|c|}
\hline & & \multicolumn{12}{|c|}{$\alpha$} \\
\hline \multirow{13}{*}{$\alpha$} & & Bernardes (2019) & 0,05 & 0,1 & 0,15 & 0,2 & 0,25 & 0,5 & 0,75 & 1,0 & APM & APP1 & APP2 \\
\hline & Bernardes (2019) & - & & & & & & & & & & & \\
\hline & 0,05 & 0,133 & - & & & & & & & & & & \\
\hline & 0,1 & 0,589 & 0,764 & - & & & & & & & & & \\
\hline & 0,15 & 0,130 & 0,674 & 0,264 & - & & & & & & & & \\
\hline & 0,2 & 0,931 & 0,574 & 0,300 & 0,020 & - & & & & & & & \\
\hline & 0,25 & 0,869 & 0,388 & 0,484 & 0,003 & 0,285 & - & & & & & & \\
\hline & 0,5 & 0,234 & 0,002 & 0,015 & 0,000 & 0,063 & 0,162 & - & & & & & \\
\hline & 0,75 & 0,233 & 0,042 & 0,048 & 0,006 & 0,009 & 0,076 & 0,727 & - & & & & \\
\hline & 1,0 & 0,000 & 0,000 & 0,000 & 0,000 & 0,000 & 0,000 & 0,000 & 0,000 & - & & & \\
\hline & APM & 0,067 & 0,005 & 0,016 & 0,000 & $\mathbf{0 , 0 3 2}$ & 0,186 & 0,123 & 0,660 & 0,000 & - & & \\
\hline & APP1 & 0,465 & $\mathbf{0 , 0 8 3}$ & $\mathbf{0 , 3 0 3}$ & 0,212 & 0,808 & 0,931 & $\mathbf{0 , 8 2 0}$ & 0,739 & 0,000 & 0,008 & - & \\
\hline & APP2 & 0,005 & 0,000 & 0,001 & 0,000 & 0,005 & 0,003 & 0,088 & 0,104 & 0,000 & 0,220 & 0,026 & - \\
\hline
\end{tabular}

Tabela 24 - Resultados do Teste de Wilcoxon do Custo Operacional para Abordagens Bi-Objetivo Cenário 2.

\begin{tabular}{|c|c|c|c|c|c|c|c|c|c|c|c|c|c|}
\hline & & \multicolumn{12}{|c|}{$\alpha$} \\
\hline \multirow{13}{*}{$\alpha$} & & Bernardes (2019) & 0,05 & 0,1 & 0,15 & 0,2 & 0,25 & 0,5 & 0,75 & 1,0 & APM & APP1 & APP2 \\
\hline & Bernardes (2019) & - & & & & & & & & & & & \\
\hline & 0,05 & 0,171 & - & & & & & & & & & & \\
\hline & 0,1 & 0,002 & 0,018 & - & & & & & & & & & \\
\hline & 0,15 & 0,000 & 0,001 & $\mathbf{0 , 0 2 9}$ & - & & & & & & & & \\
\hline & 0,2 & 0,000 & 0,000 & 0,012 & 0,478 & - & & & & & & & \\
\hline & 0,25 & 0,000 & 0,000 & 0,003 & 0,044 & 0,047 & - & & & & & & \\
\hline & 0,5 & 0,000 & 0,000 & 0,000 & 0,000 & 0,000 & 0,005 & - & & & & & \\
\hline & 0,75 & 0,000 & 0,000 & 0,000 & 0,000 & 0,000 & 0,002 & 0,421 & - & & & & \\
\hline & 1,0 & 0,000 & 0,000 & 0,000 & 0,000 & 0,000 & 0,000 & 0,000 & 0,000 & - & & & \\
\hline & APM & 0,000 & 0,000 & 0,000 & 0,001 & 0,000 & 0,091 & 0,191 & 0,014 & 0,000 & - & & \\
\hline & APP1 & 0,036 & 0,449 & 0,003 & 0,000 & 0,000 & 0,000 & 0,000 & 0,000 & 0,000 & 0,000 & - & \\
\hline & APP2 & 0,000 & 0,000 & 0,000 & 0,000 & 0,000 & 0,002 & 0,251 & 0,925 & 0,000 & 0,011 & 0,000 & - \\
\hline
\end{tabular}


Tabela 25 - Resultados do Teste de Wilcoxon do Número de Veículos para Abordagens Bi-Objetivo Cenário 2.

\begin{tabular}{|c|c|c|c|c|c|c|c|c|c|c|c|c|c|}
\hline & & & & & & & & & & & & & \\
\hline & & Bernardes (2019) & 0,05 & 0,1 & 0,15 & 0,2 & 0,25 & 0,5 & 0,75 & 1,0 & APM & APP1 & APP2 \\
\hline & Bernardes (2019) & - & & & & & & & & & & & \\
\hline & 0,05 & 0,008 & - & & & & & & & & & & \\
\hline & 0,1 & 0,000 & 0,006 & - & & & & & & & & & \\
\hline & 0,15 & 0,000 & 0,000 & 0,011 & - & & & & & & & & \\
\hline & 0,2 & 0,000 & 0,000 & 0,001 & 0,037 & - & & & & & & & \\
\hline$\alpha$ & 0,25 & 0,000 & 0,000 & 0,001 & 0,015 & 0,149 & - & & & & & & \\
\hline & 0,5 & 0,000 & 0,000 & 0,000 & 0,001 & 0,002 & 0,002 & - & & & & & \\
\hline & 0,75 & 0,000 & 0,000 & 0,000 & 0,000 & 0,001 & 0,001 & 0,072 & - & & & & \\
\hline & 1,0 & 0,000 & 0,000 & 0,000 & 0,000 & 0,001 & 0,001 & $\mathbf{0 , 0 7 2}$ & NA & - & & & \\
\hline & APM & 0,000 & 0,000 & 0,000 & 0,001 & 0,001 & 0,003 & $\mathbf{0 , 7 7 3}$ & 0,149 & 0,149 & - & & \\
\hline & APP1 & 0,766 & 0,013 & 0,000 & 0,000 & 0,000 & 0,000 & 0,000 & 0,000 & 0,000 & 0,000 & - & \\
\hline & APP2 & 0,000 & 0,000 & 0,000 & 0,000 & 0,001 & 0,001 & 0,072 & NA & NA & 0,149 & 0,000 & - \\
\hline
\end{tabular}

Tabela 26 - Resultados do Teste de Wilcoxon do Tempo de Processamento para Abordagens Bi-Objetivo Cenário 2.

\begin{tabular}{|c|c|c|c|c|c|c|c|c|c|c|c|c|c|}
\hline & & & & & & & & & & & & & \\
\hline & Bernardes (2019) & Bernardes (2019) & 0,05 & 0,1 & 0,15 & 0,2 & 0,25 & 0,5 & 0,75 & 1,0 & APM & APP1 & APP2 \\
\hline & $\begin{array}{c}\text { Bernardes (2019) } \\
0,05\end{array}$ & 0,014 & - & & & & & & & & & & \\
\hline & 0,1 & $\mathbf{0 , 0 3 2}$ & 0,800 & - & & & & & & & & & \\
\hline & 0,15 & $\mathbf{0 , 0 3 3}$ & 0,675 & $\mathbf{0 , 8 3 4}$ & - & & & & & & & & \\
\hline$\alpha$ & 0,2 & 0,014 & 0,059 & 0,295 & $\mathbf{0 , 1 7 8}$ & - & & & & & & & \\
\hline$\alpha$ & 0,25 & 0,013 & 0,402 & $\mathbf{0 , 8 3 4}$ & 0,178 & 0,361 & - & & & & & & \\
\hline & 0,5 & 0,058 & 0,834 & 1,000 & 1,000 & 0,100 & 0,201 & - & & & & & \\
\hline & 0,75 & 0,013 & 0,295 & 0,418 & 0,059 & 1,000 & 0,361 & 0,201 & - & & & & \\
\hline & 1,0 & 0,000 & 0,000 & 0,000 & 0,000 & 0,000 & 0,000 & 0,000 & 0,000 & - & & & \\
\hline & APM & 0,065 & 0,008 & 0,005 & 0,006 & 0,004 & 0,004 & 0,005 & 0,003 & 0,000 & - & & \\
\hline & APP1 & 0,164 & 0,426 & 0,445 & 0,240 & 0,464 & 0,247 & 0,234 & 0,247 & 0,000 & 0,000 & - & \\
\hline & APP2 & 0,091 & 0,217 & 0,436 & 0,427 & 0,474 & 0,455 & $\mathbf{0 , 2 3 5}$ & 0,474 & 0,000 & 0,000 & 0,114 & - \\
\hline
\end{tabular}




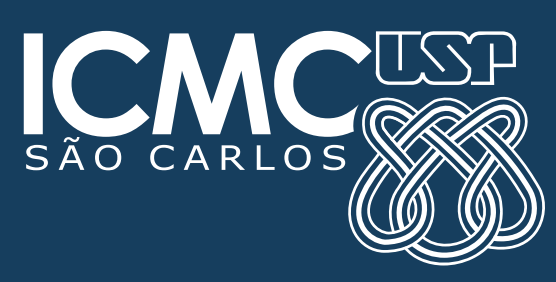

